Portland State University

PDXScholar

Spring 5-21-2015

\title{
Building Resources at Home and at Work: Day-Level Relationships between Job Crafting, Recovery Experiences, and Work Engagement
}

Allison Marie Ellis

Portland State University

Follow this and additional works at: https://pdxscholar.library.pdx.edu/open_access_etds

Part of the Family, Life Course, and Society Commons, and the Industrial and Organizational Psychology Commons

Let us know how access to this document benefits you.

\section{Recommended Citation}

Ellis, Allison Marie, "Building Resources at Home and at Work: Day-Level Relationships between Job Crafting, Recovery Experiences, and Work Engagement" (2015). Dissertations and Theses. Paper 2320. https://doi.org/10.15760/etd.2317

This Dissertation is brought to you for free and open access. It has been accepted for inclusion in Dissertations and Theses by an authorized administrator of PDXScholar. For more information, please contact pdxscholar@pdx.edu. 
Building Resources at Home and at Work: Day-Level Relationships between Job Crafting, Recovery Experiences, and Work Engagement

by

Allison Marie Ellis

A dissertation submitted in partial fulfillment of the requirements for the degree of

Doctor of Philosophy

in

Applied Psychology

Dissertation Committee:

Charlotte Fritz, Chair

Talya N. Bauer

Donald M. Truxillo

Wayne Wakeland

Portland State University

2015 
(C) 2015 Allison Marie Ellis 


\begin{abstract}
Work engagement is an increasingly popular construct in organizational and occupational health psychology. However, despite substantial advances in our understanding of work engagement at the between-person level, scholars have argued for increased investigation into what drives engagement on a daily level for individual employees. In the current study, a within-person, day-level design was employed to examine the relationships between nonwork mastery experiences, job crafting behaviors, and daily work engagement. Drawing on Conservation of Resources (Hobfoll, 1989) theory, nonwork mastery experiences and job crafting were operationalized as employee-driven, resourcebuilding strategies that assist employees in generating important psychological and job resources that can be drawn upon in order to maintain high levels of work engagement during the day. Moreover, a reciprocal relationship between work engagement during the day and nonwork mastery experiences the same evening was tested. Employees from a U.S. technology firm provided responses in the morning, at lunchtime, and after work each day for five working days. Multilevel structural equation modeling was used to test the hypotheses in the current study. Findings revealed no support for the hypothesized model at the within-person level of analysis; however, ancillary analyses suggested support for an indirect relationship between job crafting and work engagement via increased positive affect. Moreover, nearly all the proposed relationships emerged at the between-person level of analysis providing some insight into the effects of resource building strategies and work engagement across participants. Finally, seeking structural resources was identified as a person-level factor that explained variance in employees' initial levels of work engagement at the start of the week, as well as the trajectory of
\end{abstract}


engagement over the course of the week. The current findings contribute to our understanding of bottom-up, employee-driven behaviors that help to sustain engagement over time. Suggestions for future research and implications for practice are discussed. 


\section{Table of Contents}

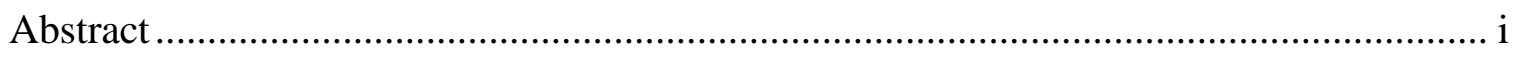

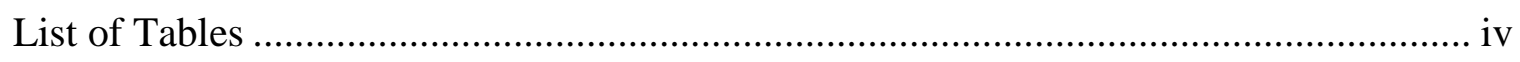

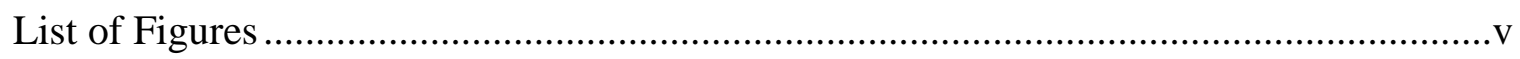

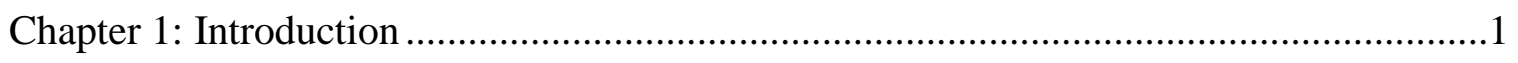

Chapter 2: State Work Engagement..........................................................................

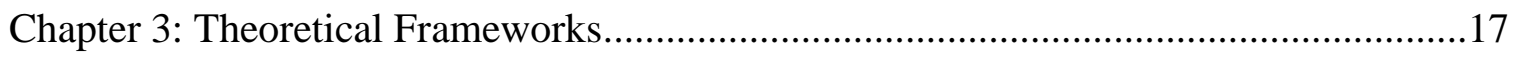

Chapter 4: Building Resources during Nonwork through Mastery Experiences...............25

Chapter 5: Building Resources during Work through Job Crafting ................................34

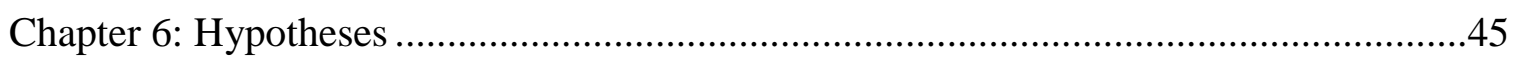

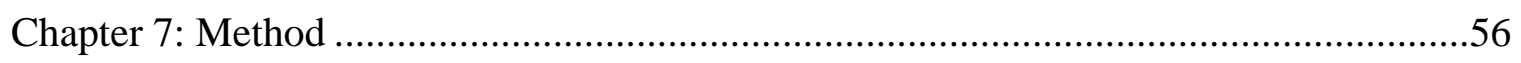

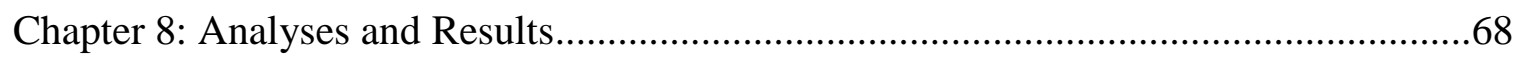

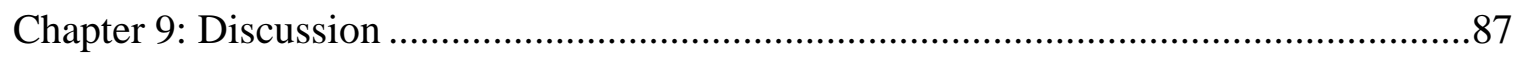

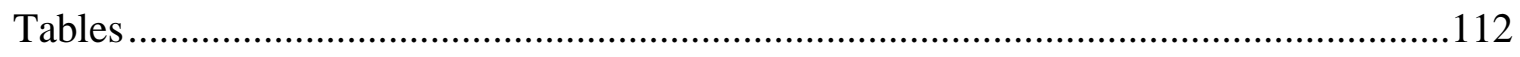

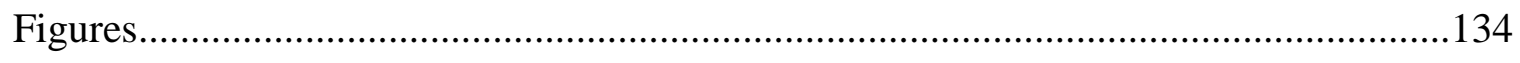

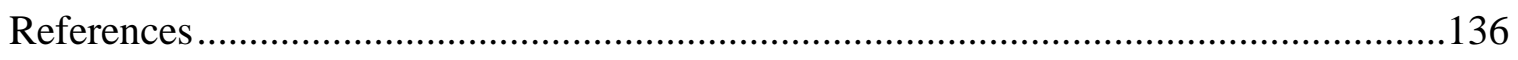

Appendix A: Standardized Announcement Email ................................................156

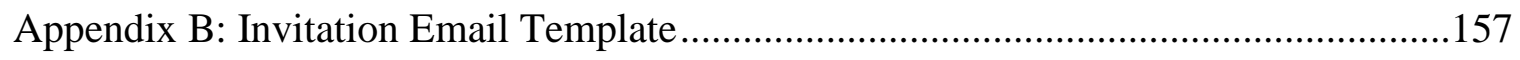

Appendix C: Additional Information Page ..........................................................

Appendix D: Trait-level Variables Assessed with Baseline Survey …..........................160

Appendix E: List of Items from Day-level Measures ..........................................162

Appendix F: Table of Means for Focal Variables from Day 1 through Day 5 ...............166

Appendix G: Additional Information on Growth Models .........................................167 


\section{List of Tables}

Table 1: Summary of Assessments

Table 2: Intercorrelations among Study Variables

Table 3a: Multilevel Models Predicting Daily Job Crafting and Work Engagement from Nonwork Mastery Experiences (Within-Person Results).

Table 3b: Multilevel Models Predicting Daily Job Crafting and Work Engagement from Nonwork Mastery Experiences (Between-Person Results). 115

Table 4a: Multilevel Models Predicting Daily Work Engagement from Job Crafting

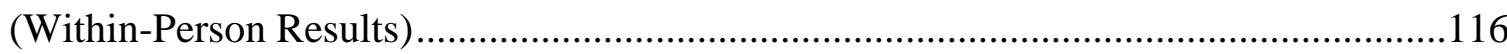

Table 4b: Multilevel Models Predicting Daily Work Engagement from Job Crafting (Between-Person Results).

Table 5a: Multilevel Models Predicting Daily Work Engagement from Nonwork Mastery Experiences and Job Crafting (Within-Person Results). .118

Table 5b: Multilevel Models Predicting Daily Work Engagement from Nonwork Mastery Experiences and Job Crafting (Between-Person Results).

Table 6a: Multilevel Models Predicting Nonwork Mastery from Work Engagement (Within-Person Results)

Table 6b: Multilevel Models Predicting Nonwork Mastery from Work Engagement (Between-Person Results).

Table 7a: Multilevel Models Predicting Daily Job Crafting and Work Engagement from NME, Positive Affect, and Efficacy Beliefs (Within-Person Results)

Table 7b: Multilevel Models Predicting Daily Job Crafting and Work Engagement from NME, Positive Affect, and Efficacy Beliefs (Between-Person Results). .126

Table 8a: Multilevel Models Predicting Daily Work Engagement from Job Crafting, Positive Affect, and Efficacy Beliefs (Within-Person Results) .......................................128

Table 8b: Multilevel Models Predicting Daily Work Engagement from Job Crafting, Positive Affect, and Efficacy Beliefs (Between-Person Results) 130

Table 9: Summary of Results. .132 


\section{List of Figures}

Figure 1: Model of Hypothesized Relationships ...........................................................134

Figure 2: Multilevel Structural Equation Model Describing 1-1-1 Mediation Model

between Day-level Nonwork Mastery Experiences, Job Crafting, and Engagement ......135 


\section{Chapter 1: Introduction}

In recent years the construct of work engagement (i.e., a motivational state in which employees feel vigorous, dedicated, and absorbed in their work; Schaufeli, Salanova, Gonzalez-Roma, \& Bakker, 2002) has experienced burgeoning interest in both scholarly and applied settings (Christian, Garza, \& Slaughter, 2011). This surge of interest has occurred, in part, because of increased focus on positive psychological processes in occupational health psychology (Luthans, 2002), and because of promising findings linking work engagement to important organizational outcomes (Bakker, Demerouti, \& Sanz-Vergel, 2014). For example, between-person studies find that work engagement is associated with positive performance-related outcomes such as task and contextual performance (Christian et al., 2011; Rich, LePine, \& Crawford, 2010) and proactive behaviors (Salanova \& Schaufeli, 2008), as well as to enhanced job attitudes such as job satisfaction and involvement (Rich et al., 2010).

Accordingly, significant scholarly attention has been focused on understanding the factors that predict work engagement (Bakker \& Demerouti, 2007). Consistent with the job demands-resources (JD-R; Demerouti, Bakker, Nachreiner, \& Schaufeli, 2001) model, findings suggest that central to the promotion of work engagement is the availability of job resources (i.e., aspects of the job that help to achieve work goals, reduce job demands, or stimulate growth and development; Bakker \& Demerouti, 2007; Demerouti et al., 2001; Halbesleben, 2010). Numerous factors have been identified that can be considered resources for employees including personal characteristics (e.g., selfefficacy; Simbula, Guglielmi, \& Schaufeli, 2011), interpersonal relationships (e.g., leadership and co-worker support; Schaufeli \& Bakker, 2004), and structural aspects of 
the work (e.g., autonomy; Halbesleben, 2010), and many of these relationships have been supported in meta-analyses (Christian et al., 2011; Halbesleben, 2010). Thus, there is a strong evidence base to suggest that job resources are important factors in explaining variation in work engagement across employees.

Despite the relatively static nature of many job resources characteristic of the work environment (Hackman \& Oldham, 1976), within-person studies point out that work engagement is a rather dynamic construct (Sonnentag, Dormann, \& Demerouti, 2010). Findings show as much as $30-40 \%$ of the variance in engagement occurs at the within-person level (in the context of diary research this refers to day-to-day variation; e.g., Sonnentag, 2003; Xanthopoulou, Bakker, Demerouti, \& Schaufeli, 2009). Sonnentag and colleagues (2010) argued that the between-person view of work engagement is useful for answering questions related to why some employees are engaged and others are not, but that such approaches do not speak to the reasons why seemingly engaged employees are not engaged every day (which requires a within-person approach). The authors reviewed the research on state work engagement (SWE) and contended that examining the construct at the within-person level provides insight into a complex phenomenon that may otherwise be lost on between-person, longitudinal investigations.

There are a number of reasons why examining work engagement at the withinlevel (versus between) is both practically and theoretically important. For example, relationships between factors at the between-person level (which consider averages across people) may be fundamentally different from relationships between factors at the within-level (which occur within-persons) (Hamaker, 2012). Moreover, Sonnentag et al., 
(2010) argued that investigating work engagement at the within-person level and on a daily basis allows for an examination of more proximal predictors and consequences, and may actually exhibit stronger relationships with these factors because they are assessed in real time and represent vivid experiences.

Further, a focus on individual employee experiences opens the door to examining employee behaviors and experiences beyond traditional job resources in relation to work engagement (i.e., job characteristics). For instance, drawing from the conservation of resources theory (COR; Hobfoll, 1989), it could be argued that employees are not passive recipients of the job resources made available to them by their organization, but rather actively engage each day in goal-directed behavior aimed at managing those resources (Halbesleben, Neveu, Paustian-Underdahl, \& Westman, 2014; Tims \& Bakker, 2010). Until very recently, with increased investigation into job crafting behaviors (i.e., behavior directed at managing the levels of demands and resources in the environment; Tims \& Bakker, 2010), individual employees' role in terms of altering the availability of job resources for the purpose of enhancing or maintaining work engagement has not been explored. This is a missed opportunity given the substantial research that indicates that employees are indeed proactive beings that regularly bring about change in their work environment (Bindl \& Parker, 2011; Crant, 2000).

Moreover, consideration of the individual necessitates a broader lens that includes both work and nonwork experiences. In addition to making changes to their work environment, employees may engage in behaviors outside of work that will either detract from or contribute to a positive state of engagement at work (Sonnentag, 2003). The 
reverse may also be true in that work experiences spill over and impact the quality of experiences in the nonwork domain (Greenhaus \& Powell, 2006). However, very few studies have examined the relationship between work engagement and experiences during nonwork, especially in the work to home direction (a notable exception is Culbertson, Mills, \& Fullagar, 2012). Understanding how positive states spill over and impact employees' experiences at home, especially in terms of how they maintain that positive state, is important for understanding how engagement might be sustained over time. A within-person approach that considers both work and nonwork behaviors in relation to each other and over time is required to address these open questions.

Therefore, the current study draws on research in the areas of job crafting and nonwork recovery (i.e., experiences outside of work that enable recovery from work stress; Sonnentag \& Kruel, 2006) to address these gaps in the literature. It is argued that these behaviors constitute employee-initiated behaviors both at work and at home that aim to build important psychological resources and are associated with daily fluctuations in work engagement. Moreover, cognizant of the dynamic and transportable nature of resources, the current study draws from COR theory and the theory of work-family enrichment (Greenhaus \& Powell, 2006) to examine how resource building efforts in one domain (work) might relate to experiences and behaviors in a secondary domain (home) and vice versa. In doing so, it is proposed that the transfer and building of resources through employee-driven work and nonwork behavior may set the stage for an upward cycle of resource acquisition, and by implication enhanced work engagement (Hobfoll, 2001). 


\section{Proposed Contributions}

The current study contributes to the literature in several important ways. First, rather than examining stable characteristics of the work environment, the focus of the current study is on specific behavioral strategies that employees might engage in in order to build psychological and job resources important for work engagement. It is well established that resources (both job and personal) are important for employee well-being and, specifically, work engagement (Bakker \& Demerouti, 2007; Bakker et al., 2014). Similarly, outside of work the rebuilding of resources is a primary explanation for why recovery experiences (e.g., relaxation, psychological detachment, mastery experiences) are proposed to be so important for individuals' well-being and subsequent work experiences (Sonnentag \& Fritz, 2007). Therefore, job crafting (i.e., one type of volitional behavior in which employees take steps to manage and build their resources at work) and nonwork mastery experiences (i.e., one type of recovery experience which is focused on engaging in activities that are challenging and present opportunities for learning something new or building skills) are two resource-building strategies identified in the current study and investigated in relation to work engagement. Thus, the role of the individual employee as an active agent in managing and building resources needed for maintaining a state of engagement is emphasized and a primary focus of the current study.

Second, a decade after seminal work on job crafting emerged in the organizational literature (Wrzesnieski \& Dutton, 2001), empirical research remains in its infancy around this concept, particularly with respect to its antecedents. Theoretical propositions by 
Wrzesnieski and Dutton (2001) suggest that crafting may be one strategy employees use to address a deficit or a particular need (e.g., need for social relationships). Alternatively, propositions from COR theory would suggest that individuals engage in resourceinvestment behaviors, like job crafting, when they have acquired a surplus and there is an opportunity for further resource gain. That is, rather than operating from a deficit of resources, the current study argues that individuals may actually be prompted to engage in job crafting when they feel they have sufficient resources to invest. To test this proposition, nonwork recovery experiences (namely, mastery experiences) are examined as a predictor of job crafting behavior. It is proposed that nonwork mastery experiences provide important psychological resources that employees bring with them to the work context and which inspire further resource acquisition behavior (i.e., job crafting). Therefore, the current study has the opportunity to expand the nomological network surrounding job crafting behavior, and contribute to our theoretical understanding of what drives this behavior on a daily basis.

Third, the academic literature focused on the relationship between work engagement and recovery from work stress has developed significantly in the recent past (Bakker, Albrecht, \& Leiter, 2011; Sonnentag \& Fritz, in press). Generally speaking, research has shown that recovery experiences predict increased engagement in the work role (Sonnentag, 2003); however, recent reports of reciprocal relationships between work engagement and recovery level suggest a bi-directional path that warrants further investigation (Sonnentag, Mojza, Demerouti, \& Bakker, 2012). These findings suggest the possibility that a high level of work engagement may be a replenishing experience in 
and of itself that has implications for employees' experiences as they transition to their nonwork roles. The current study builds on this work and provides a first test of the hypothesis that work engagement during the work day serves as an indicator of surplus resources for employees that encourages them to invest in resource building activities outside of work (i.e., mastery experiences).

Finally, a primary tenet of COR theory is that individuals are motivated to protect, maintain and acquire resources (Hobfoll, 1989). The theory posits that individuals will engage in resource investment behaviors in order to serve that purpose. In their recent review, Halbesleben and colleagues (2014) note that this resource investment process has been examined primarily in the context of coping following resource loss. In the context of the work-nonwork interface, it is important to examine the extent to which this process occurs when resources are already high. That is, by taking a positive-spillover approach to the resource-investment process it is possible to see how experiences at work (job crafting and work engagement) might be associated with nonwork behaviors at home (recovery experiences) and form the basis of gain cycles that are important for employee well-being. As such, the current study uses a day-level, within-person design to test the presence of an upward gain cycle as employees engage in resource building activities at work and at home throughout the work week.

\section{Overview}

Taken together, the current study tests a model of resource-building activities both at work and at home and their association with work engagement (Figure 1). At work, a mediation model is tested in which nonwork mastery experiences are associated with 
work engagement at the end of the work day via their relationship with increased job crafting (i.e., work-related resource-building activities). Next, work engagement is expected to spill over from work to home, prompting resource-building activities during nonwork the same day (i.e., nonwork mastery experiences) and indicating the presence of an upward gain cycle (Hobfoll, 2001).

The following chapters summarize the theoretical and empirical basis of these proposed relationships, and includes a detailed description of the proposed methods and analyses employed to test them. Specifically, Chapter 2 introduces the concept of state work engagement (SWE) and reviews pertinent research including its antecedents and outcomes. Chapter 3 provides the theoretical framework for the current study by discussing current conceptions of resources and their role in employee well-being and motivation, and the spillover and enrichment processes relevant for understanding how resources are transferred across the work and nonwork domains. Next, Chapters 4 and 5 review the literature surrounding other main constructs of interest in the current study which include nonwork mastery experiences in the context of recovery from work stress and job crafting, respectively. Chapter 6 provides an integration of the aforementioned chapters and hypothesis development. Chapters 7 and 8 provide details on the methodology employed in the current study as well as the results obtained. Chapter 9 concludes the document with a discussion of the contributions, potential limitations, and implications for future research and practice. 


\section{Chapter 2: State Work Engagement}

Early conceptualizations by Kahn (1990) defined work engagement as an investment and expression of physical, cognitive, and emotional energy. Later, Schaufeli and colleagues (2002) described work engagement as an affective motivational state characterized by vigor, dedication, and absorption. Vigor is indicated by high energy, resilience and a willingness to put forth extra effort. Dedication refers to a sense of pride, significance, and enthusiasm in one's work. And, absorption refers to being highly engrossed in one's work such that time passes quickly. While associated with certain job attitudes (job involvement, job satisfaction, organizational commitment; Hallberg \& Schaufeli, 2006; Rich et al., 2010), in most recent conceptualizations work engagement is distinct because of its energetic component (Bledow, Schmitt, Frese, \& Kuhnel, 2011; Sonnentag et al., 2010), and it has been classified as an active measure of work-related well-being (Ouwene, Le Blanc, Schaufeli, \& van Wijhe, 2012).

Notably, early conceptualizations by Macey and Schneider (2008) described work engagement as an attitude-like construct with both cognitive and affective components. In their review of the work engagement literature, Christian et al. (2011) summarized the ways in which work engagement had been conceptualized and measured in the organizational psychology literature and concluded that although work engagement constitutes a relatively enduring individual difference (with both between- and withinperson variance), its focus on the performance of work and investment of the self makes it distinct from other job attitudes such as job satisfaction which refer to evaluations of features of the organization or work. 
While job attitudes are presumed to be relatively stable over time, as much as 30$40 \%$ of the variance in work engagement has been found to fluctuate across days and within persons (Sonnentag et al., 2010). As a result, a number of recent studies have been focused on the state (rather than trait) form of work engagement (state work engagement; SWE; Breevart, Bakker, Demerouti, \& Hetland, 2012; Sonnentag et al., 2010).

State work engagement (SWE) is defined as a "transient, work-related experience that fluctuates within individuals over a short period of time" (Breevart et al., 2012, p. 2). Given the transient nature of state-like variables, daily diary designs that capture such momentary states are a practical means of studying SWE in organizations (Ohly, Sonnentag, Niessen, \& Zapf, 2010). Scholars have offered a number of advantages to examining work engagement at the state level. For example, trait-focused studies conducted at the between-person level treat fluctuations in participants' responses as error variance that should be ignored, whereas daily diary studies provide an opportunity to examine such within-person variation as a point of focus (Sonnentag et al., 2010). Breevart and colleagues (2012) argued that diary methodology allows for the examination of more proximal antecedents of work engagement (such as mood or other fleeting psychological states that vary within-person). Finally, they noted that because such methodology captures psychological phenomenon closer in time to real life experiences, it is a more reliable way of assessing and studying work engagement (Brevaart et al., 2012; Ohly et al., 2010).

Indeed, a growing body of evidence attesting to the value of examining work engagement at the daily level has emerged (Sonnentag et al., 2010). The following 
reviews the empirical literature on day-level work engagement as organized by its antecedents and outcomes. Particular focus is placed on studies examining within-person relationships as these are most pertinent to the hypotheses in the current study.

\section{Nomological Network of State Work Engagement}

Antecedents. Couched in the JD-R model, a substantial portion of the research on antecedents to SWE has been focused on identifying relevant job and personal resources. In terms of job resources, various work characteristics as well as aspects of the social context of work have been identified. For example, Kuhnel, Sonnentag, and Bledow (2012) conducted a diary study among 114 employees and found that daily perceptions of job control and team climate were predictive of work engagement. In addition, they found a significant interaction between job control and time pressure, such that on days when time pressure and job control were both high, work engagement was increased. In an investigation of the impact of flexible work arrangements (referred to in the study as New Ways of Working; NWW) on work engagement and exhaustion, ten Brummelhuis, Bakker, Hetland, and Keulemans (2012) found that on days when employees had control of the timing, location, and method of their work, they reported greater connectivity and more efficient and effective communication with their colleagues, which in turn led to greater work engagement throughout the day.

In terms of the social environment, both leadership and coworkers have been found to play a role in the promotion of daily work engagement. In a study of 42 employees over five working days, Tims, Bakker, and Xanthopoulou (2011) found that on days when leaders demonstrated transformational leadership behaviors, employees 
were more engaged, and this relationship was due to an increase in reported optimism by employees. Bakker and Xanthopoulou (2009) studied 62 coworker dyads and found that the level of engagement from one partner was positively associated with the level of engagement of the other partner, but only on days when the dyad communicated more frequently than normal. In addition, they found support for an indirect relationship between the first partner's work engagement and the other partner's daily performance, through a positive impact on the second partner's level of work engagement. These studies indicate that both work characteristics and aspects of the social environment are important job resources that impact work engagement at the daily level.

Personal resources have also been found to be important predictors of SWE. Although not originally included in the conceptualization of job resources in the JD-R model, Xanthopoulou and colleagues (2009) argued that personal resources, such as optimism, self-efficacy, and self-esteem, are important individual characteristics or states that are likely to have implications for how employees manage demands during the day and engage with their work. Indeed, these authors showed that these personal resources mediated the relationship between daily reports of autonomy and work engagement. In addition, day-level optimism and self-efficacy partially mediated the relationship between coaching and work engagement. In another diary study by Xanthopoulou and colleagues (2008), colleague support received during the day predicted self-efficacy and work engagement independently, and work engagement was found to mediate the relationship between self-efficacy and in-role and extra-role performance. Other personal resources such as positive mood before beginning work (Ouwene et al., 2012), or combinations of 
positive and negative mood (Bledow et al., 2011), and hope (Ouwene et al., 2012) have been found to be associated with SWE.

Particularly relevant to the current study is a series of daily diary studies showing that recovery-related activities or the feeling of being refreshed and recovered at the start of the work day, are important predictors of SWE. For instance, Kuhnel and colleagues (2012) found that feeling recovered in the morning before work was an important personal resource that positively predicted work engagement that day. Similarly, Sonnentag (2003) showed that feeling recovered was positively related to increased proactive behaviors through a positive association with day-level work engagement. Interestingly, the relationship between feeling recovered and work engagement during the day seems to be reciprocal, such that on days when employees are more engaged in their work, they report feeling less drained at the end of the work day (Sonnentag et al., 2012). However, this relationship is moderated by situational constraints which counteract the positive result of work engagement on feeling recovered. Ten Brummelhuis and Bakker (2012) conducted a daily diary study with 74 employees over the course of one work week and found that off-job activities (social, low effort, physical) increased next morning vigor through a positive relationship with psychological detachment and relaxation (two recovery experiences important for employee well-being; Sonnentag \& Fritz, 2007). Conversely, off-job activities associated with high-effort (work and household tasks) were associated with decreased vigor the next morning due to decreased psychological detachment and relaxation. 
Finally, emerging research also pertinent to the current study suggests that employees' efforts to manage the levels of demands and resources present during their work day (i.e., job crafting) are related to work engagement at the daily level. In the only study of day-level job crafting published to date, Petrou, Demerouti, Peeters, Schaufeli, and Hetland (2012) showed that seeking resources, such as seeking feedback from coworkers or a supervisor, was positively related to work engagement. Efforts to reduce the emotional, physical, or cognitive demands on employees during their work day were negatively related to work engagement. These findings are consistent with discussion from the proactive behavior literature which suggests that efforts to improve one's own fit with their job should result in greater motivation and effectiveness in one's role (Parker \& Collins, 2010).

Outcomes. Although a primary emphasis has been placed on establishing the antecedents to SWE, important research looking at the outcomes of SWE suggest that work engagement is important for employee well-being and effectiveness at work and at home. Within the work context, it seems that on days when employees are highly engaged they demonstrate increased proactive behaviors such as taking initiative and pursuing more learning opportunities (Sonnentag, 2003; Xanthopoulou et al., 2008) as well as increased task performance (Xanthopoulou et al., 2008). Relatedly, in a test of the motivational hypothesis posited by COR theory (Hobfoll, 1989), Xanthopoulou and colleagues (2009) found that among fast food workers, the business benefitted from greater financial returns on days when employees were more engaged. 
In a study of 52 extension agents who provided data two times per day for two weeks, Culbertson and colleagues (2012) found support for a positive spillover process between work engagement and work-family facilitation (when participation in one role enhances performance or functioning in another role; Wayne, Musisca, \& Fleeson, 2004). Specifically, they found that work engagement during the work day was positively associated with positive mood immediately following work, which was further associated with positive mood at home. In turn, that positive mood was associated with reports of work-family facilitation the same day. Thus, it seems that findings support a positive association between work engagement and enhanced effectiveness at work, and there is at least some evidence for the spillover effect of work engagement on functioning at home.

\section{Summary}

Research on the antecedents of SWE has examined both structural and social features of the work environment as well as personal factors. Consistent with the JD-R model, on days in which job resources (e.g., autonomy; Kuhnel et al., 2012) are higher than average for individual employees they are more engaged. Similarly, when employees perceive greater personal resources (e.g., self-esteem, optimism;

Xanthopoulou et al., 2008), they are more likely to experience enhanced engagement. These findings support the potential value in investigating the role employees play in building and acquiring such resources. Although few studies have examined the outcomes of SWE at the day level, initial findings suggest that on days when employees are more engaged in their work they exhibit increased task performance and proactive behavior (Sonnentag, 2003; Xanthopoulou et al., 2008), and are more likely to carry over 
that positive affective state to their experiences at home (Culbertson et al., 2012). In relation to the latter, the current study builds on these findings by further examining the relationship between work engagement and experiences outside of work. The following chapter (Chapter 3) describes the theoretical rationale for the hypothesized relationships in the current study. 


\section{Chapter 3: Theoretical Frameworks}

Chapter 3 provides an overview of the theoretical frameworks used to develop the study's hypotheses. Specifically, under the header "Resources Frameworks", COR theory and the JD-R model will be discussed. COR theory provides the conceptualization of resources as well as an understanding of their role in employee wellbeing and motivation. The current study will provide a test of important tenets of COR theory such as the extent to which employees with higher resource reserves will invest in future resource gain, and whether such investments support the existence of an upward gain cycle. The JD-R model serves a supplementary role by couching the concept of resources in the work context and providing a rationale for the relationships between work (job crafting) and nonwork (mastery experiences) behaviors and work engagement. In the final section, spillover and enrichment are discussed as these processes provide a rationale for the transference of resources between work and nonwork domains.

\section{Resources Frameworks}

Conservation of resources theory. Central to the hypotheses posed in the current study, is COR theory. COR theory is described as a stress and motivation theory (Halbesleben et al., 2014; Hobfoll, 2011) and proposes that individuals are motivated to retain, protect, and build resources important for mitigating stress associated with resource loss (Hobfoll, 1989). Hobfoll (1989) defined resources as objects, personal characteristics, conditions, or energies that are valued by the individual or that serve as a means for attainment of other valued resources. Therefore, stress is thought to be 
synonymous with loss, occurring as a result of a threat of resource loss, an actual loss of resources, or when there is a lack of resource gain after an investment.

Accordingly, studies within organizational psychology, and particularly occupational health psychology, have found support for the notion that resource loss is associated with the experience of stress and strain. However, Halbesleben et al. (2014) contend that COR theory principles that emphasize the motivational potential of losses and gains have been explored less often. For instance, Principle 2 states that people must invest resources in order to protect against future resource loss, recover from lost resources, or to gain new resources. Principles 3 and 4 take this one step further arguing that gain and loss spirals can occur when individuals possess a resource surplus or deficit, respectively. In the context of the workplace, loss spirals are expected to occur in “chronically stressful conditions, or where individuals or organizations are resource poor" (Hobfoll, 2011, p. 118), whereas gain spirals represent the acquisition of resources and position individuals and organizations to risk resources to meet new challenges and gain further resources. Taken together, these propositions of COR theory provide a rationale for individual employee behavior as it relates to managing personal well-being. That is, at any given time individuals may be engaged in the process of mitigating loss or attempting to build new resources which should result in differences in observed work behavior.

Halbesleben and colleagues (2014) used these principles to divide behavior into that which is focused on resource conservation and that which is focused on resource acquisition. In the context of experiencing stress, individuals are motivated to take 
measures to minimize the loss, promoting resource conservation efforts. Alternatively, under conditions of no stress individuals strive to build resource reserves in order to offset future losses (Hobfoll, 1989). For example, employees might make strategic decisions to invest resources in interpersonal relationships at work or take advantage of training opportunities, with the goal of building new resources. Importantly, those with greater resources are presumed to be more capable of garnering additional resources (i.e., sustaining well-being over a longer period of time), while those with fewer resources are less capable and subject to greater loss (i.e., burnout or other chronic health conditions; Hobfoll, 1989; Leiter \& Maslach, 2006).

Job demands-resources model. Incorporating the JD-R model provides guidance in terms of the factors that constitute resources in the work environment, and how such resource conservation or acquisition behaviors might impact organizationally relevant outcomes. Bakker and Demerouti (2007) define job resources as those physical, psychological, social, or organizational aspects of the job that are either functional in achieving work goals, reducing job demands, or stimulating personal growth or development. Resources are thought to occur at the organizational level (e.g., pay, job security), interpersonal level (e.g., supervisor support), the level of the organization of work (e.g., role clarity), and the task level (e.g., task variety; Tims \& Bakker, 2010). Notably, recent research has suggested an augmentation to the conceptualization of resources_ one that includes personal resources (Bakker et al., 2014). Drawing on COR theory, Xanthopoulou and colleagues (2009) found support for the role of personal resources (self-efficacy, self-esteem, and optimism) in predicting daily levels of work 
engagement. Moreover, these personal resources mediated the relationship between certain job resources (autonomy, coaching) and work engagement. Thus, the most recent conceptualization of resources, and the position taken in the current study, is that job resources constitute both aspects of the work environment itself as well as characteristics and states that employees bring with them to the work context.

The extent to which employees possess job resources will determine their level of engagement and motivation in the work role (Demerouti et al., 2001). In addition, and consistent with appraisal-focused theories of stress (i.e., transactional theory of stress; Lazarus \& Folkman, 1984), job resources are expected to moderate (attenuate) the negative association between job demands (defined as aspects of the job that are associated with sustained effort and physiological or psychological costs; Bakker \& Demerouti, 2007) and strain.

Building on COR theory, Demerouti and colleagues (2001) proposed two primary mechanisms to explain the relationship between job demands and resources and organizational outcomes: the health impairment process and the motivational process. The health impairment process refers to overtaxing work conditions (e.g., lack of autonomy, high workload) in which an employees' job resource reserves are exhausted. Bakker and Demerouti (2007) argue that employees in these circumstances must mobilize whatever resource reserves they have available in order to meet demands. The result of expending resources in this manner, and without adequately replenishing those resources, leads to heightened physiological and psychological reactions that manifest as reduced performance and health. Alternatively, the motivational process refers to conditions of 
surplus job resources (e.g., supervisor support, opportunities for learning) which foster positive affective and motivational states. Bakker and Demerouti (2007) contend that job resources are associated with intrinsic motivation because they provide opportunities for growth and development, which allows employees to meet fundamental intrinsic needs such as autonomy, relatedness, and competence (Deci \& Ryan, 1985). They should also be associated with extrinsic motivation to the extent that they help employees successfully achieve work goals (Bakker \& Demerouti, 2007). As a result, employees with more job resources are hypothesized to be more engaged in their work-a proposition that has been supported in meta-analyses (e.g., Cole, Walter, Bedeian, \& O’Boyle, 2012; Halbesleben, 2010).

\section{Work-family Enrichment and Positive Spillover}

A final framework that has relevance for the current study is the workfamily enrichment theory proposed by Greenhaus and Powell (2006). The construct of work-family enrichment is conceived as bi-directional (work can enrich family, and family can enrich work) and defined as, "the extent to which experiences in one role improve the quality of life in the other role" (Greenhaus \& Powell, 2006, p. 73). It has been investigated under other labels such as enrichment (Rothbard, 2001), positive spillover (Hanson, Colton, \& Hammer, 2006), enhancement (Ruderman, Ohlott, Panzer, \& King, 2002), and facilitation (Frone, 2003). Together these concepts refer to the ability for the work and nonwork roles to mutually benefit and enhance each other.

The theory proposed by Greenhaus and Powell (2006) explains how the quality of life in one domain can impact the quality of life in the opposing domain. 
Specifically, they argue that resources generated in one domain (or role) are transferred to the other domain (or role) via two primary mechanisms: an instrumental path and an affective path. According to the instrumental path, resources gained in one role are presumed to directly influence performance in the second role. For example, Greenhaus and Powell (2006) note that psychological resources such as self-efficacy can enhance performance in another role because of their ability to enhance motivation. In the context of the current study, self-efficacy gained through nonwork mastery experiences should transfer and directly enhance job crafting behaviors such as seeking challenges.

Alternatively, the affective path suggests that resources generated in the first role are either directly related to positive affect, which in turn relates to enhanced performance in the second role, or resources are indirectly related to positive affect in the first role through greater performance within that role. For example, resources generated at work should enhance positive affect at work either directly or because they enable greater performance at work. In turn, that positive affect positively impacts performance at home, and subsequent positive affect at home. For example, job crafting efforts that are successful could enhance positive affect at work. When an employee returns home they carry that positive affect with them, therefore contributing to greater nonwork performance (in this case, nonwork mastery experiences).

Thus, the work-family enrichment model provides support for why resources generated through work behaviors will spill over and impact functioning in the home domain, and vice-versa. Coupled with propositions by COR theory one could assume that when surplus resources (e.g., affect, self-efficacy) are transferred across 
domains, the availability of those resources should prompt resource investment behaviors aimed at building resources in the secondary domain. Similarly, the extent to which those resources are capitalized upon via successful investment behaviors and result in increased "resource pools" (Hobfoll, 1989, p. 520), should spur a gain cycle that perpetuates the enrichment process. Indeed, Hobfoll (2011) recently stated that "gain cycles are critical not only to workplaces, but also to work-family interactions" (p. 118).

\section{Summary}

Based on COR theory, the JD-R framework, and the theory of workfamily enrichment discussed above, the current study explores the process of resource acquisition through engagement in resource building strategies at work and at home (job crafting and nonwork mastery experiences, respectively). The following chapters will argue that job crafting and nonwork mastery experiences are two resource-building strategies that (a) require an investment of resources on the part of individuals, and (b) should be related to future resource gain. Mastery experiences are framed as one recovery experience that builds resources important for well-being. In turn, and according to the theory of work-family enrichment, nonwork mastery experiences that successfully build resources are expected to spill over and increase resource investment behaviors (job crafting) within the work role. The JD-R framework provides a rationale for how job crafting behaviors, in which employees actively alter the levels of demands and resources at work, are related to enhanced work engagement. Finally, drawing on both the theory of work-family enrichment and Hobfoll's (1989) discussion of gain cycles, the current study tests a reverse relationship between work engagement and nonwork mastery experiences. 
The following chapters review the relevant research literature pertaining to nonwork mastery experiences (Chapter 4) and job crafting (Chapter 5). 


\section{Chapter 4: Building Resources during Nonwork through Mastery Experiences}

A growing body of research has shown the important role that nonwork experiences play in employees' well-being and experiences at work (Fritz et al., 2010). A considerable evidence base exists now that confirms the notion that when employees travel between life domains (from work to home, or from home to work), they carry with them their experiences, cognitions, and emotions and these factors impact functioning in both domains (Edwards \& Rothbard, 2000; Greenhaus \& Powell, 2006). This is both an opportunity and potential liability for organizations as they must now consider not only the work environment, but how to support employees during nonwork as well (Weiss \& Rupp, 2011). Emerging research suggests that one way to do this is through encouraging employees to engage in recovery experiences during their nonwork time.

Recovery refers to "a process during which individual functional systems that have been called upon during a stressful experience return to their prestressor levels" (Meijman \& Mulder, 1998 as cited in Sonnentag \& Fritz, 2007, p. 205). Applied to the work context, the general assumption is that engaging in work-related activities consumes self-regulatory resources causing stress and fatigue; recovery occurs when such resources are no longer drawn upon and can be replenished or recuperated (Sonnentag \& Fritz, 2007). Drawing on COR theory, Sonnentag and Fritz (2007) argued that in addition to stopping the process of resource loss, recovery experiences that build resources (e.g., energy, positive mood) are integral in that they replenish resources that may have been lost during work. Accordingly, research has found that some recovery experiences (psychological detachment) reduce negative affective states, while others are related to 
increased positive affective states (relaxation and mastery) (Sonnentag, Binnewies, \& Mojza, 2008). The current study will focus on the experiences that help to build and restore resources during nonwork, namely, nonwork mastery experiences; however, first, the range of recovery experiences are briefly defined.

Distinct from the activities employees engage in in order to recover, recovery experiences refer to the underlying psychological experiences employees derive from various activities. For example, Sonnentag and Fritz (2007) developed a measure of recovery experiences that identified four primary recovery experiences: Relaxation, psychological detachment, mastery, and control. Relaxation refers to a state of low activation and increased positive affect. Activities that contribute to relaxation experiences could include deliberate relaxation techniques such as meditation, or other low-effort activities such as taking a walk or reading a book (Sonnentag \& Fritz, 2007). Psychological detachment refers to being physically and mentally disengaged from activities or thoughts about work. Control experiences refer to being able to decide for oneself how to spend their nonwork time which is associated with a feeling of autonomy (Sonnentag \& Fritz, in press). Finally, mastery experiences (the focus of the current study) are characterized by challenge and growth outside of work. Activities such as learning a new skill, engaging in sport activities (Sonnentag \& Jelden, 2009), or volunteering (Mojza, Sonnentag, \& Bornemann, 2011) have been cited as mastery experiences.

An important contribution of the recovery literature has been not only identifying how employees may recover from work demands, but when. Early research on respites 
focused on formal vacations as a means of recuperating and unwinding (Fritz \& Sonnentag, 2006; Westman \& Eden, 1997). Since then, research has shown that recovery can occur during the weekends (Fritz \& Sonnentag, 2005), on a day-to-day basis (Rook \& Zijlstra, 2006), and even within the work-day during lunch breaks (Krajewski, Wieland, \& Sauerland, 2010) or other short breaks (Zacher, Brailsford, \& Parker, 2014). Some scholars have argued that recovery that occurs on a daily basis may be even more important than recovery that occurs during vacations or other long respites (Demerouti, Bakker, Geurts, \& Taris, 2009). This is because the positive effects of vacation, in terms of well-being, positive mood, and feeling recuperated tend to fade out rather quickly (usually within two weeks of returning to work; de Bloom, Kompier, Geurts, de Weerth, Taris, \& Sonnentag, 2009; Westman \& Eden, 1997). Therefore, in order to have sustainable and positive effects on long-term well-being, the process of halting resource loss and regaining resources is necessary on an ongoing basis (Demerouti et al., 2009). In other words, a primary function of recovery at the daily level is to interrupt loss cycles that can develop because of sustained experiences of work stress (Hobfoll, 2001).

It can also be argued that engaging in daily activities that build resources can jumpstart gain cycles that make the experience of work demands less stressful in the first place (Hobfoll, 2001; Lazarus \& Folkman, 1984). In this sense, nonwork mastery experiences may be particularly relevant. Mastery experiences are important because unlike the other recovery experiences identified in the literature (relaxation, control, psychological detachment), mastery experiences are characterized by high activation (Sonnentag et al., 2008) and involve an investment of self-regulatory resources 
(Sonnentag \& Fritz, 2007). Sonnentag and Fritz (2007) argued that "although mastery experiences might put additional demands on the individual, these experiences are expected to result in recovery because they will help to build up new internal resources such as skills, competencies, and self-efficacy” (p. 206). From a COR perspective, mastery experiences are representative of motivated behavior in which employees invest time, energy, and other resources for the sake of restoring resources that have been lost, or simply building on current resource stores (Hobfoll, 2001). This is a critical function as resources are required in both the home and work domains in order to combat against the experience of stress (Hobfoll, 1989), and facilitate motivated and engaged psychological states (Bakker \& Demerouti, 2007).

Despite their potential importance, nonwork mastery experiences have not been examined in the literature as often as other recovery experiences, such as psychological detachment (Siltaloppi, Kinnunen, \& Feldt, 2009). This is unfortunate given their potential role in building resources needed for well-being and performance at work (Sonnentag \& Fritz, 2007; Sonnentag et al., 2008). Thus, the current study focuses specifically on nonwork mastery experiences and considers their role as an antecedent to job crafting behavior and engagement at work, as well as the reciprocal relationship with work engagement (i.e., nonwork mastery as an outcome of work engagement). These hypotheses are developed further in Chapter 6. First, the following reviews the research currently available that has examined nonwork mastery experiences, its correlates, antecedents, and outcomes.

\section{Nomological Net of Nonwork Mastery Experiences}


Antecedents. Sonnentag and Fritz (2007) have reasoned that rather than specific activities, it is the underlying psychological processes that certain activities induce that are central to the process of recovery from work. Nevertheless, in order to make practical recommendations to organizations, researchers must understand which activities constitute nonwork mastery experiences (or other recovery experiences), and that has driven the focus of some research. Interestingly, the work in this area has not often focused on the ability for sport, exercise, or learning a new skill to specifically predict mastery experiences, despite the assumption that these behaviors are important activities that promote mastery (Sonnentag \& Fritz, 2007). Rather, research has found that activities such as engaging in creative nonwork experiences (Eschelman, Madsen, Alarcon, \& Barelka, 2014), volunteering (Mojza et al., 2010), and eudaimonic entertainment experiences (i.e., feelings of meaningfulness or inspiration in response to media; Rieger, Reinecke, Frischlich \& Bente, 2014) are associated with greater reports of mastery experiences.

It is possible that engaging in mastery-inducing activities is influenced by individual difference factors. For instance, in their development of the Recovery Experience Questionnaire (REQ), Sonnentag and Fritz (2007) found that mastery experiences were associated with those who self-reported being higher on openness, extraversion, emotional stability, and engaged in more active coping strategies. It is also possible that general levels of self-efficacy are important for driving regular mastery experiences; however, this has yet to be tested in the literature. 
Finally, an important practical consideration is understanding the work factors that drive mastery experiences during nonwork. Although there is limited work in this area, initial research has found that work-related conditions are associated with the extent to which employees engage in mastery experiences during their time off work. For example, Sonnentag and Jelden (2009) found that on days when employees faced high situational constraints at work, they engaged in less effortful physical activity (exercise, sports) and more low-effort activities (watching television). Consistent with a COR approach, these authors reasoned that situational constraints (a hindrance demand, defined as that which thwarts goal accomplishment and results in frustration; LePine, Podsakoff, \& LePine, 2005) deplete employees’ self-regulatory resources, which, in turn, leaves little resources to engage in effortful activities after work.

Other research by Kinnunen and colleagues builds on the work by Sonnentag and Jelden (2009) by investigating both demands and resources in the work context, and their association with later mastery experiences. For instance, in a cross-sectional study of 527 employees from a variety of industries and occupations, Kinnunen, Feldt, Siltaloppi, and Sonnentag (2011) tested a structural model in which recovery experiences were proposed to mediate the relationship between job demands and resources and fatigue and work engagement. With respect to mastery experiences, their findings showed that mastery was positively related to work engagement, negatively related to fatigue at work, and was a partial mediator between job resources and work engagement. They followed this up with a longitudinal study in which they found that job resources (social support and supervisor justice) were positive predictors of mastery; above all other recovery experiences 
(Kinnunen \& Feldt, 2013). Thus, there is emerging evidence that job resources may be a particularly salient factor in relation to whether or not employees engage in mastery experiences during nonwork time.

Outcomes. Although still a relatively limited research area, the primary focus of research on nonwork mastery experiences to date has been focused on determining its outcomes, especially with respect to employee health and well-being, and somewhat less so to its work-related outcomes. This section reviews research on the outcomes of mastery experiences, including those studies that have taken a recovery-based perspective on activities that are indicative of mastery experiences (e.g., sport, physical activities) (Sonnentag \& Fritz, 2007).

An important outcome of mastery experiences appears to be enhanced affective states for employees, both within and outside of work. Affective experiences are important indicators of employee well-being because in the short-term they can be indicative of the experience of stress (e.g., anxiety; Ganster \& Rosen, 2013) and in the long-term they have been described as components of employee burnout or engagement (fatigue, activated positive affect, respectively; Bakker \& Demerouti, 2007). Research has supported a relationship between nonwork mastery and affect-based outcomes at various time intervals. For example, cross-sectional studies have found significant, negative relationships between nonwork mastery experiences and emotional exhaustion, depressive symptoms, need for recovery, and job exhaustion, and positive associations with life satisfaction and work engagement (Kinnunen et al., 2011; Siltaloppi et al., 2009; Sonnentag \& Fritz, 2007). Examining recovery during vacations, Fritz and Sonnentag 
(2006) showed that nonwork mastery experiences were significantly and negatively related to exhaustion immediately after vacation. Finally, studies conducted at the day level have found largely consistent results when examining either mastery experiences or other physical activities (e.g., sport, exercise), indicating significant relationships with increased well-being and mood (Sonnentag, 2001; Sonnentag \& Natter, 2004), happiness, vigor, feelings of being recovered before bed (Bakker, Demerouti, Oerlemans, \& Sonnentag, 2013), increased positive emotions at bedtime (Feurerhahn, Sonnentag, \& Woll, 2014), and decreased fatigue (Rook \& Zijlstra, 2006). Other research has indicated that these positive affective states persist and are evident the following morning before work (Sonnentag et al., 2008; ten Brummelhuis \& Bakker, 2012).

Research focused on work-related outcomes of nonwork mastery or other activities indicative of mastery have supported this spillover process. For example, ten Brummelhuis and Bakker (2012) found that physical activities (sports, dancing, cycling, going for a hike) were positively associated with next day work engagement, which was mediated by psychological detachment, relaxation, and vigor. Engaging in sport activities has also been associated with feeling recovered, vigorous and having low exhaustion the next morning (ten Brummelhuis \& Bakker, 2012). Very few studies have examined the extent to which these positive affective states impact work-related functioning and effectiveness while at work. A notable exception is a week-level study by Binnewies, Sonnentag, and Mojza (2009) which showed that nonwork mastery experiences (among other recovery experiences) were related to feeling recovered at the beginning of the work week. Feeling recovered significantly predicted personal initiative, organizational 
citizenship behaviors, and lower perceived effort during the week. However, Fritz and Sonnentag (2006) did not find support for a relationship between weekend mastery experiences and task performance or effort expenditure over the course of the following week. Thus, the extent to which mastery experiences are related to work-relevant behavior is not entirely clear-a gap the current study addresses. 


\section{Chapter 5: Building Resources during Work through Job Crafting}

Research supports the notion that employees are not passive in their roles, but active agents in constructing their work environments (Crant, 2000). Indeed, early discussions by Kulik, Oldham, and Hackman (1987) acknowledged that employees play a role in altering the characteristics of their work and considered this a type of bottom-up job redesign. Since then, this type of behavior has been termed job crafting, and has received recent attention in the academic literature. Wrzesnieski and Dutton (2001) defined job crafting as proactive changes employees make to the task, relational, and cognitive aspects of their jobs. Task crafting refers to changes made to specific tasks, the addition of tasks, or alterations in the time spent on tasks. Relational crafting refers to changes in interpersonal interactions at work, such as avoiding or increasing interaction with certain others. Finally, cognitive crafting refers to deliberate changes in the way work is perceived; for instance, in terms of its meaningfulness or impact. Wrzesnieski and Dutton (2001) argued that employees engage in this behavior for the purpose of finding and maintaining enhanced meaning and identity in their work-important components of work-related well-being (Wrzesnieski, LoBuglio, Dutton, \& Berg, 2013).

Bakker and colleagues (Bakker et al., 2012; Tims \& Bakker, 2010) have taken a slightly different approach to their conceptualization of job crafting, and this approach is adopted in the current study. Couched within the JD-R model, they define job crafting as “changes employees make regarding the demands and resources in their work environment” (Bakker et al., 2012, p. 1362). Tims, Bakker, and Derks (2012) used this conceptualization to develop a measure of job crafting behavior and found support for the 
validity of their hypothesized four-factor model. Specifically, they showed that job crafting behavior can be categorized into four types of behavior: Increasing social resources, increasing structural resources, increasing challenging job demands, and decreasing hindering job demands.

According to the JD-R framework, increasing resources (both structural and social) are expected to result in positive outcomes, such as increased motivation and engagement (Bakker \& Demerouti, 2007). In terms of increasing social resources, these behaviors might include reaching out to other colleagues or one's supervisor to ask for guidance or feedback. Increasing structural resources has to do with learning and development and could be associated with feelings of mastery within the work context, for example, attempts to acquire a new skill. Job demands are slightly more complicated. The challenge-hindrance stressor framework suggests differential associations between demands and outcomes based on the nature and appraisal of the demand as either a challenge (i.e., provides potential opportunities for growth and development) or hindrance (i.e., blocks goal attainment and results in frustration) (Cavanaugh, Boswell, Roehling, \& Boudreau, 2000). Therefore, efforts to increase challenge demands, such as taking on additional responsibility or workload, are expected to result in positive outcomes (Tims \& Bakker, 2010). Conversely, one would not be expected to take efforts to increase hindrance demands. Rather, Tims and colleagues (2012) proposed that decreasing hindering demands (i.e., efforts to reduce the emotional, cognitive, or physical intensity of work) would result in reduced strain. 
There are two notable implications that arise from Bakker and colleagues' (Tims \& Bakker, 2010) conceptualization of job crafting as compared to earlier definitions. First, their conceptualization deliberately excludes the cognitive component noted by Wrzesnieski and Dutton (2001). Bakker and colleagues have argued that rather than proactive attempts to alter job demands and resources, cognitive changes are passive adaptations or reactions to the work (Bakker et al., 2012). According to these authors, the benefit of this approach is the emphasis on behaviors that can be easily operationalized and observed (Petrou et al., 2012).

Second, this approach has implications for the frequency with which the behavior can be observed (Demerouti \& Bakker, 2013; Petrou et al., 2012). Although Wrzesnieski and Dutton (2001) suggested that job crafting was an "everyday behavior", most empirical studies have not examined it at this level. Indeed, to date only one published study has examined job crafting at the day level (Petrou et al., 2012). Petrou and colleagues (2012) reasoned that specific behaviors aimed at altering the levels of demands and resources will be observed more frequently than actual changes in job scope which occur less often (Lyons, 2008). In support of this, they examined job crafting using daily diary methods and found that $41 \%$ of the variance in seeking resources, $40 \%$ in seeking challenges, and $47 \%$ of the variance in reducing demands occurred withinpersons.

This is in contrast to reports by Lyons (2008) who conducted structured interviews with 107 salespersons asking participants to identify a time in the last year when they made a self-initiated change to their work which resulted in "substantial 
influence on their work activities" (p. 30). These authors found that on average, employees reported only 1.49 instances of job crafting over the course of one year, and $22 \%$ of the sample reported experiencing zero instances of job crafting. Although the differences in these reports in terms of the frequency of job crafting behavior can be attributed at least in part to methodological differences (daily reports versus retrospective reports that rely on participant memory), there does seem to be some evidence that conceptualizing job crafting as specific behaviors aimed at managing demands and resources on a regular basis appears to elicit more frequent observations. Nevertheless, it is assumed that job crafting can occur both in the short-term (daily; Petrou et al., 2012) and over longer time spans (weeks, months, years) depending on the scope and nature of the changes and job.

\section{Nomological Net of Job Crafting}

Although research on the topic of job crafting is quite new (Tims \& Bakker, 2010), theoretical discussion and initial empirical investigations have begun to elucidate the nomological network surrounding job crafting. The following provides a brief review of the literature surrounding job crafting and its correlates, antecedents, and outcomes.

Job crafting can be considered one type of proactive behavior (Parker \& Collins, 2010; Tims \& Bakker, 2010). Proactive behaviors involve self-initiated and changefocused behaviors (Fay \& Frese, 2001; Griffin, Neal, \& Parker, 2007). Parker and Collins (2010) used factor analysis to compare and categorize an array of proactive constructs. Their results showed support for a higher-order classification of proactive behaviors into three general categories: proactive work behaviors, proactive strategic behaviors, and 
person-environment fit behaviors. Proactive work behaviors are aimed at enhancing the internal organizational environment (e.g., taking charge, personal initiative). Proactive strategic behaviors include those focused at the organizational level and aimed at improving the organizations fit within the external environment (e.g., issue selling). Lastly, person-environment fit behaviors refer to those focused on facilitating a match between the person and their immediate work environment (e.g., feedback seeking). Within this framework, job crafting can be considered one type of proactive personenvironment fit behavior that is correlated with other forms of proactive behavior (Bakker et al., 2012).

Notably, discussions within the literature with regard the relationship between proactive behavior and job crafting have been somewhat contradictory. For example, Tims et al. (2012) and Demerouti and Bakker (2014) have argued that job crafting is distinct from proactive behavior because the outcome of the behavior is not necessarily organizational effectiveness (rather, the behavior is more likely to be inward focused and may or may not be aligned with organizational goals; Wrzesnieski \& Dutton, 2001). Other statements by this group of authors have described job crafting as "related to" or “one type of proactive behavior" (Tims \& Bakker, 2010; Tims et al., 2012). Most recently, Tims and colleagues (2013) discussed job crafting as one type of proactive person-environment fit behavior, citing Grant and Parker (2009). As indicated above, in the current study job crafting is considered one form of proactive behavior, categorized as a person-environment fit behavior per Parker and Collins (2010), and in accordance with most recent discussions by Tims and colleagues (2013). 
Other constructs theoretically and conceptually similar to job crafting include job change negotiation (Ashford \& Black, 1996), role innovation (Van Maanen \& Schein, 1979), idiosyncratic deals ( $i$-deals; Hornung, Rousseau, Glaser, Angerer, \& Weigl, 2010), and task revision (Staw \& Boettger, 1990). In each case, the behaviors involve some alteration to the work role or tasks performed within the role, and so are expected to be positively correlated with job crafting, although no empirical evidence currently exists to substantiate this. Distinctions in the context, focus, or motivation of the various behaviors differentiate them from each other and from job crafting as a construct (Tims \& Bakker, 2010).

Job change negotiation is considered a proactive socialization tactic used by new employees to alter their work tasks (Ashford \& Black, 1996). Similarly, role innovation has been investigated in the context of organizational entry as an outcome of organizational practices (i.e., organizational socialization tactics). Van Maneen and Schein (1979) reasoned that in some cases employees may disagree or reject the socialization process or their role in general leading them to essentially rewrite the "mission" or practices related to their role. Similarly, $i$-deals involve a negotiation around work arrangements (e.g., flexible work arrangements) between an employee and their supervisor. Finally, task revision is considered a form of counter-role behavior in which employees react to inaccurate or dysfunctional aspects of the work by making necessary changes to the work tasks (Staw \& Boettger, 1990). Tims and Bakker (2010) point out that job crafting is distinct from these behaviors in that it does not necessarily require the involvement of a supervisor or manager, and may or may not even be in line with 
organizational goals (Lyons, 2008). Rather, the behavior is focused inward, toward meeting individual needs and goals (Wrzesnieski \& Dutton, 2001).

Antecedents. Antecedents of job crafting behavior that have been investigated in the literature can be organized by person-related factors and work environment factors. Person-related factors found to be significantly associated with job crafting behavior include proactive personality (Bakker et al., 2012; Crant, 2000; Tims et al., 2012), career orientation (Leana, Appelbaum, \& Shevchuk, 2009), and cynicism, which was negatively related (Tims et al., 2012). In a qualitative study among sales persons, Lyons (2008) found support for a positive association between cognitive ability, quality of one's selfimage, perceived level of control, and readiness for change and job crafting. Other person-related factors assumed to either predict job crafting directly, or moderate the relationship between person-environment fit and job crafting, include self-efficacy and regulatory focus (Tims \& Bakker, 2010); however, these have yet to be tested in the literature. Wrzesnieski and Dutton (2001) have theorized that job crafting results from the need for control, the need for a positive self-image, and the need for human connections, needs that Deci and Ryan (1985) identified as fundamental to intrinsic motivation and well-being for humans.

Work-related factors examined in the literature to date have identified work characteristics, such as autonomy and task interdependence as important boundary conditions on job crafting behavior. In their theoretical paper, Tims and Bakker (2010) considered autonomy a "pre-condition" for job crafting to occur. This was supported by findings from Leana and colleagues (2009) that showed that discretion, in the methods 
and timing of work, was positively associated with both individual and collaborative job crafting. Petrou and colleagues (2012) reported similar findings in a day-level study of job crafting. Taking this one step further, they showed that it was the interaction between high autonomy and high work pressure (active jobs) that was positively related to job crafting during the day_-specifically, seeking resources and reducing demands dimensions of job crafting.

Interestingly, Berg, Wrzesnieski, and Dutton (2010) conducted a qualitative study among employees from two organizations, and found that higher rank employees (a proxy in their study for responsibility and autonomy) expressed challenges to job crafting stemming from limitations related to how they felt they should be spending their time. Conversely, lower-ranked employees expressed that challenges to job crafting resulted from limitations imposed on them by others. However, despite these limitations, and despite having less formal autonomy and power, lower ranked employees expressed that they felt they had more opportunities to craft their job than higher-ranked employees. It seems future research is needed to understand better the complex relationship between autonomy and job crafting.

Other work characteristics such as task interdependence have been identified as potentially important conditions that determine whether job crafting can and will occur (Tims \& Bakker, 2010; Wrzesnieski \& Dutton, 2001). Notably, Leana and colleagues (2009) found that task interdependence was only positively related to collaborative job crafting, and not related to individual job crafting. Also relevant for promoting 
collaborative crafting, is the extent to which one feels supported by their supervisor and the number of social ties they have within an organization (Leana et al., 2009).

Outcomes. Studies investigating outcomes of job crafting behavior are scarce. Of those available, findings support the JD-R perspective taken by Bakker and colleagues which is that job crafting enhances work engagement and performance (Bakker et al., 2012; Petrou et al., 2012; Tims et al., 2012). For example, Bakker and colleagues (2012) sampled 95 co-worker dyads and found that seeking challenges was positively associated with work engagement and co-worker reported in-role performance. Similarly, Petrou and colleagues (2012) reported a positive association between daily seeking challenges and work engagement, while daily reducing demands was negatively, albeit weakly, related to work engagement. Tims and colleagues (2012) tested and found support for the criterion validity of their measure of job crafting via positive associations between job crafting (increasing structural and social resources, and increasing challenging demands) and other-reported work engagement (decreasing hindering job demands was not related to work engagement). Finally, Tims, Bakker, Derks, and van Rhenen (2013) investigated job crafting at the individual and team levels, and found support for their model in which individual work engagement mediated the relationship between individual job crafting and individual performance; team work engagement mediated the relationship between team job crafting and team performance; and, team job crafting was positively associated with individual performance. Together, these results provide an initial body of evidence for the positive impact of job crafting on individual well-being and effectiveness. 
Other outcomes found in relation to job crafting behavior have included more favorable job attitudes (Leana et al., 2009), decreased boredom (Van Hooff \& van Hooft, 2014), and enhanced employability (Tims et al., 2012). Leana and colleagues (2009) examined both individual and collaborative job crafting and found that both were associated with enhanced job satisfaction, collaborative crafting was also positively associated with increased organizational commitment; however, neither was significantly related to turnover intentions. Van Hooff and colleagues (2014) conducted a study of employees of various organizations, and found that job crafting was negatively related to work-related boredom, and moderated (attenuated) the relationship between boredom and bored behavior at work. These findings support propositions by Tims and colleagues (2010) which suggest that job crafting is a means of mobilizing important resources that facilitate engagement in the work role. Finally, Tims and colleagues (2012) have found positive relationships between job crafting and employability, reasoning that employees who craft more difficult tasks and demonstrate a desire to take on additional responsibility will be considered more employable compared to others who do not take such initiative.

Conceptual discussions and theoretical models propose a number of outcomes that have yet to be tested in the research literature. For instance, Kira, van Eijnatten, and Balkin (2010) argue that job crafting facilitates organizational learning and the translation of personal resources that build sustainable work ability. These authors point out that constantly changing conditions (characteristic of today's workplace) require employees that can develop the necessary resources (i.e., learning) and employ those resources as 
conditions demand (i.e., translation). Tims and Bakker (2010) have argued that job crafting should result in enhanced resilience, thriving, increased person-job fit, and greater perceived meaning of work, but these relationships have yet to be tested empirically. Finally, Wrzesnieski and colleagues (Wrzesnieski \& Dutton, 2001; Wrzesnieski et al., 2013) have proposed that the primary purpose of job crafting is to enhance meaning and identity with one's work.

The current study contributes to our understanding of the nomological network surrounding individual job crafting behavior by examining one untested antecedent, nonwork mastery experiences. Further, the current study couches job crafting in the context of a mediational model to elucidate how resource building activities at work (job crafting) may be one mechanism by which activities and psychological process that occur during nonwork (nonwork mastery experiences), are translated into work engagement during the work day. This is the first study to examine job crafting in terms of its association with nonwork experiences, and as such makes an important contribution to the literature on the work-nonwork interface. 


\section{Chapter 6: Hypotheses}

The previous chapters introduced the overall model and hypotheses of the study (Chapter 1), discussed the theoretical frameworks that support these hypotheses (Chapter 3), and reviews the relevant literature surrounding nonwork mastery experiences (Chapter 4), job crafting (Chapter 5), and state work engagement (Chapter 2). Here, I provide a more specific discussion and statement of the study hypotheses in light of recent theoretical and empirical research.

\section{Nonwork Mastery Experiences and Daily Work Engagement}

Consistent with work-family enrichment theory (Greenhaus \& Powell, 2006), and research on nonwork recovery experiences (Kuhnel et al., 2012; Sonnentag, 2003; ten Brummelhuis, \& Bakker, 2012), such experiences are expected to generate important psychological resources that either directly or indirectly enhance work engagement the following work day (Kinnunen et al., 2011; Siltaloppi et al, 2009). Because nonwork mastery experiences are associated with opportunities for challenge and learning (Sonnentag \& Fritz, 2007), they provide employees the ability to rebuild resources lost during work time and are associated with feeling refreshed and recovered

the following morning (Binnewies, Sonnentag, \& Mojza, 2010). In turn, employees who start the day feeling positive, efficacious, and recovered from the previous day will perceive the availability of resources that enable them to be vigorous, dedicated, and absorbed in their work throughout the day (Bakker \& Demerouti, 2007; Sonnentag, Mojza, Demerouti, \& Bakker, 2012; Xanthopoulou et al., 2009). Employees equipped with resources from engaging in nonwork mastery experiences should be better able to 
cope with job demands (Bakker \& Demerouti, 2007) and are more likely to experience feelings of positive affect and energy (Sonnentag et al., 2008). Therefore, consistent with prior research that has found positive relationships between feeling recovered in the morning and work engagement (Binnewies et al., 2010; Sonnentag, 2003), it is hypothesized that on days when employees have engaged in more nonwork mastery experiences, such as engaging in novel experiences or challenging themselves to push through boundaries, the evening before, they will be more likely to experience high levels of work engagement while at work.

H1: Nonwork mastery experiences will be positively related to work engagement.

\section{Nonwork Mastery Experiences and Daily Job Crafting}

COR theory (Hobfoll, 1989) posits that surplus resources can motivate resource investment behaviors focused on acquiring new resources for the purpose of stocking reserves that protect against future resource loss (Halbesleben et al., 2014). To the extent that nonwork mastery experiences successfully generate personal resources such as positive mood, a sense of efficacy, or energy (Sonnentag et al., 2008; see additional analyses for tests of some of these relationships), they should signal to employees that they have adequate resources to risk investing in behaviors that have the potential for future resource gain. Indeed, Rodriguez-Munoz, Sanz-Vergel, Demerouti, and Bakker (2012) stated, "recovery opportunities may help one to have a more positive view of the work environment, so that people feel full with energy and they invest it in creating new resources (e.g., by organizing their tasks or by asking for feedback)" (p. 88). Job crafting behaviors that are focused on building resources (seeking resources and 
increasing challenging job demands) represent one type of work-related investment behavior that provides opportunities for future gain, and has been found to be more likely in the context of the availability of resources. For instance Petrou and colleagues (2012) found that daily accounts of job crafting were more likely when employees perceived a high degree of autonomy during the day. Similarly, Clegg and Spencer (2007) argued that employees are more likely to engage in job crafting behaviors when they perceive themselves as being competent. Therefore, mastery experiences that build important personal resources should prompt employees to engage in additional resource acquisition or resource building behaviors at work. That is, on days when employees engaged in higher than usual nonwork mastery experiences the evening before, they will be more likely to exhibit job crafting behavior at work.

Hypothesis 2a-b: Nonwork mastery experiences will be positively related to (a) seeking resources and (b) seeking challenges at work.

\section{Job Crafting and Daily Work Engagement}

Tims and Bakker (2010) have argued that job crafting behavior represents active attempts by an employee to manage the levels of demands and resources at work. Drawing on the JD-R model and the motivation hypothesis in particular, job resources prompt both intrinsic and extrinsic forms of motivation - intrinsic because job resources provide opportunities for learning and development, and extrinsic because they help employees achieve work goals (Bakker \& Demerouti, 2007)—which can be observed as increased work engagement. It follows then, that the extent to which employees successfully mobilize the resources available to them through their own job crafting 
efforts, they will be more engaged during the work day (Petrou et al., 2012). Indeed, research at the day level by Petrou and colleagues (2012) has supported this association; although, both job resources and work engagement were assessed at the same time point within the work day so the reverse relationship cannot be ruled out. The current study builds on these findings by temporally separating the assessment of job crafting and work engagement, and proposes that on days when efforts are made to increase one's available resources and seek out opportunities for learning and growth, they will be more likely to exhibit enhanced work engagement the same day.

Hypothesis 3a-b: (a) Seeking resources and (b) Seeking challenges will be positively associated with work engagement.

\section{Nonwork Mastery Experiences, Job crafting, and Work Engagement}

Taken together, the arguments above suggest a mediational path in which nonwork mastery experiences relate to increased work engagement indirectly through enhanced job crafting efforts. COR theory suggests that when employees perceive a surplus of resources (i.e., a lack of loss and therefore a lack of experienced stress), they will be motivated to engage in resource building behaviors and can afford to invest resources for the sake of future resource gain. Indeed, a primary principle of the theory states that those who possess high resources will more easily attain additional resources (versus those operating from a resource deficit). The current study proposes that engaging in nonwork mastery experiences builds important affective and energetic resources that are transferred to the work domain (Edwards \& Rothbard, 2000; Greenhaus \& Powell, 2006) and signal to an employee that they have enough resource reserves to engage in 
behaviors that provide opportunities for additional resource gain-job crafting behaviors. In turn, job crafting efforts, such as seeking feedback or taking on additional responsibilities at work, allow employees to build additional resources that can help employees view demands as challenges rather than hindrances (Cavanaugh et al., 2000) and is related to increased work engagement (LePine et al., 2005). Therefore, on days when employees engaged in higher than average nonwork mastery experiences the evening before, they will be more likely to invest energy in job crafting behaviors, which in turn will be associated with enhanced work engagement.

Hypothesis 4: (a) Seeking resources will mediate the relationship between nonwork mastery experiences and work engagement.

Hypothesis 4: (b) Seeking challenges will mediate the relationship between nonwork mastery experiences and work engagement.

\section{Work Engagement and Nonwork Mastery Experiences}

Finally, work engagement in and of itself can be considered a high resource state to the extent that is associated with activated positive affect (Bledow et al., 2012) and a sense of vigor. Work-family enrichment theory (Greenhaus \& Powell, 2006) suggests that when employees generate resources in one role (work) that have relevance in a secondary role (home), those resources can facilitate a greater quality of life in the second role. The process occurs through a direct impact of resources from the first role on performance and affect in the second role, or indirectly through enhanced positive affect in the first role that translates into enhanced performance in the second role. In the current study, employees who effectively build resources through engaging in job 
crafting behaviors will be more engaged at the end of the work day. This state of engagement, which is characterized by high positive affect and vigor, should therefore directly impact functioning in the work domain. Accordingly, prior research by Culbertson and colleagues (2012) found that daily work engagement carried over and was positively associated with positive affect at home and increased reports of work-family facilitation.

In relation to recovery from work, research supports a positive relationship between experiences at work and engagement in recovery activities and experiences. For example, van Hooff, Geurts, Beckers, and Kompier (2011) found that when employees reported greater pleasure with their work, they experienced greater vigor and less fatigue at bedtime. Sonnentag and Jelden (2009) showed that on days when employees faced high situational constraints, they engaged less in effortful physical activity (exercise, sports) and more in low-effort activities. They reasoned that depleted resources hindered employees' engagement in effortful activities. Similarly, in a two-wave longitudinal study by Kinnunen and Feldt (2013), results showed that characteristics of the work environment (social support and justice of the supervisor) were positively related to nonwork mastery experiences. They reasoned that "employees who have high resources on the job are likely to have more internal resources (e.g., energy) available for learning and decision making during nonwork time" (p. 372). Based on this rationale, it is expected that high levels of work engagement at the end of the work day are indicative of a high resource state that employees take with them as they transfer to the home domain. In turn, this availability of resources encourages employees to engage in nonwork 
experiences that offer opportunities for future resource gain (i.e., nonwork mastery experiences).

Hypothesis 5: Work engagement will be positively associated with nonwork mastery experiences the same evening.

\section{Additional Analyses}

Critical to the proposed relationships discussed above is the actual building, or generation of psychological resources that can be leveraged during engagement in work-related tasks or outside of work during nonwork time. Although these processes are implicit in the above discussion and analysis, the explicit testing of the extent to which resource building behaviors and psychological resources are related could serve to underscore and support findings from the proposed model. In their recent review of research on COR theory in the organizational sciences, Halbesleben and colleagues (2014) note that it is not uncommon for research to assume the presence of resources rather than explicitly test their existence. He argues that the drawback of this approach is that it is impossible to know what resources are important for driving the outcomes measured making it difficult to generate recommendations for interventions aiming to target specific resources.

Therefore, in addition to the hypotheses formally stated above, exploratory analyses examining the extent to which nonwork mastery experiences and job crafting behaviors are related to psychological resources (positive affect, efficacy beliefs), and whether these resources do indeed mediate the proposed relationships in the model, were tested. Positive affect and efficacy beliefs have been selected as relevant psychological 
resources for a number of reasons. First, both have been found to be important indicators of well-being (Deci \& Ryan, 1985; Fredrickson \& Joiner, 2002) as well as drivers of motivated work behavior (Bindl, Parker, Totterdell, \& Hagger-Johnson, 2012; Parker, Bindl, \& Strauss, 2010). For instance, Tims, Bakker, and Derks (2014) conducted a daily study and found that on days when employees felt more efficacious they were more likely to engage in job crafting behaviors. Other work in the general proactivity literature has found positive associations between positive affect and proactive behaviors, such as taking charge (Fritz \& Sonnentag, 2009).

In addition, both should be proximal outcomes of nonwork mastery experiences and job crafting. In the case of the former, Fritz, Sonnentag, Spector, and McInroe (2010) examined the relationship between weekend recovery experiences and affect. Results from their analyses showed that engaging in mastery experiences over the weekend was positively related to feelings of joviality, self-assurance, and serenity at the end of the weekend. Sonnentag and colleagues (2008) conducted a daily diary study with 166 public administration employees and found that mastery experiences were positively related to activated positive affect the following morning. Similarly, other day-level findings support the relationship between engaging in sport or physical activities indicative of mastery experiences, and well-being (in part characterized by high positive mood and vigor) the same evening (Sonnentag, 2001; Sonnentag \& Natter, 2004). To date no daylevel study has examined the relationship between mastery experiences and efficacy beliefs, however Sonnentag and Fritz (2007) and others (e.g., Fritz et al., 2010) have argued that mastery experiences should promote a sense of competence to the extent that 
employees are successfully engaging in challenging situations that offer opportunity for growth and development.

To the extent that job crafting behavior successfully mobilizes important job resources and enables performance in the work role, it should be related to increased efficacy beliefs and positive affect. For example, an employee who receives positive feedback as a result of engaging in job crafting behavior will feel more confident about their abilities and more positive about their work experience that day. Although no studies to date have examined efficacy beliefs and positive affect as outcomes of job crafting behavior, other research suggests support for this relationship. For instance, Xanthopoulou and colleagues (2009) sampled 42 fast food employees and found that personal resources (self-efficacy, self-esteem, optimism) partially mediated the relationship between job resources (autonomy, coaching, team climate) and work engagement. Therefore, to the extent that job crafting behaviors do indeed mobilize job resources, there should be a positive relationship with other personal resources, and by extension work engagement. The proposed additional analyses will provide a test of these questions.

Specifically, the following research questions are posed:

RQ1: Do efficacy beliefs and positive affect mediate the relationship between nonwork mastery experiences and job crafting behavior (a: Seeking resources; $b$ : Seeking challenges) at work?

RQ2: Do efficacy beliefs and positive affect mediate the relationship between nonwork mastery experiences and work engagement? 
RQ3: Do efficacy beliefs and positive affect mediate the relationship between job crafting (a: Seeking resources; b: Seeking challenges) and work engagement?

\section{Summary}

Taken together, the hypotheses proposed in the current study suggest that on days when employees have engaged in nonwork mastery experiences the prior evening, they should come to work the next morning with the perception of surplus resource reserves that prompt engagement both directly (Hypothesis 1) and indirectly through additional resource building behaviors at work-specifically, job crafting (Hypothesis 2). In turn, employees who successfully mobilize and increase the resources they have available to them through job crafting efforts they will be more engaged at the end of the work day (Hypothesis $3 \& 4$ ). High levels of work engagement that are characterized by the availability of affective and energetic resources will then spill over to employees' experiences during nonwork time through the work-enrichment process and impact functioning in the nonwork role (Greenhaus \& Powell, 2006), specifically the willingness and motivation to engage in further resource building efforts during nonwork (nonwork mastery experiences; Hypothesis 5). Therefore, to the extent that the previous hypotheses in the study are supported, this reciprocal process between work and nonwork experiences supports the existence of an upward gain cycle (Hobfoll, 1989; Salanova, Llorens, \& Schaufeli, 2011). Further, additional analyses will be conducted in order to examine the validity of characterizing job crafting and nonwork mastery experiences as resource-building strategies (i.e., To what extent do are psychological resources actually associated with these behaviors?) as well as better understand the mechanisms that 
explain the formally proposed relationships in the study. The following chapters summarize the method (Chapter 7) and analysis approach (Chapter 8) used to test these hypotheses and additional analyses. 


\section{Chapter 7: Method}

\section{Participants}

Participants were recruited from a global technology firm. However, only employees based in the United States and belonging to selected departments were included as potential participants in the study. Sampling in this fashion was conducted for two primary reasons. First, research from cross-cultural psychology suggests that culture can impact factors relevant to intrinsic motivation (e.g., self-efficacy) as well as volitional behaviors such as feedback seeking, exploration, and curiosity (Gelfand, Erez, \& Aycan, 2007). Given the focus in the current study on motivation-related constructs (e.g., job crafting, work engagement), an effort was made to limit the sample to a single national culture (i.e., United States) in order to examine common psychological processes.

Second, the organization requested that the study be limited to selected departments rather than administered across the entire organization. Organizational leaders were concerned with survey fatigue of employees who were asked to participate in other company-driven surveys, as well as the current workloads of certain departments that might preclude them from participating. To maintain as much consistency across the departments as possible, departments were ultimately selected if the majority of employees within the department were white-collar, office workers, and if the leaders of those departments agreed to help promote and drive participation in the study within those departments. 
Based on these criteria, two departments participated in the study, Supply Chain and Information Technology. Supply Chain is responsible for seeing products through from the manufacturer, or supplier, to the customer. These employees (i.e., Supply Chain) held largely administrative and processing positions; almost half (49.2\%) of the sample came from Supply Chain. The Information Technology department comprises those with expertise in computer hardware, software, and/or systems management. Information Technology employees comprised $11.1 \%$ of the total sample. As a final effort to collect additional responses, a local office from the same organization was approached and agreed to participate in the study. This business group is primarily tasked with the design and development of new products. This group is not its own department as in the case of the other two groups, but is comprised mostly of participants with engineering or design backgrounds. Other participants included those doing administrative jobs or other miscellaneous positions (e.g., facilities manager, procurement, human resources/corporate). Approximately $40 \%$ (39.7\%) of the total sample belonged to departments operating within this local business group.

Some research has suggested that job characteristics can impact the extent to which employees have the capacity to engage in certain job crafting behaviors (Leana et al., 2009; Petrou et al., 2012). As such, selected job characteristics were assessed as part of the baseline survey in order to garner a more comprehensive picture of the types of jobs held by participants. Across the groups, participants reported relatively high task variety $(M=4.32, S D=.76$; assessed on a 5-point scale; refer to Appendix D for scale information), moderate task interdependence $(M=3.76, S D=.84)$ and autonomy $(M=3.22$, 
$S D=.81)$, and somewhat low job complexity $(M=1.78 ; S D=.67)$ within their respective positions. The following describes the sample in further detail.

On average, participants in this sample were 42.1 years of age $(S D=11.13)$. Almost two-thirds of the sample was male (63.5\%). Just over half of the sample (58.7\%) identified themselves as Caucasian (non-Hispanic), followed by Asian (25.4\%), Hispanic/Latino (9.5\%), African American (3.2\%), Native Alaskan or Pacific Islander (1.6\%), and other, not-specified (1.6\%). Over half the sample was college educated with $34.9 \%$ indicating that they held a 4-year degree or equivalent, and $34.9 \%$ an advanced degree. $12.7 \%$ indicated that they held a 2 -year degree or equivalent, $15.9 \%$ some college, and $1.6 \%$ a high school diploma. Approximately one quarter (27\%) of the sample described themselves as holding supervisory positions (defined as having staff that directly report to you), with the remainder (73\%) describing themselves as "nonsupervisory". On average, participants worked within the organization for $6.37(S D=4.42)$ years. All participants worked at least five days per week $(M=5.06 ; S D=.25)$ and a minimum of 40 hours per week ( $M=46.57 ; S D=5.58)$. Participants were also asked to report the average days per week they worked remotely. Three quarters of the sample $(n=47,75 \%)$ indicated they did not work remotely at all. Of those that did work remotely, $19 \%(n=12)$ reported typically working one day per week from home, $1.6 \%(n=1)$ three days per week, and $4.8 \%(n=3)$ five days per week.

Non-work demographic information was also included in order to garner a more comprehensive picture of the sample as it relates to non-work circumstances. A majority of the sample indicated that they were married, or living with a romantic partner (74.6\%), 
and over half reported that they had at least one child under the age of 18 living with them at least half time $(57.1 \%)$.

In order to recruit as many employees as possible, a two-stage procedure was employed as recommended by Ohly and colleagues (2010) for use in diary research. According to this approach, leaders serve as a first touch point for researchers and an important part of the recruitment strategy. In the second phase, potential participants are targeted for recruitment in the study itself. In the first stage, discussions with leaders from each group were undertaken to describe the potential benefits and challenges of conducting the study with their group. The goal of these meetings was to ensure leaders understood the time commitment involved for employees and to obtain their commitment to assist in driving participation in the study. Although leaders were not aware of which employees chose to participate in the study, leaders were provided information on the response rates for their group and could therefore contribute through helping to boost energy and excitement around the project internally. In the second phase, group leaders first sent out a standardized announcement email that informed employees about the study and that an invitation email from PSU researchers would follow in the next several days. The intention was to demonstrate organizational and senior leadership support for participation in the study in order to increase participation rates. Appendix A includes a copy of the announcement email template provided to the organization. This was followed by an invitation email sent directly by me to potential study participants that provided additional details on the study, and asked them to contact me directly if they were interested in participating. Appendices B and C provide a copy of the email 
template, as well as the description of the study that was attached to the email. As recommended by Green, Rafaeli, Bolger, Shrout, and Reis (2006), this information was provided to potential participants in order to facilitate a sense of collaboration and respect necessary when studies require a heightened level of effort for participants. If employees expressed interest in participating in the study, a reply email with a link to the baseline survey was sent, and they were included in the participant list in Qualtrics to receive automatic invitations to the daily surveys.

Sampling in the context of diary studies represents a "two-stage cluster sampling" in which individuals are sampled as a first step followed by daily observations as a second step (Ohly et al., 2010, p. 87). Although there is some variation in how response rates are computed and reported among diary studies in organizational research, it is not uncommon to focus on the reporting of compliance rates (which reference the second step: sampling of daily observations) rather than traditional response rates (which refer to the first step: sampling of individuals). However, for the purpose of the current study, both compliance rates and traditional response rates are calculated to provide additional context on the representativeness of the data. In the first step, response rate is calculated based on the ratio of the number of participants that completed the baseline survey $(n=64)$ to the total number of participants that were invited to participate in the study $(n=186)$, resulting in a response rate of $34 \%$. (These data serve as the basis of the demographic and work characteristics information discussed above.) Relative to traditional organizational research, this response rate is somewhat low. However, scholars have noted the difficulty 
of recruiting participants for dairy research given the involvement required to participate in the study (Iida, Shrout, Laurenceau, \& Bolger, 2012).

In the second step, compliance rate is calculated based on the ratio of completed daily observations to the total number of possible observations (based on the number of participants that registered to participate in the study). Based on the current research design, participants could provide a maximum of five days of daily data. A total of 76 participants expressed initial interest in the study and asked to be registered to participate; therefore 380 daily observations were possible $(76 * 5=380)$. At the completion of the study, 73 participants completed at least one daily survey $(73 / 76=96 \%)$ resulting in a total of 360 daily observations $(360 / 380=94.7 \%)$. The average number of daily observations per participant was 4.93 as calculated by Mplus (Muthén \& Muthén, 19982012).

Nonresponse analyses comparing those who completed both the baseline survey and the daily surveys with those who completed only the baseline survey were not conducted as originally intended because there were only two participants who provided only baseline data and no daily data.

\section{Procedure}

All surveys were administered using Qualtrics, a third-party administration software (www.qualtrics.com). There are a number of advantages to employing a webbased data collection methodology in daily diary research. For instance, a primary benefit of diary research is the reduction in retrospective bias (Reis \& Gable, 2000). However, 
the data collection device used in the study can play a role in the extent to which this advantage is realized (Ohly et al., 2010). Some reports indicate that as few as $11 \%$ of entries using paper-pencil methods are compliant in terms of the time of survey completion (Stone, Shiffman, Schwartz, Broderick, \& Hufford, 2002). Alternatively, use of a web-based data collection methodology ensures that participants provide responses that adhere to the design of the study. In addition, online data collection is associated with relatively low cost and provides both researchers and participants added convenience and flexibility.

Although there are many potential advantages, it is also important to note the potential limitations of this methodology. For example, an important consideration when using web-based methods is participants' ability and willingness to access a computer and the internet. It is possible that this requirement may prohibit some employees from participating. Therefore, prior to selecting a final sample, it was confirmed with the organization that participants would have regular access to email (in order to view study invitations) and be able to complete surveys using the internet without drastically interrupting their regular work tasks or location. Another possible limitation is the absence of a researcher on-site to help answer questions about participation in the study itself or follow up with participants on survey responses that are unclear or require additional detail. Therefore, the reliability of the data is largely dependent on the assumption that participants understand what is being asked of them and are able and willing to provide accurate responses to the survey. 
Participants were first invited to complete a baseline survey capturing demographic and trait-level variables (Ohly et al., 2010). Data collected in this phase enables the inclusion of stable characteristics of the employee or work environment (Hox, 2010). Although the current study is concerned primarily with within-person relationships at Level-1, the baseline survey was used as an opportunity to gather relevant demographic information necessary to describe the sample. Participants were given at least one work week to complete the baseline survey. The following work week, participants completed three surveys per day (upon arriving to work in the morning, lunchtime, at the completion of the workday) for five consecutive work days (Monday through Friday). Table 1 provides a summary of measurement occasions. As with any research study, the optimal design of diary studies is dependent on the research question being addressed. In the current study, the focus is on relationships between experiences and behaviors expected to fluctuate within-person and within a workday (Oerlemans \& Bakker, 2014; Petrou et al., 2012; Sonnentag, 2003). In these instances, multiple time points per day are recommended (Ohly et al., 2010). Moreover, because these relationships are being examined within-day, it is important to make efforts to temporally separate the measurement of study variables. Doing so allows for a more rigorous test of the study hypotheses and attempts to reduce common method bias present when study variables are assessed using a single source (Podsakoff, MacKenzie, Lee, \& Podsakoff, 2003).

For each daily survey, participants received an invitation and link to the survey. Participants were informed in the invitation email the amount of time that the survey 
would remain "open" (e.g., "This survey can only be accessed until 3:00PM today." See Table 1). If participants missed a survey, they were not permitted to go back and take it later; rather, they were advised to continue taking the subsequent surveys. As noted previously, a primary benefit of diary methodology is that participants do not rely as heavily on retrospection and thus are able to provide more accurate data about current experiences and recent behavior. In order to maintain this level of quality in the data, it was important that participants were not permitted to complete surveys outside the specified time frames. Participants who completed at least $60 \%$ of the daily surveys over the course of the week were sent a $\$ 10$ gift card to Amazon.com via email.

\section{Measures}

\section{Person-Level Variables}

In the current design, stable characteristics of the participant and their work environment are considered Level-2 variables at the person level (Hox, 2002). When the research question concerns relationships entirely between Level-1 variables, as in the current study, centering on the person-mean (which refers to the mean across days for each person) is most appropriate and aids in interpretation of results (Enders \& Tofighi, 2007; Raudenbush \& Bryk, 2002). A further discussion of centering decisions in the current study is included in the following chapter under "Analytic Strategy". However, relevant to the current discussion, is that centering on the person-mean removes all between-person variance in the model (Hox, 2002) resulting in Level-1 scores that are uncorrelated with all other Level-2 variables (Enders \& Tofighi, 2007). By implication, a 
model that examines the impact of a person-centered independent variable at Level-1 on a dependent variable is not adjusted for variables at Level-2 (i.e., control variables). This logic, then, precludes the use of Level-2 control variables in a traditional sense unless there is a substantive interest in between-person effects (Enders \& Tofighi, 2007).

\section{Day-Level Variables}

Internal consistency scores for daily scales were computed for each day and then averaged across the five days. These estimates are provided in Table 2.

Daily job crafting. Consistent with other day-level research examining job crafting behavior (Petrou et al., 2012), ten items adapted from Tims et al.'s (2012) job crafting scale were used. Included in this scale are three subscales, namely Seeking Resources ${ }^{1}$, Seeking Challenges, and Reducing Hindering Job Demands. However, only Seeking Resources and Seeking Challenges were pertinent to the current study, and those were measured with four and three items, respectively. An example Seeking Resources item was, “This morning, I asked my supervisor for advice.” An example Seeking Challenges item was, "This morning, I asked for more tasks if I finished my work.” (A full list of items is provided in Appendix 5.) For all items, employees were asked to respond regarding how frequently they had engaged in each of these behaviors "so far today", providing responses at the lunch time survey. Responses were provided on a 1 (Not at all) to 5 (Most of my day so far has been spent doing this) scale.

\footnotetext{
${ }^{1}$ The original scale by Tims and colleagues (2012) includes four dimensions (i.e., seeking structural resources, seeking social resources, reducing hindering job demands, and increasing challenging job demands). Based on factor analyses of daily reports of job crafting, Petrou and colleagues (2012) combined the seeking structural resources and seeking social resources into a single factor (i.e., seeking resources). This combined factor is assessed in the current study.
} 
Daily work engagement. Daily work engagement was assessed using nine items from the short-form Utrecht Work Engagement scale (Schaufeli \& Bakker, 2003).This scale measures three subscales including Vigor, Dedication, and Absorption, which were assessed with three items each. An example Vigor item was, "Today during work, I felt bursting with energy." An example Dedication item was, “Today, my job inspired me." An example Absorption item was, "I completely lost myself in my work." For all items, employees were asked to respond at the end of their workday, and in consideration of their entire workday. Consistent with other day-level research, items from the subscales were summed to produce a single work engagement score (Breevart et al., 2012). Responses were provided on a 1 (Not true at all) to 7 (Totally true) scale.

Daily nonwork mastery experiences. Nonwork mastery experiences were assessed in the morning before starting work with four items from the Recovery Questionnaire (Sonnentag \& Fritz, 2007). Participants were asked to respond to each item in consideration of how they spent their time "yesterday after work." An example item was, "I did things that challenged me." Responses were provided on a 1 (Strongly Disagree) to 5 (Strongly Agree) scale.

\section{Supplementary Variables}

Positive affect. Positive affect was assessed in the morning before starting work and at lunchtime with 10 items from the Positive Affect and Negative Affect scale (PANAS; Watson et al., 1988). Sample items were "excited" and "enthusiastic". 
Efficacy beliefs. Efficacy beliefs were assessed in the morning before starting work and at lunchtime with four items from the Work-related Basic Need Satisfaction Scale (Van den Broeck, Vansteenkiste, De Witte, Soenens, \& Lens, 2010). A sample item is, "I feel competent at my job". 


\section{Chapter 8: Analyses and Results}

\section{Analytic Strategy}

The design of the current study results in a data structure containing two levels: Individual participants at the highest level (Level 2; person level) and their daily assessments at the lowest level (Level 1; day level). By implication of this structure, measurements taken at the daily level are nested within persons and are therefore expected to exhibit correlated residuals (Hox, 2002). Importantly, the hierarchical structure of the data causes a violation of the assumption of independence of errors that is required for standard ordinary least squares regression, and if ignored can result in an inflated Type I error rate (MacKinnon, 2008; Tabachnik \& Fidell, 2007). To account for this structure, multilevel structural equation modeling (MSEM) was used to test the hypotheses in the current study. MSEM is a multilevel analysis technique that integrates traditional structural equation modeling with aspects of multilevel modeling and in doing so allows for additional flexibility in specifying model structure (Preacher, Zyphur, \& Zhang, 2010; Preacher et al., 2011) and estimation method (Muthén \& Muthén, 19982012) as when compared to other multilevel techniques (e.g., HLM). The inherent benefits of MSEM over other multilevel techniques are especially salient in the case of modeling multilevel mediation (including multiple mediator models; Preacher et al., 2010, Preacher et al., 2011) which is an objective of the additional analyses in the current study.

Hypotheses 1 - 3 refer to main effect relationships between daily assessments of nonwork mastery experiences, job crafting, and work engagement. Hypothesis 1 stated 
that nonwork mastery experiences would be positively related to work engagement. Hypotheses $2 \mathrm{a}$ and $2 \mathrm{~b}$ stated that nonwork mastery experiences would be positively related to seeking resources and seeking challenges, respectively. In turn, Hypotheses $3 \mathrm{a}$ and $3 \mathrm{~b}$ stated that seeking resources and seeking challenges would be positively related to work engagement, respectively. In all cases, the substantive interest was in within-person relationships among the study variables, rather than differences between individuals; as such, random intercepts were modeled (and slopes were fixed). For each hypothesis, path analyses with a latent covariate were conducted using Mplus Version 7 (Muthén \& Muthén, 2012). In this procedure, the Level 1 predictor variable variance is decomposed into two latent components representing the distinct (i.e., uncorrelated) within- and between-person parts of the model (see Figure 2; Muthén \& Muthén, 2012) allowing for differential relationships at the within- and between-person levels. In this way, one may examine more accurately true within-person relationships that are unaffected by betweenperson variation (Preacher et al., 2010), as is the primary substantive interest in the current study.

By implication of this approach, the within-person component of the model is implicitly centered around a person's mean score (referred to as person-mean centering; Muthén \& Muthén, 2012; Preacher et al., 2010). Accordingly, variation within persons (i.e., at Level 1) refers to day-to-day deviations from individuals' average reports of the study variables (e.g., work engagement). For example, a significant within-person relationship between nonwork mastery experiences and work engagement would indicate that on days when an individual's mastery experiences were higher than normal, they 
reported greater work engagement. In other words, this relationship represents the average day-level relationship between mastery experiences and work engagement across individuals. In contrast, the between-person portion of the model represents the latent mean of participants' daily scores over the course of the week and refers to variation between individuals in the study.

Hypotheses 4, as well as the additional mediation analyses proposed, were tested in accordance with recommendations by Preacher and colleagues (2011) for testing lower level mediation models in which all variables are assessed on Level 1 (i.e., 1-1-1). In this analysis, the ability to partition the within- and between-person components of the model is advantageous in that it overcomes some key limitations of previous methods for examining indirect effects with multilevel data; specifically, these earlier methods tended to confound the within- and between-person variance by estimating a single mean slope (leading to a downward bias of the between-person effects; Preacher et al., 2010). Alternatively, by using MSEM it is possible to estimate the latent within- and betweenperson scores for variables in the model providing a more holistic and unbiased understanding of how variables are operating on different levels, even if the substantive interest is on one particular portion of the model (e.g., in this study the focus is on withinperson relationships, but estimates are also provided at the between-person level; Preacher et al., 2010; Preacher et al., 2011).

In accordance with recent recommendations by Koopman, Howe, Hollenbeck, and Sin (2015) and Yuan and MacKinnon (2009), Bayesian estimation was used as the default estimation method in all tests of indirect effects (i.e., Hypotheses $4 \mathrm{a}$ and $4 \mathrm{~b}$ and 
the proposed additional analyses with positive affect and efficacy beliefs). Scholars have noted that Bayesian methods are particularly useful in the context of multilevel mediation because they "do not impose restrictive normality assumptions on sampling distributions of estimates and do not rely on large sample approximations" (Yuan \& MacKinnon, 2009, p. 2). Empirical support for the use of these methods over other often used tests of indirect effects was provided by Koopman et al. (2015) who conducted a simulation study focused specifically on multilevel mediation models with a small number of groups (which they defined as less than 50). Results of their study showed that Bayesian methods outperformed more common bootstrapping approaches leading the authors to recommend the use of Bayesian analysis over other techniques when testing multilevel mediation. Therefore, consistent with this analysis approach, 95\% credibility intervals were obtained for all tests of indirect effects in order to determine their significance level. Credibility intervals that do not contain zero are considered statistically significant and would indicate support for the proposed indirect effect.

Hypothesis 5 tested work engagement as a daily predictor of nonwork mastery experiences. Because nonwork mastery experiences were assessed the morning following when they actually occurred, the data had to be restructured such that work engagement (day $t$ ) was aligned with the following day's reports of nonwork mastery experiences (day $t+1)$. For example, work engagement reported on Monday was restructured to align with nonwork mastery experiences that were reported on Tuesday (but that actually occurred on Monday). This allowed for examination of these variables within a given day (the effect of work engagement on that evening's nonwork mastery experiences). 
Hypothesis 5 was tested following the same approach as described above for Hypothesis 1 through $3 \mathrm{ab}$.

\section{Preliminary Analyses}

Prior to testing the hypotheses in the current study, the data were checked to determine whether the required assumptions underlying multilevel modeling were sufficiently met (Tabachnik \& Fidell, 2007). First, an examination of descriptive statistics (e.g., range, skewness, kurtosis, Mahalanobis distance) and a visual investigation of the data (e.g., histograms, Q-Q plots) indicated nothing problematic in terms of the distributions of errors at each level or the presence of outliers. The average number of observations per participant was 4.92 indicating missing data was not problematic ${ }^{2}$; however, in order to examine whether the data met the assumption of missing at random (MAR) required by multilevel modeling, I created a missing data variable and ran bivariate day-level correlations with all other variables in the study. A significant bivariate correlation was found for day of week and missing data $(r=.20)$ suggesting that responses provided later in the week contained more missing data. As such, day of week was included as a control variable at the within-person level in all subsequent analyses ${ }^{3}$. No other patterns of missingness were found.

Inspection of the within-person and between-person correlations indicated a moderate to strong relationship between the unique dimensions of job crafting behavior (i.e., seeking resources and seeking challenges; $r=.54$ within-person, $r=.68$ between-

\footnotetext{
${ }^{2}$ Analyses in Mplus capitalize on all available data using full information maximum likelihood estimation (Muthén \& Muthén, 2012).

${ }^{3}$ Analyses were also run without controlling for day of the week. Results did not substantively change as a result.
} 
person). The within-person relationship is consistent with prior research by Petrou and colleagues (2012) who found a day-level correlation between seeking resources and seeking challenges of .60. At the between-person level, Petrou et al. (2012) reported a correlation of .41 which is weaker than that found in the current sample. In their scale development paper, Tims and colleagues (2012) reported correlations of .40 to .61 among their three subscales: increasing structural resources, increasing social resources, and increasing challenging job demands. Consistent with this prior research, job crafting behaviors were examined as independent constructs in the current study. However, given the relatively strong relationship between these dimensions in the current sample, it could be argued that they represent a single job crafting factor. Therefore, as additional analyses, a single job crafting factor score was computed and all analyses were re-run with this variable. Results of these analyses were not substantively different from those reported in the current study.

Another notable relationship identified in the preliminary analysis was that of work engagement and positive affect. Specifically, at the between-person level the bivariate correlations between work engagement and positive affect ranged from .78 to .81. As previously indicated, very high correlations between variables introduce the possibility that the variables are not distinguishable, but rather indicators of a common higher order factor. One potential reason for this relationship is that in the current study work engagement is assessed at the state-level rather than the trait-level. State-level work engagement is characterized as an affective, motivational state (Schaufeli et al., 2003) and is therefore more likely to overlap with specific items on the positive affect scale 
such as "enthusiastic" and "excited." Conversely, some scholars have argued that work engagement at the trait-level is indicative of more attitude-like features which would be less likely to correlate as strongly with positive affect (Christian et al., 2011). Therefore, although positive affect and work engagement are treated as distinct variables in the additional analyses conducted in the current study, these findings are tempered by the relatively strong relationships found at the correlational level and discussed here.

Variance decomposition. As a preliminary step to testing the study hypotheses, unconditional random coefficient models were run in order to calculate the relative within-person and between-person variance for each study variable. The intraclass coefficients (ICC) indicated that $57 \%$ of the variance in nonwork mastery experiences, $53 \%$ in seeking resources, $35 \%$ in seeking challenges, and $22 \%$ in work engagement occurred at the within-person level. In addition, positive affect showed $26 \%$ and $36 \%$ within-person variation at the morning and lunchtime occasions, respectively, and efficacy beliefs varied $35 \%$ and $40 \%$ within-person at the morning and anchtime assessments. These ICC values indicate that each of the study variables exhibits variation at both the within- and between-person levels and supports the use of multilevel modeling. ICC values along with intercorrelations among the study variables are provided in Table 2 .

In addition, Appendix F provides a breakdown of descriptive statistics (means and standard deviations) for the focal variables for each day of the week (Monday-Friday) along with a plot of these mean levels over the course of the week. 


\section{Results}

Hypothesis testing. Means, standard deviations, and intercorrelations among the study variables are provided in Table 2. A summary of the results of all hypothesis tests and additional analyses is provided in Table 9. Hypothesis 1 stated that nonwork mastery experiences would be positively related to work engagement at the day level. Table $3 \mathrm{a}$ provides the results of these analyses. As previously indicated, both within- and betweenperson components of the model were obtained. The results indicate that when controlling for the day of week the relationship between nonwork mastery experiences and work engagement was not significant at the within-person level $(.09, S E=.07, \mathrm{z}=$ 1.36, $n s)$, indicating no support for Hypothesis 1.

Similar results were found when examining the relationship between nonwork mastery experiences and job crafting behaviors. Specifically, when controlling for day of week, the relationship between nonwork mastery experiences and seeking resources was not significant at the within-person level $(.09, S E=.07, \mathrm{z}=1.36, n s)$, nor was it significant for seeking challenges $(-.09, S E=.06, \mathrm{z}=-1.48, n s)$, providing no support for Hypotheses $2 \mathrm{a}$ and $2 \mathrm{~b}$.

Hypotheses $3 \mathrm{a}$ and $3 \mathrm{~b}$ predicted that job crafting behaviors would positively relate to daily work engagement. Table 4a provides the results of these analyses and shows that at the within-person level of analysis neither seeking resources $(-.03, S E=.06, \mathrm{z}=-.44$, $n s)$ nor seeking challenges $(-.05, S E=.07, \mathrm{z}=-.78, n s)$ was a significant predictor of work engagement when controlling for the day of the week, providing no support for Hypotheses $3 \mathrm{a}$ and $3 \mathrm{~b}$. 
Hypothesis $4 \mathrm{a}$ and $4 \mathrm{~b}$ predicted an indirect effect of nonwork mastery experiences on work engagement via enhanced job crafting efforts during the work day (that is, it was expected that job crafting would mediate the relationship between nonwork mastery experiences and work engagement). Table 5a provides a summary of these results. Seeking resources was tested as a mediator in the first model. A random intercepts and fixed slopes model showed that at the within-person level of analysis the indirect effect was not significant $(.00, S D=.01,95 \% \mathrm{CI}:-.02, .02)$ providing no support for Hypothesis 4a. When seeking challenges was included in the model, results showed that again at the within-person level of analysis, there was no significant indirect effect $(.00, S D=.01,95 \%$ CI: -.01, .04) providing no support for Hypothesis $4 \mathrm{~b}$.

Finally, Hypothesis 5 stated that work engagement at the end of the work day would be positively related to nonwork mastery experiences the same evening. Results are provided in Table 6a, and show that the relationship between work engagement and nonwork mastery experiences was not significant at the within-person level of analysis ($.05, S E=.08, z=-.66, n s)$. Therefore, Hypothesis 5 was not supported.

\section{Between-person results for the hypothesized relationships ${ }^{4}$. As previously}

discussed, the analytic technique used in the current study allows for the simultaneous modeling of between-person relationships among study variables. In this case, between-

\footnotetext{
${ }^{4}$ An additional set of analyses were run in which the trait level of the outcome variable was included as a covariate as it may influence results at the between-person level. Specifically, trait work engagement was included in models where daily work engagement was the focal outcome; Trait seeking structural resources and trait seeking social resources were included as covariates where daily seeking resources was the outcome of interest; Trait seeking challenging demands was included as a covariate where daily seeking challenges was the outcome of interest. Under these conditions, the between-person relationship between nonwork mastery and work engagement was no longer significant, nor was the relationships between both job crafting types and work engagement. Nonwork mastery remained a significant predictor of both types of job crafting at the between-person level.
} 
person results are based on data points that represent individual participants' latent mean scores (accounting for unreliability) across the week in relation to other participants in the study. For example, Hypothesis 1 stated that nonwork mastery experiences would be positively elated to work engagement. A between-person analysis of this hypothesis addresses the question of whether, on average, participants who reported greater nonwork mastery experiences during the week were also more likely to report greater work engagement across the week. Results showed that at the between-person level this relationship was positive and statistically significant $(.72, S E=.31, \mathrm{z}=2.32, p<.05)$ suggesting that employees who engaged in greater mastery experiences outside of work were also more likely to report higher levels of engagement.

Hypotheses $2 \mathrm{a}$ and $2 \mathrm{~b}$ referred to the relationship between nonwork mastery experiences and job crafting behaviors. At the between-person level, results indicate positive and significant relationships between nonwork mastery and seeking resources $(.14, S E=.06, \mathrm{z}=2.32, p<.05)$ and between nonwork mastery and seeking challenges (.94, $S E=.25, \mathrm{z}=3.80, p<.001)$. Therefore, on average participants who reported greater nonwork mastery experiences were also more likely to report greater job crafting behaviors during work.

Hypotheses $3 \mathrm{a}$ and $3 \mathrm{~b}$ examined the relationships between job crafting behaviors and work engagement. Similar to the previous findings, results at the between-person level were positive and significant for both seeking resources $(.96, S E=.24, \mathrm{z}=4.05$, $p<.01)$ and seeking challenges $(.44, S E=.17, \mathrm{z}=2.60, p<.01)$. This indicates that when 
employees engaged in greater levels of these behaviors on average, they were more likely to report being engaged during their work day.

Hypothesis $4 \mathrm{a}$ and $4 \mathrm{~b}$ assessed the indirect effect of nonwork mastery experiences on work engagement via job crafting behaviors. First, seeking resources was included as a mediator in the model. At the between-person level of analysis the indirect effect was significant (.76, $S D=.36,95 \% \mathrm{CI}: .21,1.64)$, indicating that employees who engaged in nonwork mastery experiences were more likely to report enhanced seeking resources behavior at work. In turn, seeking resources behavior was positively related to higher levels of work engagement. When examining seeking challenges in the model, betweenperson level results showed a significant and positive relationship between nonwork mastery experiences and seeking challenges $(.93, S D=.30, p<.01)$; however, the relationship between seeking challenges and work engagement was not significant (.32, $S D=.23, n s)$, and therefore the indirect effect was not significant $(.28, S D=.24,95 \%$ CI: $.21, .71)^{5}$.

Finally, Hypothesis 5 tested a reciprocal relationship between work engagement and nonwork mastery experiences. Similar to the within-person results, work engagement was not found to be a significant predictor of nonwork mastery experiences at the between-person level of analysis $(.09, S E=.05, z=1.68, n s)$.

Taken together, these results provide evidence that the relationships among study variables are stronger at the between-person level as opposed to the within-person level. Bliese and Jex (2002) have argued that this pattern may indicate the existence of an

\footnotetext{
${ }^{5}$ In order to examine the potential for a cumulative effect of nonwork mastery experiences and job crafting on work engagement, a 1-1-2 model was run in which nonwork mastery and job crafting reside at the day level and work engagement is considered at the person level. Results of these analyses were not significant.
} 
emergent process in which an aggregate variable is not just the sum of its parts. For example, these authors argued that what is not true for an individual may be true for a group. In the context of day-level research, this logic could be extended to indicate that what is not true for a participant on a given day may be true for the participant on average. That is, the theoretical meaning of variables differs at different levels. In the current study, daily variation in one's nonwork mastery experiences was not significantly related to daily job crafting or work engagement. However, significant findings at the between-person level suggest that one's level of nonwork mastery experiences are significantly related to job crafting and work engagement over the course of the week. Therefore, it follows that these experiences and behaviors when considered across days have conceptually distinct meaning in relation to these same experiences and behaviors at the day level.

Additional analyses with proximal mediators. In addition to the formal hypotheses proposed and tested above, additional analyses concerning the mediating role of state positive affect and efficacy beliefs were included in the current study. These factors represent specific psychological resources that may be generated through nonwork mastery experiences (Sonnentag et al. 2008; Sonnentag \& Fritz, 2007) and job crafting behaviors at work (Tims et al. 2012), and therefore were proposed as important proximal variables relevant to the relationships hypothesized in the current study. As with prior analyses and in accordance with recommendations from Preacher and colleagues (Preacher et al.,2010; 2011), MSEM was used to model a series of multiple mediator 
models in which the indirect effect was of substantive interest. Results of these analyses are presented in Tables 7a, 7b, $8 \mathrm{a}$ and $8 \mathrm{~b}$ and summarized below.

The first exploratory research question was whether the relationship between nonwork mastery experiences and job crafting could be explained by the generation of positive affect and efficacy beliefs. To test this question, the indirect relationship between nonwork mastery experiences and seeking resources via enhanced positive affect and efficacy beliefs was tested. Results showed that this indirect relationship was not supported at the within- or between-level for either positive affect (within-level: .03, $S D=.03,95 \%$ CI: -.02, .09; between-level: .12, SD=.09, 95\% CI: -.03, .34) or efficacy beliefs (within-level: .00, $S D=.01,95 \% \mathrm{CI}$ : -.01, .03; between-level: $-.00, S D=.03,95 \%$ CI: $-.08, .05)$. However, a positive relationship was found between nonwork mastery experiences and positive affect at the within-level of analysis $(.17, S D=.05, p<.01)$ suggesting that on days employees engage in a greater degree of nonwork mastery they return to work the following morning with enhanced positive affect. At the betweenperson level, the relationship between nonwork mastery experiences and positive affect was not significant $(.29, S D=.19, p=.06)$; however, nonwork mastery did remain a positive predictor of seeking resources (as previously reported; .41, $S D=.16, p<.01$ ), and positive affect was positively and significantly associated with seeking resources $(.44, S D$ $=.12, p<.01)$. That is, positive affect explained significant variation in daily seeking resources behavior between individuals.

Similar findings emerge when examining the indirect relationship between nonwork mastery experiences and seeking challenges via positive affect and efficacy 
beliefs. Specifically, the indirect effects at both the within- and between-levels of analysis are non-significant for both positive affect (within-level: .03, $S D=.03,95 \%$ CI: -.003, .10; between-level: .07, $S D=.08,95 \%$ CI: -.04, .28) and efficacy beliefs (within-level: .00, $S D=.01,95 \%$ CI: -.02, .02; between-level: .00, $S D=.04,95 \%$ CI: -.08, .07). However, consistent with the prior model, nonwork mastery experiences positively predicted positive affect at the within-person level $(.17, S D=.06, p<.01)$, but not efficacy beliefs $(.02, S D=.05, p=.37)$. At the between-person level positive affect was not significantly related to seeking challenges $(.30, S D=.17, p=.05)$.

A second question was whether positive affect and efficacy beliefs would explain the relationship between nonwork mastery experiences and work engagement. Results of the analysis showed that the indirect effect was not significant at the within- or betweenperson level of analysis for either positive affect (within-level: .02, $S D=.02,95 \%$ CI: -.01, .07 ; between-level: $.36, S D=.22,95 \%$ CI: -.04, .81) or efficacy beliefs (within-level: .00, $S D=.02,95 \%$ CI: -.04, .05; between-level: .00, $S D=.04,95 \%$ CI: -.06, .11). However, again nonwork mastery experiences did show a significant positive relationship with positive affect in the morning before starting work at the within-person level $(.13, S D=$ $.06, p<.05)$. Nonwork mastery was not a significant predictor of morning efficacy beliefs at the within-person level $(.01, S D=.05, p=.44)$, however efficacy beliefs at the start of the work day were positively related to daily engagement $(.33, S D=.14, p<.05)$. At the between-person level positive affect was found to be positively related to work engagement $(1.10, S D=.15, p<.01)$. 
Finally, research question 3 referred to the indirect relationship between job crafting and work engagement via positive affect and efficacy beliefs. When seeking resources was included as the independent variable, results showed that there was a significant indirect effect of seeking resources on work engagement via positive affect $(.08, S D=.03,95 \% \mathrm{CI}: .03, .14)$, but not efficacy beliefs (.01, $S D=.01,95 \% \mathrm{CI}:-.01, .04)$ at the within-person level of analysis. At the between-person level this indirect relationship was also significant for positive affect $(.29, S D=.17,95 \% \mathrm{CI}: .01, .67)$, however the relationship between seeking resources and work engagement at the between-person level remained statistically significant $(.42, S D=.16, p<.01)$ suggesting there may be other mechanisms at play other than positive affect (e.g., increases in job resources). When seeking challenges was included in the model as the primary independent variable, results at the within-person level of analysis were similar to those above; seeking challenges was significantly related to work engagement via enhanced positive affect $(.05, S D=.02,95 \% \mathrm{CI}: .01, .10)$. Seeking challenges was also positively and significantly related to efficacy beliefs at the within-person level $(.11, S D=.05$, $p<.05)$; however, the indirect relationship with engagement was not significant (.02, $S D=.02,95 \%$ CI: -.01, .06) due to a non-significant relationship between efficacy beliefs and work engagement within-person $(.18, S D=.14, p=.09)$. At the between-person level of analysis there were no significant indirect effects for either positive affect (.17, $S D=.17,95 \%$ CI: $-.15, .51)$ or efficacy beliefs $(.00, S D=.03,95 \%$ CI: -.07, .08); with that said, the relationship between positive affect and work engagement was significant (1.55, $S D=.23, p<.01)$ 
Additional analyses using growth modeling. Implicit in the discussion of gain cycles (Hobfoll, 1989) is the notion that there is a building of resources over time. Although an indirect test, one way to gather additional information about the presence of such a gain cycles is through examining the trajectory of resources, or resource-rich states, over time. As a supplementary analysis to those described previously, I used the R (R Core Team, 2014) multilevel package (Bliese, 2013) to conduct a series of growth models using random coefficient modeling with day-level work engagement as the primary variable of interest. Specifically, day-level work engagement was regressed on to day of the week to examine any patterns of change over the course of the week. The results of these analyses indicate that day of week was positively and significantly related to work engagement over the course of the work week (Appendix G, Table G2). ${ }^{6}$ Importantly, a random intercepts, random slopes model showed significantly better fit to the data over a fixed slopes model indicating that the change in work engagement over the week varies by person. ${ }^{78}$

Following recommendations by Bliese and Ployhart (2002), a series of steps were undertaken to garner a greater understanding of this variation. First, data from a random draw of ten study participants were plotted (Appendix G, Figure G1). A visual inspection of these plots supports the finding that there is variation across participants, both in terms of the level of work engagement at the start the week as well as the trajectory (or slope)

\footnotetext{
${ }^{6}$ The relationship between day of week and work engagement was modeled as a linear function. I also modeled a quadratic trend to see if this provided a better fit to the data. Results indicated that the quadratic model did not fit the data better than a linear model: estimate $=.04, p=.316$.

${ }^{7}$ I also tested for autocorrelation and heterogeneity in error structures in accordance with recommendations by Bliese and Ployhart (2002). Results indicated that modeling these features did not improve the model fit and were therefore excluded from subsequent models.

${ }^{8}$ Missing data is omitted using the code na.action=na.omit which runs the analyses using only non-missing data.
} 
of work engagement over the week. Following this visual check, a series of person-level moderators were tested to examine whether these factors could explain variation in participants' initial level of work engagement or the degree of change in work engagement over the week. Namely, trait work engagement (as assessed with the baseline survey) was tested as a person-level moderator. Results showed that one's level of trait work engagement was positively, and significantly associated with one's initial level of work engagement during the week (that is, work engagement on Monday; Table G2); however, trait work engagement was not a significant predictor of slopes (Table G2). Although the interaction between day of week and trait work engagement was not significant, Figure G2 shows the relatively large difference in intercepts as a function of trait work engagement. Participants with low trait work engagement started the week with higher day-level work engagement ( $M=2.65$ on Monday) as compared to participants with low trait work engagement $(M=4.82$ on Monday). Further, a test of the simple slopes indicates that those low in trait work engagement showed a significant positive gain in work engagement, while those already high in trait work engagement did not show a significant increase. These results, although descriptive, must be tempered by the fact that the interaction term was not significant.

Trait levels of job crafting behavior were also tested as person-level (i.e., time invariant) moderators to the relationship between day of the week and work engagement. Appendix G, Tables G3 - G5 provide the results of these analyses. A significant crosslevel interaction was found for day of the week and job crafting aimed at seeking structural resources. Increasing structural resources refers to behaviors aimed at building 
personal capabilities, learning new things, and growing professionally (Tims et al., 2012). Figure G3 provides a plot of this interaction which shows that for those low on seeking structural resources, the relationship between day of week and work engagement was positive (a test of the simple slope was also significant: .23, $p<.01$ ). Conversely, for those high on seeking structural resources, this relationship was not significant $(.02, p=$ .72). However, what is notable is that those high in seeking structural resources started the week substantially higher on work engagement compared to those low in seeking structural resources, and despite the positive slope in work engagement for the low seeking structural resources group, it appears they never quite "catch up" to the high group in terms of work engagement. That is, even on Friday there remains almost a half point difference in work engagement between the groups. Seeking social resources and seeking challenging job demands were also tested as person-level moderators to the day of week-work engagement relationship. Seeking challenging job demands was significantly related to one's initial level of work engagement; however, neither were significant moderators to the day of week-work engagement relationship (See Appendix G, Tables G4 and G5).

Taken together, these findings suggest that on average, work engagement did increase over the course of the work week. Perhaps more interesting was that this trajectory differed significantly between individuals in the study. That is, significant variation existed in terms of the level of work engagement with which employees started the work week, as well as the degree and direction of change in work engagement over the week. This variation in slopes (that is the change in work engagement over the week) 
was explained in part through one's typical (trait) level of work engagement as well as the extent to which they regularly engage in job crafting aimed at increasing their structural resources. Chapter 9 summarizes these results further and provides a discussion of the contributions of these findings as well as potential limitations that should be considered and addressed by future research. 


\section{Chapter 9: Discussion}

The current study examined resource-building strategies used by employees to self-manage work engagement within a work day. Specifically, withinperson relationships among nonwork mastery experiences, job crafting behavior, and work engagement were examined. COR theory suggests that individuals are motivated to maintain, protect, and acquire resources. In the context of high resources, Halbesleben and colleagues (2014) suggested that individuals will focus their efforts on the acquisition of resources including investing resources for the sake of future resource gain. Consistent with propositions from COR theory, this focus on resource acquisition can spur a gain cycle in which the availability of resources promotes further resource investment and acquisition. The work-family enrichment theory supports the notion that these resourcebuilding behaviors can occur both within and outside the work context having mutually beneficial effects on both domains. Finally, the JD-R model delineates that in the context of the workplace, resources that serve a functional purpose promote enhanced work engagement. Together, it was proposed that nonwork mastery experiences and job crafting behaviors would serve as two employee-initiated, resource-building strategies that would help to sustain work engagement during the work day.

Another key purpose of the current study was to better understand how work and nonwork experiences can mutually impact one another on a day-to-day basis; that is, whether reciprocal, within-person relationships exist that would support the existence of an upward gain cycle as proposed by COR theory. The work-family enrichment theory provides a rationale for the transference of such resources between the work and nonwork 
domains; specifically, that through instrumental or affective paths, resources generated in one domain can spill over and positively impact functioning and experiences in the secondary domain. Drawing on this notion, a bi-directional relationship was proposed and tested between nonwork mastery experiences and work engagement. Although the hypotheses in the current study were generally not supported at the within-person level, a number of additional analyses revealed some interesting and informative results. The following summarizes the findings from the current study and how these findings contribute to theoretical and empirical literature.

\section{Summary of Findings}

In the first hypothesis, it was proposed that on days when nonwork mastery experiences were high, next-day work engagement would also be high. That is, a positive, within-person relationship was expected between nonwork mastery experiences and work engagement. Drawing on COR theory and the work-family enrichment theory, it was argued that nonwork mastery experiences generate important personal resources that spill over and contribute to enhanced engagement on the job. Results of the analyses revealed that at the within-person level of analysis, nonwork mastery experiences were not significantly related to work engagement indicating no support for Hypothesis 1. Interestingly, additional analyses at the between-person level of analysis did support a positive and significant relationship between nonwork mastery experiences and work engagement. In contrast to within-person relationships which focus on variation around a person's mean (i.e., day-to-day variation in the current study), between-person relationships represent variation around the sample mean (i.e., differences in mean scores 
across people). Therefore, the significant relationship between nonwork mastery experiences and work engagement at the between-person level suggests that those who reported higher average nonwork mastery experiences were also more likely to report greater work engagement relative to other participants in the sample. This finding extends prior cross-sectional research that has found a positive association between nonwork mastery and work engagement (Kinnunen et al., 2011), and supports the broader notion that nonwork recovery experiences, like mastery experiences, are important means by which employees restore resources needed to cope with the demands of work and maintain work engagement (Sonnentag \& Fritz, 2007).

A similar pattern emerged when examining the relationship between nonwork mastery experiences and job crafting behaviors. Specifically, Hypothesis $2 \mathrm{a}$ and $2 \mathrm{~b}$ stated that nonwork mastery experiences would be positively related to seeking resources and seeking challenges, respectively. It was argued that nonwork mastery experiences represent an important resource-building recovery strategy that results in greater resources (e.g., energetic resources, positive affect) and signals to employees the opportunity to invest additional effort in job crafting behaviors upon their return to work. Drawing on COR theory, it was expected that to the extent that employees perceived the availability of surplus resources when starting the work day, they should be motivated to invest in the acquisition of additional resources at work (Halbesleben et al., 2014). At the within-person level of analysis, these hypotheses were not supported, indicating that on days when employees engaged in greater nonwork mastery experiences they were not 
necessarily more likely to exhibit greater job crafting behaviors than usual the following work day.

Notably, additional analyses of these relationships at the between-person level resulted in statistically significant and positive relationships suggesting that, on average, those who tend to engage in nonwork mastery experiences outside of work are more likely to report greater job crafting behavior when back at work the following day. Although between-person relationships were not the focus of the current study, these findings are interesting and support the association between recovery experiences and discretionary work behavior found in other research (Binnewies et al., 2010). Therefore, a contribution of the current research is the identification of nonwork mastery experiences as a novel antecedent to job crafting behaviors at work. This is particularly important given that very few studies have examined nonwork mastery experiences as a recovery experience and even fewer examine performance-related behavior (like job crafting) as an outcome of such an experience. Additionally, despite conceptual and theoretical advancement related to the construct of job crafting, very few empirical studies to date have been conducted testing these propositions. The current research, therefore, provides empirical support to a small but growing body of research on job crafting behaviors.

Hypotheses $3 \mathrm{a}$ and $3 \mathrm{~b}$ proposed that job crafting behaviors would be positively associated with work engagement at the within-person level. That is, it was expected that on days when employees engaged in greater job crafting they would report higher engagement during the same work day. Scholars have argued that job crafting behaviors can enhance employees' perceptions of fit with their environment or job (Tims et al., 
2010) and can facilitate the fulfillment of needs (e.g., need for relatedness, need for competence; Wrzesnieski \& Dutton, 2001). Building on findings by Petrou and colleagues (2012) who reported a positive association between job crafting behaviors and work engagement within the workday, it was expected that every day activities such as seeking out feedback or taking on additional responsibilities would function to enhance resources for employees and explain variation in daily work engagement. Contrary to this expectation, no significant relationships were found between job crafting behaviors and work engagement at the within-person level.

It is notable that these findings are not in line with the positive within-person association found by Petrou and colleagues (2012). One possibility is that the relationship exists in the opposite direction; that is, work engagement is an antecedent rather than an outcome of daily job crafting behaviors (Bakker et al., 2012). Because Petrou and colleague's (2012) study was designed such that work engagement and job crafting were assessed at the same time point during the workday, it is not possible to disentangle the direction of the relationship. Unfortunately, in the current study it was not possible to test a reciprocal relationship between work engagement and job crafting within a single work day due to the timing of the assessments (i.e., job crafting was assessed at lunch time, work engagement was assessed at the end of the work day). Another possible explanation is that the relationship between job crafting and work engagement plays out over a longer period of time.

Lending some support for this latter notion, a significant and moderate to strong relationship was found between job crafting behaviors and work engagement at the 
between-person level. Indeed, both seeking resources and seeking challenges emerged as significant predictors of work engagement at this level. This finding indicates that employees who reported greater average job crafting were more likely to report higher work engagement at the end of the work day. Although the substantive interest was not in between-person relationships, these findings support the broader notion that proactive behaviors aimed at mobilizing important job resources are one way that employees selfmanage their level of work engagement over time. This finding adds to a growing body of research concerned with the role of employees' proactive self-management of work behavior and well-being related psychological states like work engagement (c.f., Bindl \& Parker, 2012; Zacher et al., 2014). Indeed, a primary aim of the current study was to provide greater insight on the everyday behavioral strategies that employees engage in in order to build and maintain psychological and energetic resources important to sustaining work engagement. Findings suggest that one's mean level of nonwork mastery experiences and job crafting behaviors are important for explaining variation in work engagement throughout the week, while deviations from one's typical level of nonwork mastery experiences and job crafting behaviors on a given day seem to be less relevant. Although future research is needed to more closely examine these processes over time, this study provides some support for the role of self-initiated employee behavior in relation to work engagement.

Next, Hypothesis $4 \mathrm{a}$ and $4 \mathrm{~b}$ examined the joint effect of nonwork mastery experiences and job crafting on work engagement by testing an indirect relationship between nonwork mastery experiences and work engagement through daily job crafting 
behaviors. Specifically, it was proposed that on days employees engaged in greater nonwork mastery experiences they would come to work feeling refreshed and energized. In turn, and consistent with COR theory, this would signal to employees the capacity to engage in resource-building behaviors (i.e., job crafting), which facilitates work engagement throughout the work day. Consistent with the previous results, results revealed that the indirect effects were not statistically significant at the within-person level, providing no support for Hypotheses $4 \mathrm{a}$ and $4 \mathrm{~b}$. This is not surprising given the lack of support for the independent paths in the model as discussed in Hypotheses 1 through 3.

However, again at the between-person level of analysis somewhat different findings emerged. Specifically, a significant indirect relationship was found between nonwork mastery experiences and work engagement via enhanced seeking resources at the between-person level (but not via seeking challenges). These findings suggest greater average nonwork mastery experiences are associated with higher levels of work engagement throughout the week, at least in part due to greater seeking resources behavior. COR theory proposes that those who possess greater pools of resource reserves are in a better position to grow their reserves because they have enough resources to risk investing some for the sake of future gain (Hobfoll, 1989). Using COR theory to interpret the findings state above, one could deduce that employees who have generally high levels of nonwork mastery experiences are regularly engaging in behaviors that support their recovery from work and enable the building of important psychological resources. At work these employees can afford to risk resources in the form of expending additional 
effort, taking on new tasks that appeal to their interests, or taking time to cultivate relationships that enhance their social capital (i.e., job crafting behaviors). In turn, the process of building resources contributes to enhanced work engagement.

The final hypothesis in the current study (Hypothesis 5) stated that a reciprocal, within-person relationship between work engagement and nonwork mastery experiences exists. Based on the work-family enrichment theory, it was expected that positive affective states generated in the work domain would spill over and positively impact experiences in the nonwork domain. Coupled with COR theory, it was argued that work engagement represents a high resource state that prompts employees to focus their efforts on resource acquisition (as opposed to resource conservation) at the end of the workday. In contrast to other diary research that has found positive associations between pleasurable or engaged states at work and individual recovery level (Sonnentag et al., 2012; Van Hooff et al., 2011), the propositions in the current study were not supported. That is, on days when employees reported higher than their typical level of work engagement, they were no more likely to engage in nonwork mastery experiences as compared to other days.

One possible reason for the inconsistency in these results as compared to other studies is how recovery is operationalized. Rather than assessing recovery experiences or behaviors (as in the current study), these studies examined the state of being recovered or other affective indicators of recovery level (e.g., feelings of vigor and fatigue or selfreports of 'feeling recovered'). For instance, Van Hooff and colleagues (2011) found that pleasure in work activities related positively to feelings of vigor and negatively to fatigue 
in the evening. Therefore, it may be that positive work experiences impact affective states related to a sense of recovery, but may not necessarily translate into specific recoverytargeted behaviors for a number of reasons. For example, nonwork circumstances (e.g., household activities or elder care responsibilities) might preclude, or disallow, one from engaging in recovery behaviors despite a conducive psychological state. Alternatively, it may be that high levels of work engagement translate into other types of recovery experiences, like relaxation or psychological detachment, which are characterized by a reduction in activation (Sonnentag \& Frtiz, 2007).

Another possibility is that high engagement may actually result in fewer recovery experiences. For example, research by Sonnentag and colleagues (2012) found that engagement during the work day positively predicted feelings of being recovered at the end of the workday. The position in the current study, as inspired by COR theory, argues that this state of being recovered is perceived as a state of available resources that can be invested in further resource-building activities (such as nonwork mastery). However, drawing on the Effort-Recovery model (a commonly cited theoretical framework in recovery research; Mejiman \& Mulder, 1998), a state of being recovered would indicate a low need for recovery causing individuals to engage in less recovery activity during nonwork. These contradictory hypotheses and inconsistent empirical findings suggest additional research is required in order to better understand how high resource states at work or at home are related to nonwork recovery.

Nevertheless, the current study provides further insight into the directionality of the recovery-work engagement relationship. One key purpose of the current investigation 
was to test the existence of an upward gain cycle. It was proposed that positive, reciprocal relationships between nonwork mastery experiences and work engagement at the within-person level would be found. Although no support for this process was found in the form of reciprocal relationships on a day-to-day basis, the current study did provide some insight into the direction of these relationships. That is, nonwork mastery experiences were found to relate to work engagement (at the between-person level of analysis) but work engagement was not significantly associated with nonwork mastery experiences.

The role of positive affect and efficacy beliefs. Three exploratory research questions were posed as part of the current research. The purpose of these questions was to two-fold: first, to assess the validity of conceptualizing nonwork mastery experiences and daily job crafting behaviors as resource-building strategies. A second purpose of the additional analyses was to better understand the underlying processes implicit in the relationships proposed in the current study. Specifically, positive affect and efficacy beliefs were tested as mediators to the proposed relationships in the study; that is, between nonwork mastery experiences and work engagement, nonwork mastery experiences and job crafting behavior, and between job crafting behavior and work engagement.

A number of interesting findings emerged when examining positive affect and efficacy beliefs as potential mediators in the proposed relationships. For instance, consistent with prior daily diary research (Sonnentag et al., 2008) the within-person relationship between nonwork mastery experiences and positive affect the following 
morning was statistically significant. That is, on days when participants engaged in more nonwork mastery experiences during the evening prior, they came to work the next day in a more positive affective state. Although positive affect in the morning did not appear to translate into increased job crafting behaviors at the within-person level (no indirect effect of nonwork mastery on job crafting through positive affect), positive affect has been shown to be an important antecedent to a number of other positive organizational behaviors such as proactive behaviors (Bindl et al., 2012) and creativity (Amabile, Barsade, Mueller, \& Staw, 2005). Also notable was that nonwork mastery experiences were significantly related to enhanced positive affect in the morning before starting work, but this relationship dissipated by lunchtime (i.e., nonwork mastery experiences were not significantly related to positive affect assessed at lunchtime). These results underscore the dynamic and fleeting nature of psychological resources (like positive affect) during the work day and point to the importance of conducting diary research to better understand these processes.

Interestingly, in no circumstances (either within- or between-person levels) did nonwork mastery experiences predict efficacy beliefs. This finding is contrary to current theoretical arguments for the recovery mechanisms underlying nonwork mastery experiences, which predict that nonwork mastery experiences allow employees to expand their horizons and build skills that contribute to an enhanced sense of efficacy (Sonnentag \& Fritz, 2007). One potential explanation for this latter finding may be the focus in the current study on work-related efficacy beliefs rather than more global or nonwork-related efficacy beliefs. Some research suggests that self-efficacy is domain specific (Parker, 
Williams, \& Turner, 2006) and therefore nonwork-related efficacy beliefs built through engagement in nonwork mastery experiences may not translate into work-related efficacy beliefs. Efficacy beliefs were, however, a significant predictor of work engagement at the within-person level suggesting that on days when employees feel more confident than usual in their work-related capabilities, they report greater engagement in their work.

Other findings at the within-person level of analysis showed that although the direct relationship between seeking resources and work engagement was not statistically significant, the inclusion of positive affect as a mediator in the model resulted in a significant indirect effect of seeking resources on work engagement. This means that on days when employees engaged in higher seeking resources behavior than usual, they also reported increased positive affect and were more engaged throughout the day. The between-person results mirrored these findings supporting the notion that regular seeking resources behavior is important to work engagement due to the increase in positive mood associated with the behavior. A similar result was found for seeking challenges (although only at the within-person level) suggesting that positive affect is an important outcome of both job crafting behaviors. Interesting, seeking challenges was also a significant predictor of efficacy beliefs at the within-person level, although the indirect effect on work engagement was not significant. These data support the notion that on days in which employees successfully take on challenging tasks or are granted additional responsibility they benefit from an enhanced sense of competence.

Taken together, these findings provide some validity to the conceptualization of nonwork mastery experiences and job crafting behaviors as resource acquisition 
behaviors as suggested by COR theory (Hobfoll, 1989) and delineated explicitly by Halbesleben and colleagues (Halbesleben et al., 2014). Both daily nonwork mastery experiences and seeking resources behavior were significant predictors of positive affect at the within-person level. Further, on days when employees sought challenges they reported greater positive affect and efficacy beliefs. A significant, within-person, indirect effect between job crafting and work engagement via positive affect supports the important role that this particular psychological resource plays in facilitating work engagement over the workday.

\section{Potential Limitations}

Findings from the current research should be considered in light of the potential limitations. For instance, although there are many benefits to diary research over other survey methods (Ohly et al., 2010) the burden of participating in this research can be higher than in other types of study designs. Therefore, it is possible that the current study may have oversampled employees who were already highly engaged and motivated. However, the mean level of work engagement when averaged over days and participants was only 4.54 out of 7 which suggests this may not have been an issue in the current study.

Another potential limitation is that the data were all self-reported by individuals in the study. Podsakoff and colleagues (2003) have pointed out the potential drawbacks of data from a single source; particularly, that this enhances the possibility of findings being biased due to common methods. In order to address this concern, we assessed the focal variables in the study at different time points during the work day. However, future 
research that collects other-source data may be particularly useful especially when the behaviors are readily observable (e.g., nonwork mastery experiences, job crafting behaviors).

Finally, given the daily nature of the current design, we operationalized job crafting as a behavioral strategy in line with prior research by Tims and colleagues (Tims et al., 2012; Petrou et al., 2012); however, one potential drawback of this conceptualization is that employee attempts at cognitive crafting are not included. Although Wrzesnieski and Dutton (2001) have argued that this is an important aspect of job crafting, it is not clear whether this type of crafting varies from day to day. Implications for addressing this potential limitation in future research are discussed below.

\section{Implications for Future Research}

Although between-person relationships were not the focus of the current study, the differential results found at the within- versus the between-levels speak to the need for future research that delineates how behavioral strategies and work-related wellbeing unfold over time. For example, our results suggest that at the within-person level, fluctuations in nonwork mastery experiences, job crafting, and work engagement were not significantly related, however in most cases, these same relationships were significant when examined at the between-person level. One interpretation of these results is that the resource-acquisition process does not unfold over a single day, but is an emergent process that is highlighted by typical or habitual engagement in these strategies. This interpretation is in line with at least one other study that examined employees' energy 
management strategies at work across a single workday and found that micro-breaks (short breaks during the work day) were associated with fluctuations in vitality and fatigue throughout the day, but that work-related strategies (e.g., talking to a coworker) exhibited effects only at the between-person level (Zacher, Brailsford, \& Parker, 2014). The authors concluded that this supported the short-term effects of micro-breaks on occupational well-being, while work-related strategies are effective in the long-term. Future research that examines these short- (daily) and long-term (over multiple weeks) processes more explicitly would be important.

One potential way of examining these processes is looking more closely at the trajectory of resource-building behaviors and work engagement over time periods longer than one week. The additional analysis of growth models in the current study suggests that individual employees differ both in their initial level of work engagement at the start of the work week, as well as their trajectory of work engagement over the course of that week. In part, trait work engagement and job crafting aimed at seeking structural resources and building challenging job demands explained differences in the initial level of work engagement at the start of the week, but only seeking structural resources was a significant predictors of the variation in slopes. This finding raises the question of what additional moderators (i.e., person-level or work-related factors) can explain why individual employees show differential patterns of work engagement over time. It is possible that certain personality traits, such as proactive personality, or more habitual behaviors, like regular recovery experiences, explain such variation in slopes. Alternatively, it could be that certain features of the work context, such as the work 
climate or differential opportunities to interact with others, are responsible for this variation. Future work examining both the longer-term change in work engagement as well as the factors driving these patterns of change would be an interesting and practically informative next step for future research.

Relatedly, it would be interesting to examine the trajectory of job crafting behaviors over longer periods of time and how these changes relate to work engagement. Halbesleben and colleagues (2014) proposed that trajectories of resources are likely to vary quite dramatically depending on the context and the resource being examined. Therefore, rather than a linear increase in job crafting behavior, it is possible that these behaviors may spike or decline depending on factors such as tenure or in accordance with promotion or other job changes (Ellis, Bauer, Mansfield, Erdogan, Truxillo, \& Simon, 2015). For example, one could argue that newcomers may be more likely to engage in job crafting because their job tasks may not be fully formed yet. Conversely, newcomers may be worried about engaging in proactive behaviors like job crafting that could be considered "risky". In the case of the latter, they may be less likely than more tenured employees to make changes to their roles or those they interact with. Understanding when, and under what conditions, employees are more likely to engage in job crafting can provide important practical information on critical points of intervention.

Findings from both Zacher and colleagues (2014) as well as the current study also speak to the need to delineate what behavioral strategies are most relevant for maintaining engagement. For instance, Zacher and colleagues examined work-related energy management strategies such as checking email, talking to a coworker, and setting 
goals in relation to work-related well-being. Nonwork-related strategies included things like stretching, having a snack or caffeinated beverage, or surfing the web. The current study suggests that nonwork mastery experiences and job crafting efforts aimed at seeking resources have implications for work engagement. Still other recent research by Breevaart and colleagues (2014) has found that self-management strategies like self-goal setting, self-observation and self-cueing (i.e., using reminders to prompt behavior) are behaviors that are related to changes in perceived job resources and work engagement at the daily-level. Therefore, research aimed at understanding which behavioral strategies will be more effective at enhancing work engagement is important in order to glean practical information for organizations and guide future theoretical development in this area.

In addition to other resource-building strategies, future research would benefit from clearly showing the proximal outcomes of such behaviors; that is, the psychological and job-related changes that explain the relationships between resourcebuilding strategies and well-being. For example, in the current study behaviors considered to be resource building (i.e., job crafting, nonwork mastery experiences) were tested as antecedents to positive affect and efficacy beliefs. While both positive affect and a sense of competence were presumed to be highly relevant to the proposed model, research suggests that other personal resources (e.g., feeling recovered, optimism, selfesteem; Binnewies et al., 2010; Xanthopoulou et al., 2008) and job resources (e.g., autonomy, task variety; Petrou et al., 2012) may also be relevant and should be tested in relation to employees' attempts at managing work engagement. Ten Brummelhuis and 
Bakker (2012) proposed the work-home resources framework to assist in the categorization of various resources and their expected fluctuation over time. Future research aimed at delineating the unique proximal outcomes of distinct employee resource-building or other management strategies could use this framework to make predictions as well as provide insight into what resources matter most to sustaining work engagement over time.

Related to this, it was not possible within the current study to assess relationships between job crafting behavior and changes in daily job resources (e.g., task significance, perceived autonomy). Bakker and colleagues (2014) suggested that job crafting may increase work engagement indirectly through building relevant job resources. By extension, Xanthopoulou and colleagues (2008) showed that changes in job resources were predictive of changes in personal resources. Both represent what Hobfoll (2011) termed "resource caravans," or "a pattern of resources that typically occur together" (Halbesleben et al., 2014, p. 1344). Thus far, empirical examinations of resource caravans are few (Halbesleben et al., 2014), however extending the current research to examine concurrent changes in personal and job resources as a result of job crafting efforts would be an interesting next step and important test of theoretical propositions made by COR theory.

Another possible area for future research is related to the social context within which job crafting occurs. In the current study, data were collected on participants perceptions of work characteristics (such as perceived autonomy and task interdependence) to gauge the extent to which participants were likely to have sufficient 
flexibility with their roles to engage in daily job crafting behaviors. Indeed, within-person variation in seeking resources and seeking challenges behaviors was found supporting the validating of examining job crafting in this context. However, in addition to work characteristics, it is likely that the social context would have an impact on the extent to which employees engaged in job crafting behaviors at work. Moreover, the extent to which job crafting is "successful" - that is, whether it results in enhanced fit or greater perceptions of personal need fulfillment - is likely to be dependent on certain elements of the social environment at work. For example, it may not be possible to garner social resources from seeking feedback when contact with others is highly limited. Future research that examines things like perceptions of LMX, the frequency of contact with one's supervisor or coworkers, or perceived social acceptance into one's work group could provide important contextual information related to when and why job crafting "works."

Other potential moderators that qualify the spillover process would also be an interesting avenue for future research. For example, the work-family enrichment theory argues that the extent to which enrichment across domains can occur is, in part, dependent on the salience of an individual's work or family role (Greenhaus \& Powell, 2006). In the context of the current study, it is possible that a highly salient home role would encourage one to engage in high levels of nonwork mastery experiences, but may limit the extent to which resources readily flow to the work domain and impact functioning there. Similarly, we might expect that one's boundary management preferences (i.e., "the approaches individuals use to demarcate boundaries and attend to 
work and family and other nonwork roles;” Kossek, Rudderman, Braddy, \& Hannum, 2012, p. 112) could moderate the ease with which resources transfer across domains. For instance, those who prefer to integrate their work and nonwork roles may be more adept at drawing on resources in one domain for use in a secondary domain as compared to those with strict boundary segmentation.

Finally, future research will want to test the relationships posed in the current study in other populations in order inform the generalizability of these results. One could argue that the current sample may have already possessed a high level of resources (e.g., financial, educational, work-related) which enables them the ability to engage in resource acquisition efforts, whereas other working populations may chronically lack resources and therefore not possess this ability. Indeed, a review of the demographic and trait information collected from the current sample confirms that on average they were highly educated (probably indicating higher socioeconomic status) and reported relatively high levels of perceived autonomy in their work (an important precondition to job crafting). It is possible that the average levels of nonwork mastery and job crafting may have been limited in other populations, such as employees with more than one job or those that work a great deal of overtime, employees with reduced autonomy and increased repetition in their work, and those who may lack other important resources like financial resources or social resources outside of work. Accordingly, a core proposition of COR theory is that in the context of resource loss, it is extremely difficult to acquire or build resources (Hobfoll, 2001). Rather, individuals in this state are more likely to experience stress as a result of threatened or actual loss of resources (Hobfoll, 
1989). Research that examines these employee behaviors in the context of other industries and occupations can provide insight into whether these processes unfold in a similar manner.

\section{Implications for Practice}

The current study has the potential to inform organizational practice and individual employee behavior in a number of ways. For instance, research examining job crafting behavior remains in its infancy; however, the current study provides support for emerging research that has pointed to employees' role in constructing a work environment that is personally meaningful and fosters work engagement (e.g., Bakker et al., 2012; Berg et al., 2010; Leana et al., 2009). Practically speaking, empowering employees to self-manage their work engagement and personal work-related well-being can support bottom-up processes that complement other top-down, management driven approaches aimed at improving work engagement (Breevart et al., 2014). Practitioneroriented tools (e.g., the Job Crafting Tool ${ }^{\mathrm{TM}}$; Berg, Dutton, \& Wrzesnieski, 2013) have recently become available that are intended to facilitate and train employees to engage in job crafting behavior. Organizations could consider use of these tools to promote job crafting especially that which is directed at seeking and acquiring job resources. The current study supports that these behaviors, in particular, can be beneficial to employees' level of work engagement.

Critical to the success of such interventions would be a work environment that supports employees to craft their roles. Prior research has indicated that certain work characteristics such as autonomy and task interdependency are important antecedents to 
job crafting behavior in that they may facilitate or constrain this type of self-initiated employee action (Tims \& Bakker, 2010). For instance, efforts to build structural resources such as making changes to work tasks or engaging in personal development efforts may be less likely if autonomy is limited. Organizational efforts to garner a comprehensive understanding of actual and perceived work characteristics are likely to be an important foundational step to creating an environment conducive to job crafting. Moreover, aspects of the work climate may also play a role in the "success" of employee job crafting efforts. For example, in regards to increasing social resources, in an environment that emphasizes collaboration and teamwork it is more likely that an employee will be successful in building valuable social capital and fulfilling their needs for relatedness and social belonging (Deci \& Ryan, 1985). Similarly, managers who take time to develop trusting and authentic relationships with their employees are more likely to foster an environment in which employees feel open and willing to propose job changes or seek feedback (Ashford, Blatt, \& VandeWalle, 2003). Therefore, organizations seeking to encourage job crafting behaviors would benefit from critically evaluating the extent to which the work environment supports job crafting behaviors. In addition, the current research reinforces the connection between the work and nonwork domains by showing how activities during nonwork can impact functioning in the work domain. Although support was not found for within-person relationships between nonwork mastery experiences and work factors (job crafting and work engagement), between-person results were significant. As indicated above, one possible interpretation of these findings is that nonwork mastery experiences are beneficial for 
employees when they are engaged in regularly over the course of many days. That is, the return on investment for individual employees, in the form of greater personal resources, may be delayed rather than immediate. Although the former explanation is speculative, what can be derived from the current research is that nonwork mastery experiences are important experiences that covary with enhanced job crafting behavior and work engagement. This association supports the potential for organizations to benefit in the form of enhanced employee engagement when they encourage employees to engage in regular and frequent recovery activities outside of work. In practice, recovery from work could be supported by multiple levels within the organization; for instance, in the form of workplace flexibility policies that allow employees greater control over their work and nonwork schedules, the establishment of team norms for segmenting work and nonwork (e.g., policies that discourage email communication during nonwork time), or direct supervisor support for recovery during nonwork time.

At an individual level, employees who use nonwork time to challenge themselves and engage in novel activities may benefit in the form of greater psychological resources and improved engagement in the workplace. The recovery literature has identified a number of activities that promote mastery experiences including the pursuit of sport or other physical activities (Rook \& Zijlstra, 2006), learning a new skill (Sonnentag \& Jelden, 2009), or volunteering in the community (Mojza et al., 2011). The current research provides initial support for the resource-building nature of these nonwork activities and points to the relative spillover effects of nonwork mastery experiences on work experiences and behavior. 
At a general level, the current research suggests that organizational initiatives intended to drive enhanced work engagement could benefit from an employee-centric perspective that considers employees' perceptions of meaning and fulfillment of psychological needs, their experiences within and outside of the work context, and how these experiences play out over time (Weiss \& Rupp, 2011). Emphasis should be placed on not only how to build resources through organizational and individual interventions, but how to sustain work engagement over time. As advancements in technology and globalization occur and place increasing demands on employees (e.g. 24/7 connectivity, increased job demands) it will be important to invest in programs that take a balanced approach to helping employees mitigate and manage stress, and at the same time support the building of important psychological and job resources that enable growth and thriving in the work role.

\section{Conclusion}

The current study took into account the dynamic and transportable nature of psychological resources by examining reciprocal relationship between work and home. It was predicted that daily nonwork mastery experiences and job crafting (seeking resources and seeking challenges) would jointly impact daily levels of work engagement. Although findings were largely unsupportive of the proposed relationships at the withinperson level of analysis, ancillary analyses provided insight into the proximal role of positive affect as both an outcome of resource-building behavior as well as predictor of work engagement. In addition, significant results at the between-person level provided some support for the notion that both nonwork mastery experiences and job crafting 
behaviors can be viewed as resource-acquisition behaviors that result in enhanced psychological resources and greater work engagement over time. Taken together, the current study contributes to the literature on employee-initiated strategies used to maintain or enhance work engagement and answers the call for more research on understudied tenets of COR theory. 
Table 1

Summary of Assessments

\begin{tabular}{|c|c|c|c|}
\hline \multicolumn{2}{|r|}{ Variables } & Frequency & Time of Assessment \\
\hline $\begin{array}{l}\text { Between-person } \\
\text { level }\end{array}$ & $\begin{array}{l}\text { Demographic and work } \\
\text { characteristics }\end{array}$ & Once & About one week before daily surveys \\
\hline \multirow{3}{*}{$\begin{array}{l}\text { Within-person } \\
\text { level }\end{array}$} & Nonwork mastery experiences & \multirow{3}{*}{$\begin{array}{c}5 \text { consecutive } \\
\text { work days }\end{array}$} & $\begin{array}{l}\text { Upon arriving to work and before beginning } \\
\text { work (recalling the previous night) } \\
\text { (Monday through Friday between } 7 \mathrm{am} \text { and } \\
11 \mathrm{am} \text { ) }\end{array}$ \\
\hline & Job crafting & & $\begin{array}{l}\text { During lunch break in reference to } \\
\text { experiences since beginning work } \\
\text { (Monday through Friday between } 11 \text { am and } \\
3 \mathrm{pm})\end{array}$ \\
\hline & Work engagement & & $\begin{array}{l}\text { At the end of the workday before leaving for } \\
\text { home } \\
\text { (Monday through Friday between } 3 \mathrm{pm}-9 \mathrm{pm} \text { ) }\end{array}$ \\
\hline
\end{tabular}


Table 2.

Intercorrelations Among Study Variables

\begin{tabular}{|c|c|c|c|c|c|c|c|c|c|c|c|c|c|}
\hline Variable & $\begin{array}{c}\text { Cronbach's } \\
\alpha\end{array}$ & ICC & $M$ & $S D$ & 1 & 2 & 3 & 4 & 5 & 6 & 7 & 8 & 9 \\
\hline \multicolumn{14}{|l|}{ Day-level } \\
\hline 1. Day & & & & & & & & & & & & & \\
\hline 2. Nonwork Mastery & .78 & .43 & 2.91 & .78 & $\begin{array}{c}- \\
.23 * *\end{array}$ & & $.44 * *$ & $.43 * *$ & $.30 * *$ & $.30 * *$ & $.34 * *$ & .02 & .07 \\
\hline 3. Seeking Resources & .75 & .47 & 2.60 & .97 & $\begin{array}{c}- \\
.22 * *\end{array}$ & .01 & & $.68 * *$ & $.46^{* *}$ & $.51 * *$ & $.47 * *$ & $.16^{*}$ & $.13 *$ \\
\hline 4. Seeking Challenges & .89 & .65 & 2.07 & 1.09 & $\begin{array}{c}- \\
.32 * *\end{array}$ & -.02 & $.54 * *$ & & $.30 * *$ & $.37 * *$ & $.37 * *$ & .12 & .12 \\
\hline 5. Work Engagement & .92 & .78 & 4.54 & 1.28 & $.22 * *$ & .03 & -.10 & $-.11 *$ & & $.78 * *$ & $.81 * *$ & $.44 * *$ & $.40 * *$ \\
\hline 6. Morning PA & .95 & .74 & 3.16 & .96 & $.18 * *$ & $.22 * *$ & .09 & .00 & $.37 * *$ & & $.87 * *$ & $.50 * *$ & $.35 * *$ \\
\hline 7. Lunchtime PA & .95 & .64 & 3.33 & .88 & .08 & .06 & $.29 * *$ & .02 & $.36^{* *}$ & $.54 * *$ & & $.53 * *$ & $.52 * *$ \\
\hline 8. Morning Efficacy & .86 & .65 & 4.12 & .65 & $.13 *$ & .01 & .07 & -.00 & $.37 * *$ & $.47 * *$ & $.35^{* *}$ & & $.75^{* * *}$ \\
\hline 9. Lunchtime Efficacy & .88 & .60 & 4.12 & .69 & $-.11 *$ & .09 & .08 & $.11 *$ & $.24 * *$ & $.23 * *$ & $.32 * *$ & $.31 * *$ & \\
\hline
\end{tabular}

Note. Below the diagonal, pooled within-person correlations are displayed $(n=360)$; above the diagonal, correlations are person level averages across the five days $(n=73)$. For variables assessed at the day level, Cronbach's $\alpha$ was calculated individually for every day, and then the respective five reliabilities were averaged. ICC $=$ Intraclass correlation coefficient. PA $=$ Positive affect.

$* p<.05 . * * p<.01$. 
Table 3a

Multilevel Models Predicting Daily Job Crafting and Work Engagement from Nonwork Mastery Experiences (Within-Person Results)

\begin{tabular}{|c|c|c|c|c|c|c|c|c|c|}
\hline \multirow[b]{2}{*}{ Parameter } & \multicolumn{3}{|c|}{ Daily Job Crafting: SR } & \multicolumn{3}{|c|}{ Daily Job Crafting: SC } & \multicolumn{3}{|c|}{ Daily Work Engagement } \\
\hline & Estimate & $S E$ & $\begin{array}{l}\text { Standardized } \\
\text { estimate }\end{array}$ & Estimate & $S E$ & $\begin{array}{l}\text { Standardized } \\
\text { estimate }\end{array}$ & Estimate & $S E$ & $\begin{array}{l}\text { Standardized } \\
\text { estimate }\end{array}$ \\
\hline \multicolumn{10}{|l|}{$\begin{array}{l}\text { Within-person } \\
\text { level (Level 1) }\end{array}$} \\
\hline $\begin{array}{l}\text { Control: } \\
\text { day } \rightarrow \\
\text { outcome }\end{array}$ & -.05 & .03 & $-.12^{\dagger}$ & $-.13 * *$ & .03 & $-.29 * *$ & $.10^{*}$ & .04 & $.24 *$ \\
\hline NME & .09 & .07 & .09 & -.09 & .06 & -.08 & .09 & .07 & .09 \\
\hline $\begin{array}{l}\text { Residual } \\
\text { variance }\end{array}$ & $.32 * *$ & $.06^{* *}$ & & $.37 * *$ & .08 & & $.34 * *$ & .07 & \\
\hline
\end{tabular}

త్ర 
Table $3 b$

Multilevel Models Predicting Daily Job Crafting and Work Engagement from Nonwork Mastery Experiences (Between-Person Results)

\begin{tabular}{|c|c|c|c|c|c|c|c|c|c|}
\hline \multirow[b]{2}{*}{ Parameter } & \multicolumn{3}{|c|}{ Daily Job Crafting: SR } & \multicolumn{3}{|c|}{ Daily Job Crafting: SC } & \multicolumn{3}{|c|}{ Daily Work Engagement } \\
\hline & Estimate & $S E$ & $\begin{array}{c}\text { Standardized } \\
\text { estimate }\end{array}$ & Estimate & $S E$ & $\begin{array}{l}\text { Standardized } \\
\text { estimate }\end{array}$ & Estimate & $S E$ & $\begin{array}{c}\text { Standardized } \\
\text { estimate }\end{array}$ \\
\hline \multicolumn{10}{|l|}{$\begin{array}{l}\text { Between- } \\
\text { person level } \\
\text { (Level 2) }\end{array}$} \\
\hline Intercept & $2.41 * *$ & .28 & & & .72 & & $2.12 *$ & .93 & \\
\hline NME & $.14^{*}$ & .06 & $.32 *$ & $.94 * *$ & .25 & $.54 * *$ & $.72 *$ & .31 & $.32 *$ \\
\hline $\begin{array}{l}\text { Residual } \\
\text { variance }\end{array}$ & $.22 * *$ & .05 & & $.53 * *$ & .11 & & $1.14^{* *}$ & .21 & \\
\hline
\end{tabular}

Note. Models are random intercepts models; $n=73$ at the person level. Average number of observations per person $=4.93$.

$S E=$ standard error. Standardized estimates are indicted for path coefficients. SR = Seeking Resources. SC = Seeking Challenges. Day $=$ Day of Week. NME $=$ Nonwork mastery experiences.

$* p<.05$ (two-tailed). $* * p<.01$ (two-tailed). ${ }^{\dagger} p<.10$ (two-tailed) 
Multilevel Models Predicting Daily Work Engagement from Job Crafting (Within-Person Results)

\begin{tabular}{|c|c|c|c|c|c|c|}
\hline \multirow[b]{2}{*}{ Parameter } & \multicolumn{3}{|c|}{ Daily Job Crafting: SR $\rightarrow$ Work Engagement } & \multicolumn{3}{|c|}{ Daily Job Crafting: SC $\rightarrow$ Work Engagement } \\
\hline & Estimate & $S E$ & $\begin{array}{l}\text { Standardized } \\
\text { estimate }\end{array}$ & Estimate & $S E$ & $\begin{array}{c}\text { Standardized } \\
\text { estimate }\end{array}$ \\
\hline \multicolumn{7}{|l|}{$\begin{array}{l}\text { Within-person level } \\
\text { (Level 1) }\end{array}$} \\
\hline $\begin{array}{l}\text { Control: day } \rightarrow \\
\text { outcome }\end{array}$ & $.09 *$ & .04 & $.22 *$ & $.09 *$ & .04 & $.21 *$ \\
\hline Job Crafting & -.03 & .06 & -.03 & -.06 & .07 & -.06 \\
\hline $\begin{array}{l}\text { Residual } \\
\text { variance }\end{array}$ & $.33 * *$ & .07 & & $.33^{* *}$ & .07 & \\
\hline
\end{tabular}

Note. Models are random intercepts models; $n=73$ at the person level. Average number of observations per person $=4.93$. $S E=$ standard error. Standardized estimates are indicted for path coefficients. SR = Seeking Resources. SC = Seeking Challenges. Day = Day of Week.

$* p<.05 . * * p<.01 .{ }^{\dagger} p<.10$. 
Table $4 b$

Multilevel Models Predicting Daily Work Engagement from Job Crafting (Between-Person Results)

\begin{tabular}{|c|c|c|c|c|c|c|}
\hline \multirow[b]{2}{*}{ Parameter } & \multicolumn{3}{|c|}{ Daily Job Crafting: SR $\rightarrow$ Work Engagement } & \multicolumn{3}{|c|}{ Daily Job Crafting: SC $\rightarrow$ Work Engagement } \\
\hline & Estimate & $S E$ & $\begin{array}{l}\text { Standardized } \\
\text { estimate }\end{array}$ & Estimate & $S E$ & $\begin{array}{c}\text { Standardized } \\
\text { estimate }\end{array}$ \\
\hline \multicolumn{7}{|l|}{$\begin{array}{l}\text { Between-person } \\
\text { level (Level 2) }\end{array}$} \\
\hline Intercept & $1.80^{*}$ & .59 & & $3.37 * *$ & .39 & \\
\hline Job Crafting & $.96^{* *}$ & .24 & $.56^{* *}$ & $.44^{*}$ & .17 & $.34^{*}$ \\
\hline $\begin{array}{l}\text { Residual } \\
\text { variance }\end{array}$ & $.86^{* *}$ & .21 & & $1.12 * *$ & .25 & \\
\hline
\end{tabular}

Note. Models are random intercepts models; $n=73$ at the person level. Average number of observations per person $=4.93$.

$S E=$ standard error. Standardized estimates are indicted for path coefficients. SR = Seeking Resources. SC = Seeking Challenges. Day $=$ Day of Week.

$* p<.05 . * * p<.01 .{ }^{\dagger} p<.10$ 
Table 5a

Multilevel Mediation Models Predicting Daily Work Engagement from Nonwork Mastery Experiences and Job Crafting (WithinPerson Results)

\begin{tabular}{|c|c|c|c|c|c|c|}
\hline \multirow[b]{2}{*}{ Parameter } & \multicolumn{3}{|c|}{$\begin{array}{l}\text { 1-1-1 mediation model (Job Crafting: SR as a } \\
\text { mediator) }\end{array}$} & \multicolumn{3}{|c|}{$\begin{array}{l}\text { 1-1-1 mediation model (Job Crafting: SC as a } \\
\text { mediator) }\end{array}$} \\
\hline & Estimate & $S D$ & $\begin{array}{c}\text { Standardized } \\
\text { estimate }\end{array}$ & Estimate & $S D$ & $\begin{array}{c}\text { Standardized } \\
\text { estimate }\end{array}$ \\
\hline \multicolumn{7}{|l|}{$\begin{array}{l}\text { Within-person level } \\
\text { (Level 1) }\end{array}$} \\
\hline Control: day $\rightarrow$ eng & $.10^{* *}$ & .03 & $.22 * *$ & $.09 *$ & .03 & $.20 *$ \\
\hline $\begin{array}{l}\text { Control: day } \rightarrow \\
\text { craft }\end{array}$ & $-.08^{*}$ & .03 & $-.16^{*}$ & $-.13 * *$ & .04 & $-.28 * *$ \\
\hline $\begin{array}{l}\text { Path } a_{w} \\
(N M E \rightarrow \text { craft })\end{array}$ & .05 & .09 & .04 & -.10 & .09 & -.08 \\
\hline $\begin{array}{l}\text { Path } b_{w} \\
\text { (craft } \rightarrow \text { eng) }\end{array}$ & -.03 & .08 & -.03 & -.05 & .09 & -.05 \\
\hline $\begin{array}{l}\text { Path } \mathrm{c}_{\mathrm{w}} \\
(\mathrm{NME} \rightarrow \mathrm{eng})\end{array}$ & .11 & .09 & .12 & .10 & .08 & .09 \\
\hline $\begin{array}{l}\text { Indirect effect } \\
(\mathrm{NME} \rightarrow \mathrm{craft} \rightarrow \text { eng })\end{array}$ & .00 & .01 & & .00 & .01 & \\
\hline Residual variance & $.34 * *$ & .04 & & $.35^{* *}$ & .04 & \\
\hline
\end{tabular}


Residual variance

craft
$.48 * *$
$.37 * *$

.04

Note. Models are 1-1-1 mediation models with random intercepts and fixed slopes. Paths refer to Figure 2.

$S D=$ Posterior standard deviation. Standardized estimates are indicted for path coefficients. NME = Nonwork mastery experiences;

Day = Day of the Week; Eng = Work engagement; Craft=Job Crafting.

$* p<.05 . * * p<.01$. 
Table $5 b$

Multilevel Mediation Models Predicting Daily Work Engagement from Nonwork Mastery Experiences and Job Crafting (BetweenPerson Results)

\begin{tabular}{|c|c|c|c|c|c|c|}
\hline \multirow[b]{2}{*}{ Parameter } & \multicolumn{3}{|c|}{$\begin{array}{l}\text { 1-1-1 mediation model (Job Crafting: SR as a } \\
\text { mediator) }\end{array}$} & \multicolumn{3}{|c|}{$\begin{array}{l}\text { 1-1-1 mediation model (Job Crafting: SC as a } \\
\text { mediator) }\end{array}$} \\
\hline & Estimate & $S D$ & $\begin{array}{c}\text { Standardized } \\
\text { estimate }\end{array}$ & Estimate & $S D$ & $\begin{array}{c}\text { Standardized } \\
\text { estimate }\end{array}$ \\
\hline \multicolumn{7}{|l|}{$\begin{array}{l}\text { Between-person level } \\
\text { (Level 2) }\end{array}$} \\
\hline Intercept & 1.67 & .95 & & $2.41 *$ & 1.12 & \\
\hline $\begin{array}{l}\text { Path } a_{b} \\
(\mathrm{NME} \rightarrow \text { craft })\end{array}$ & $.77 * *$ & .21 & $.59 * *$ & $.93 * *$ & .30 & $.51 * *$ \\
\hline Path $b_{b}($ craft $\rightarrow$ eng $)$ & $1.02 * *$ & .34 & $.60 * *$ & .32 & .23 & .24 \\
\hline $\begin{array}{l}\text { Path } c_{b} \\
(N M E \rightarrow \text { eng })\end{array}$ & -.11 & .46 & -.04 & .39 & .45 & .17 \\
\hline $\begin{array}{l}\text { Indirect effect } \\
(\mathrm{NME} \rightarrow \mathrm{craft} \rightarrow \mathrm{eng})\end{array}$ & $.76^{* *}$ & .36 & & .28 & .24 & \\
\hline $\begin{array}{l}\text { Residual variance } \\
\text { eng }\end{array}$ & $.89 * *$ & .19 & & & & \\
\hline $\begin{array}{l}\text { Residual variance } \\
\text { craft }\end{array}$ & $.30 * *$ & .10 & & & & \\
\hline
\end{tabular}


Note. Models are 1-1-1 mediation models with random intercepts and fixed slopes. Paths refer to Figure 2.

$S D=$ Posterior standard deviation. Standardized estimates are indicted for path coefficients. NME = Nonwork mastery experiences;

Eng $=$ Work engagement; Craft=Job Crafting.

$* p<.05 . * * p<.01$. 
Table $6 \mathrm{a}$

Multilevel Models Predicting Nonwork Mastery Experiences from Work Engagement (Within-Person Results)

\begin{tabular}{cccc}
\hline & \multicolumn{2}{c}{ Daily Work Engagement $\rightarrow$ Nonwork Mastery Experiences } \\
\cline { 2 - 3 } Parameter & Estimate & $S E$ & Standardized estimate \\
\hline Within-person level (Level 1) & .05 & .03 & .11 \\
Control: day $\rightarrow$ NME & -.05 & .08 & -.05 \\
Work Engagement & $.35^{* *}$ & .05 & \\
Residual variance & & & \\
\end{tabular}

Note. Models are random intercepts models; $n=73$ at the person level. Average number of observations per person $=4.93$.

$S E=$ standard error. Standardized estimates are indicted for path coefficients. NME $=$ Nonwork mastery experiences. Day $=$ Day of Week.

$* p<.05 . * * p<.01 .{ }^{\dagger} p<.10$. 
Table $6 \mathrm{~b}$

Multilevel Models Predicting Nonwork Mastery Experiences from Work Engagement (Between-Person Results)

\begin{tabular}{cccc}
\hline & \multicolumn{2}{c}{ Daily Work Engagement $\rightarrow$ Nonwork Mastery Experiences } \\
\cline { 2 - 4 } Parameter & Estimate & $S E$ & Standardized estimate \\
\hline Between-person level (Level 2) & $2.35^{* *}$ & .25 & .22 \\
Intercept & .09 & .05 & .06 \\
Work Engagement & $.20^{* *}$ & & \\
Residual variance & & & \\
\end{tabular}

Note. Models are random intercepts models; $n=73$ at the person level. Average number of observations per person $=4.93$. $S E=$ standard error. Standardized estimates are indicted for path coefficients. NME=Nonwork mastery experiences.

${ }^{*} p<.05 . * * p<.01 .{ }^{\dagger} p<.10$. 
Table $7 \mathrm{a}$

Multilevel Mediation Models Predicting Daily Job Crafting and Work Engagement from NME, Positive Affect, and Efficacy Beliefs (Within-Person Results)

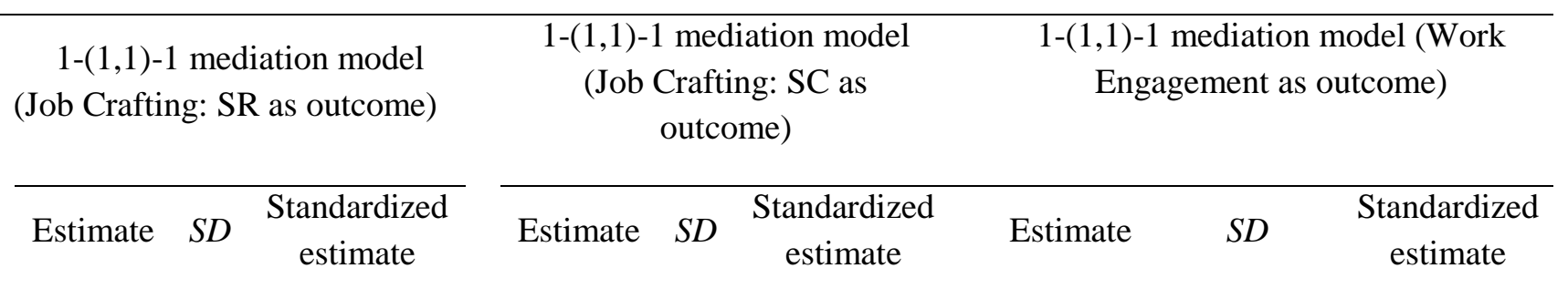

\begin{tabular}{|c|c|c|c|c|c|c|c|c|c|}
\hline $\begin{array}{l}\text { Within-person level } \\
\text { (Level 1) }\end{array}$ & & & & & & & & & \\
\hline $\begin{array}{l}\text { Control: day } \rightarrow \\
\text { outcome }\end{array}$ & $-.10 * *$ & .04 & $-.18 * *$ & $-.14 * *$ & .03 & $-.30 * *$ & $.09 * *$ & .03 & $.20 * *$ \\
\hline Control: day $\rightarrow$ PA & $.06^{*}$ & .02 & $.16^{* *}$ & $.06^{*}$ & .02 & $.16^{*}$ & $.05 *$ & .02 & $.14^{*}$ \\
\hline Control: day $\rightarrow$ Eff & $.04^{*}$ & .02 & $.14^{*}$ & $.04 *$ & .02 & $.13^{*}$ & $.04^{\dagger}$ & .02 & $.12^{\dagger}$ \\
\hline $\begin{array}{l}\text { Path } \mathrm{a}_{\mathrm{w} 1} \\
(\mathrm{NME} \rightarrow \mathrm{PA})\end{array}$ & $.17 * *$ & .05 & $.26^{*}$ & $.17 * *$ & .06 & $.26^{* *}$ & $.13^{*}$ & .06 & $.19 *$ \\
\hline $\begin{array}{l}\text { Path } \mathrm{a}_{\mathrm{w} 2} \\
(\mathrm{NME} \rightarrow \mathrm{Eff})\end{array}$ & .03 & .04 & .06 & .02 & .05 & .03 & .01 & .05 & .01 \\
\hline $\begin{array}{l}\text { Path } b_{w 1} \\
\text { (PA } \rightarrow \text { outcome) }\end{array}$ & .18 & .14 & .13 & $.23^{\dagger}$ & .13 & $.17^{\dagger}$ & .17 & .12 & .14 \\
\hline $\begin{array}{l}\text { Path } b_{w 2} \\
(\text { Eff } \rightarrow \text { outcome })\end{array}$ & .10 & .18 & .05 & .02 & .16 & .01 & $.33 *$ & .14 & $.20 *$ \\
\hline
\end{tabular}




\begin{tabular}{|c|c|c|c|c|c|c|c|c|c|}
\hline $\begin{array}{l}\text { Path } c_{w} \\
\text { (NME } \rightarrow \text { outcome) }\end{array}$ & .02 & .04 & .02 & $-.17^{\dagger}$ & .09 & $-.19^{\dagger}$ & .09 & .09 & .12 \\
\hline Indirect effect $_{1(\mathrm{PA})}$ & .03 & .03 & & $.03^{\dagger}$ & .03 & & .02 & .02 & \\
\hline Indirect effect $_{2 \text { (Eff) }}$ & .00 & .01 & & .00 & .01 & & .00 & .02 & \\
\hline $\begin{array}{l}\text { Residual variance } \\
\text { outcome }\end{array}$ & $.49 * *$ & .06 & & $.38 * *$ & .05 & & $.31 * *$ & .04 & \\
\hline $\begin{array}{l}\text { Residual variance } \\
\text { PA }\end{array}$ & $.23 * *$ & .03 & & $.23 * *$ & .03 & & $.24 * *$ & .03 & \\
\hline $\begin{array}{l}\text { Residual variance in } \\
\text { Eff }\end{array}$ & $.14 * *$ & .02 & & $.14 * *$ & .02 & & $.14 * *$ & .02 & \\
\hline
\end{tabular}

Note. Models are 1-(1,1)-1 mediation models with random intercepts and fixed slopes. Indirect Effect 1 refers to indirect path through Positive Affect. Indirect Effect 2 refers to indirect path through Efficacy Beliefs. $S D=$ Posterior standard deviation. Standardized estimates are indicted for path coefficients; NME = Nonwork Mastery Experiences; Day = Day of the Week; PA=Positive Affect. Eff $=$ Efficacy Beliefs.

$* p<.05 . * * p<.01 .{ }^{\dagger} p<.10$ 
Table $7 b$

Multilevel Mediation Models Predicting Daily Job Crafting and Work Engagement from NME, Positive Affect, and Efficacy Beliefs (Between-Person Results)

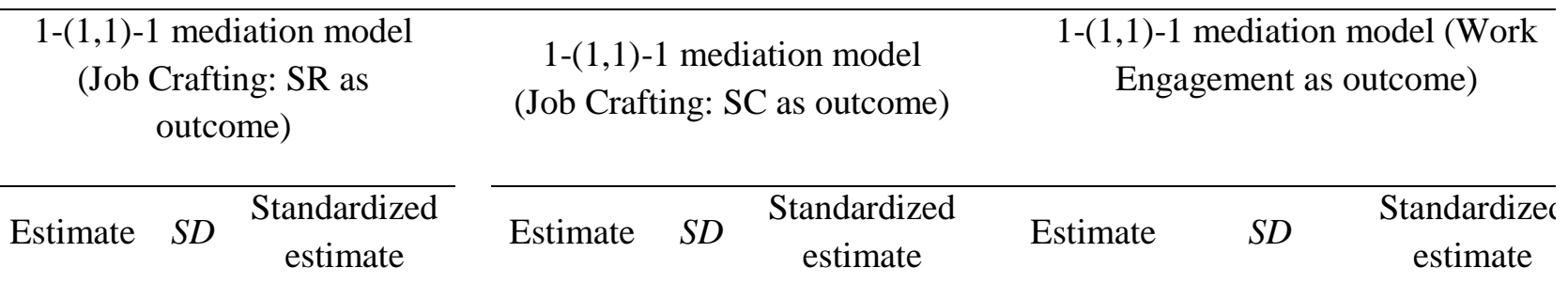

\begin{tabular}{|c|c|c|c|c|c|c|c|c|c|}
\hline \multicolumn{10}{|l|}{$\begin{array}{l}\text { Between-person level } \\
\text { (Level 2) }\end{array}$} \\
\hline Intercept & .97 & .79 & & .05 & 1.08 & & -.14 & .92 & \\
\hline $\begin{array}{l}\text { Path } a_{b 1} \\
(\mathrm{NME} \rightarrow \mathrm{PA})\end{array}$ & .29 & .19 & .19 & .30 & .19 & .20 & $.34^{\dagger}$ & .19 & $.23^{\dagger}$ \\
\hline $\begin{array}{l}\text { Path } \mathrm{a}_{\mathrm{b} 2} \\
(\mathrm{NME} \rightarrow \mathrm{Eff})\end{array}$ & .03 & .13 & .04 & .04 & .13 & .04 & .05 & .14 & .06 \\
\hline $\begin{array}{l}\text { Path } b_{b 1} \\
(\mathrm{PA} \rightarrow \text { outcome })\end{array}$ & $.44 * *$ & .12 & $.56^{* *}$ & .30 & .17 & .26 & $1.10 * *$ & .15 & $.78 * *$ \\
\hline $\begin{array}{l}\text { Path } b_{b 2} \\
(\text { Eff } \rightarrow \text { outcome })\end{array}$ & -.14 & .19 & -.12 & -.04 & .26 & -.02 & .17 & .23 & .08 \\
\hline $\begin{array}{l}\text { Path } c_{b} \\
(\mathrm{NME} \rightarrow \text { outcome })\end{array}$ & $.41 *$ & .16 & $.36^{*}$ & $.76^{* *}$ & .21 & $.44 * *$ & .13 & .20 & .06 \\
\hline Indirect $_{\text {effect }}{ }_{(\mathrm{PA})}$ & .12 & .09 & & .07 & .08 & & $.36^{\dagger}$ & .22 & \\
\hline
\end{tabular}




$\begin{array}{lcccccc}\text { Indirect effect } 2 \text { (Eff) } & -.00 & .03 & .00 & .04 & .00 & .04 \\ \begin{array}{l}\text { Residual variance } \\ \text { outcome }\end{array} & .22 * * & .08 & .63 * * & .15 & .39 * * & .11 \\ \begin{array}{l}\text { Residual variance } \\ \text { PA }\end{array} & .67 * * & .13 & .67 * * & .14 & .66^{* *} & .13 \\ \begin{array}{l}\text { Residual variance } \\ \text { Eff }\end{array} & .30^{* *} & .08 & .29 * * & .06 & .30^{* *} & .11\end{array}$

Note. Models are 1-(1,1)-1 mediation models with random intercepts and fixed slope. Indirect Effect 1 refers to indirect path through Positive Affect. Indirect Effect 2 refers to indirect path through Efficacy Beliefs. $S D=$ Posterior standard deviation. Standardized estimates are indicted for path coefficients. NME = Nonwork Mastery Experiences; PA=Positive Affect. Eff=Efficacy Beliefs. $* p<.05 . * * p<.01 .{ }^{\dagger} p<.10$. 
Table 8a

Multilevel Mediation Models Predicting Daily Work Engagement from Job Crafting, Positive Affect, and Efficacy Beliefs (WithinPerson Results)

\begin{tabular}{|c|c|c|c|c|c|c|}
\hline \multirow[b]{2}{*}{ Parameter } & \multicolumn{3}{|c|}{$\begin{array}{l}\text { 1-(1-1)-1 mediation model (Job Crafting: } \\
\text { SR as predictor) }\end{array}$} & \multicolumn{3}{|c|}{$\begin{array}{l}\text { 1-(1,1)-1 mediation model (Job Crafting } \\
\text { SC as predictor) }\end{array}$} \\
\hline & Estimate & $S E$ & $\begin{array}{l}\text { Standardized } \\
\text { estimate }\end{array}$ & Estimate & $S E$ & $\begin{array}{l}\text { Standardized } \\
\text { estimate }\end{array}$ \\
\hline
\end{tabular}

Within-person level (Level 1)

\begin{tabular}{|c|c|c|c|c|c|c|}
\hline Control: day $\rightarrow$ eng & $.08 *$ & .03 & $.18^{*}$ & $.07 *$ & .03 & $.16^{*}$ \\
\hline Control: day $\rightarrow$ PA & $.05^{*}$ & .02 & $.11 *$ & .04 & .02 & .11 \\
\hline Control: day $\rightarrow$ Eff & -.03 & .02 &.- .01 & -.01 & .02 & -.03 \\
\hline Path $\mathrm{a}_{\mathrm{w} 1}(\mathrm{craft} \rightarrow \mathrm{PA})$ & $.24 * *$ & .04 & $.42 * *$ & $.16^{* *}$ & .05 & $.32 * *$ \\
\hline Path $\mathrm{a}_{\mathrm{w} 2}(\mathrm{craft} \rightarrow \mathrm{Eff})$ & .06 & .05 & .14 & $.11^{*}$ & .05 & $.26^{*}$ \\
\hline Path $b_{\mathrm{w} 1}(\mathrm{PA} \rightarrow \mathrm{eng})$ & $.33 * *$ & .10 & $.30 * *$ & $.32 * *$ & .10 & $.28 * *$ \\
\hline Path $b_{\mathrm{w} 2}(\mathrm{Eff} \rightarrow \mathrm{eng})$ & .19 & .14 & .14 & .18 & .14 & .13 \\
\hline Path $\mathrm{c}_{\mathrm{w}}(\mathrm{craft} \rightarrow \mathrm{eng})$ & -.09 & .07 & -.14 & -.08 & .07 & -.14 \\
\hline Indirect effect $_{1(\mathrm{PA})}$ & $.08^{* *}$ & .03 & & $.05^{* *}$ & .02 & \\
\hline Indirect effect ${ }_{2(\mathrm{Eff})}$ & .01 & .01 & & .02 & .02 & \\
\hline
\end{tabular}

$6^{*}$
11
.03
$2 * *$
$13 *$
$13 * *$
$14 \quad \bar{N}$




$\begin{array}{lllll}\text { Residual variance eng } & .31^{* *} & .04 & .31^{* *} & .04 \\ \text { Residual variance PA } & .26^{* *} & .03 & .28^{* *} & .03 \\ \text { Residual variance Eff } & .19^{* *} & .02 & .19^{* *} & .02\end{array}$

Note. Models are 1-(1,1)-1 mediation models with random intercepts and fixed slopes. Indirect Effect 1 refers to indirect path through Positive Affect. Indirect Effect 2 refers to indirect path through Efficacy Beliefs. $S E=$ standard error. Standardized estimates are indicted for path coefficients. Day = Day of Week. Eng = work engagement. SR = Seeking Resources. SC = Seeking Challenges . Craft=Job Crafting.

$* p<.05 . * * p<.01$. 
Table $8 b$

Multilevel Mediation Models Predicting Daily Work Engagement from Job Crafting, Positive Affect, and Efficacy Beliefs (BetweenPerson Results)

\begin{tabular}{|c|c|c|c|c|c|c|}
\hline \multirow[b]{2}{*}{ Parameter } & \multicolumn{3}{|c|}{$\begin{array}{l}\text { 1-(1-1)-1 mediation model (Job Crafting: } \\
\text { SR as predictor) }\end{array}$} & \multicolumn{3}{|c|}{$\begin{array}{l}\text { 1-(1,1)-1 mediation model (Job Crafting: } \\
\text { SC as predictor) }\end{array}$} \\
\hline & Estimate & $S E$ & $\begin{array}{l}\text { Standardized } \\
\text { estimate }\end{array}$ & Estimate & $S E$ & $\begin{array}{l}\text { Standardized } \\
\text { estimate }\end{array}$ \\
\hline \multicolumn{7}{|c|}{ Between-person level (Level 2) } \\
\hline Intercept & -.02 & .88 & & -.08 & .86 & \\
\hline Path $a_{b 1}(\operatorname{craft} \rightarrow P A)$ & $.22 *$ & .11 & $.26^{*}$ & .12 & .12 & .16 \\
\hline Path $\mathrm{a}_{\mathrm{b} 2}(\mathrm{craft} \rightarrow \mathrm{Eff})$ & .05 & .10 & .07 & -.06 & .10 & -.10 \\
\hline Path $b_{b 1}(P A \rightarrow$ eng $)$ & $1.42 * *$ & .26 & $.77 * *$ & $1.55^{* *}$ & .23 & $.86^{* *}$ \\
\hline Path $b_{b 2}($ Eff $\rightarrow$ eng $)$ & -.11 & .26 & -.05 & -.18 & .27 & -.08 \\
\hline Path $\mathrm{c}_{\mathrm{b}}(\mathrm{craft} \rightarrow$ eng $)$ & $.42^{*}$ & .16 & $.27 *$ & .19 & .15 & .15 \\
\hline Indirect effect $_{1(\mathrm{PA})}$ & $.29 *$ & .17 & & .17 & .17 & \\
\hline Indirect effect $_{2(\mathrm{Eff})}$ & -.00 & .03 & & .00 & .03 & \\
\hline Residual variance eng & $.38 * *$ & .12 & & $.38 * *$ & .13 & \\
\hline Residual variance PA & $.39 * *$ & .09 & & $.45^{* *}$ & .10 & \\
\hline
\end{tabular}


Note. Models are 1-(1,1)-1 mediation models with random intercepts and fixed slopes. Indirect Effect 1 refers to indirect path through Positive Affect. Indirect Effect 2 refers to indirect path through Efficacy Beliefs. $S E=$ standard error. Standardized estimates are indicted for path coefficients. Eng = work engagement. SR = Seeking Resources. SC = Seeking Challenges. Craft=Job Crafting. $* p<.05$. ** $p<.01$. 
Table 9

Summary of Results

\begin{tabular}{|l|l|l|}
\hline Description & Within-person Findings & $\begin{array}{l}\text { Between-person } \\
\text { Findings }\end{array}$ \\
\hline $\begin{array}{l}\text { H1: NME positively } \\
\text { related to work } \\
\text { engagement }\end{array}$ & Ns; Not supported & Supported \\
\hline $\begin{array}{l}\text { H2a: NME positively } \\
\text { related to seeking } \\
\text { resources behavior }\end{array}$ & Ns; Not supported & Supported \\
\hline $\begin{array}{l}\text { H2b: NME positively } \\
\text { related to seeking } \\
\text { challenges behavior }\end{array}$ & Ns; Not supported & \\
\hline $\begin{array}{l}\text { H3a: Seeking } \\
\text { resources positively } \\
\text { related to work } \\
\text { engagement }\end{array}$ & Ns; Not supported & Supported \\
\hline $\begin{array}{l}\text { H3b: Seeking } \\
\text { challenges positively } \\
\text { related to work } \\
\text { engagement }\end{array}$ & Ns; Not supported & \\
\hline $\begin{array}{l}\text { H4a: Seeking } \\
\text { resources mediates the } \\
\text { relationship between } \\
\text { NME and work } \\
\text { engagement }\end{array}$ & Ns; Not supported & Supported \\
\hline $\begin{array}{l}\text { H4b: Seeking } \\
\text { challenges mediates } \\
\text { the relationship } \\
\text { between NME and } \\
\text { work engagement }\end{array}$ & Ns; Not supported & Supported \\
\hline $\begin{array}{l}\text { H5: Work engagement } \\
\text { positively related to } \\
\text { NME }\end{array}$ & Ns; Not supported & \\
\hline $\begin{array}{l}\text { RQ1a: Positive affect } \\
\text { and efficacy beliefs } \\
\text { mediate the } \\
\text { relationship between } \\
\text { NME and seeking } \\
\text { resources behavior }\end{array}$ & $N s ;$ Not supported & Supported \\
\hline $\begin{array}{l}\text { RQ1b: Positive affect } \\
\text { and efficacy beliefs } \\
\text { mediate the } \\
\text { relationship between } \\
\text { NME and seeking }\end{array}$ & Ns; Not supported & \\
\hline
\end{tabular}




\begin{tabular}{|c|c|c|}
\hline challenges behavior & & \\
\hline $\begin{array}{l}\text { RQ2: Positive affect } \\
\text { and efficacy beliefs } \\
\text { mediate the } \\
\text { relationship between } \\
\text { NME and work } \\
\text { engagement }\end{array}$ & $N s$; Not supported & $N s$; Not supported \\
\hline $\begin{array}{l}\text { RQ3a: Positive affect } \\
\text { and efficacy beliefs } \\
\text { mediate the } \\
\text { relationship between } \\
\text { seeking resources } \\
\text { behavior and work } \\
\text { engagement }\end{array}$ & $\begin{array}{l}\text { Supported (via positive affect, } \\
\text { not efficacy beliefs) }\end{array}$ & $\begin{array}{l}\text { Supported (via positive } \\
\text { affect, not efficacy } \\
\text { beliefs) }\end{array}$ \\
\hline $\begin{array}{l}\text { RQ3b: Positive affect } \\
\text { and efficacy beliefs } \\
\text { mediate the } \\
\text { relationship between } \\
\text { seeking challenges } \\
\text { behavior and work } \\
\text { engagement }\end{array}$ & $\begin{array}{l}\text { Supported (via positive affect, } \\
\text { not efficacy beliefs) }\end{array}$ & $N s$; Not supported \\
\hline
\end{tabular}

Note. NME=Nonwork mastery experiences. 
Figure 1. Model of Hypothesized Relationships

Day $d$

Day $d+1$

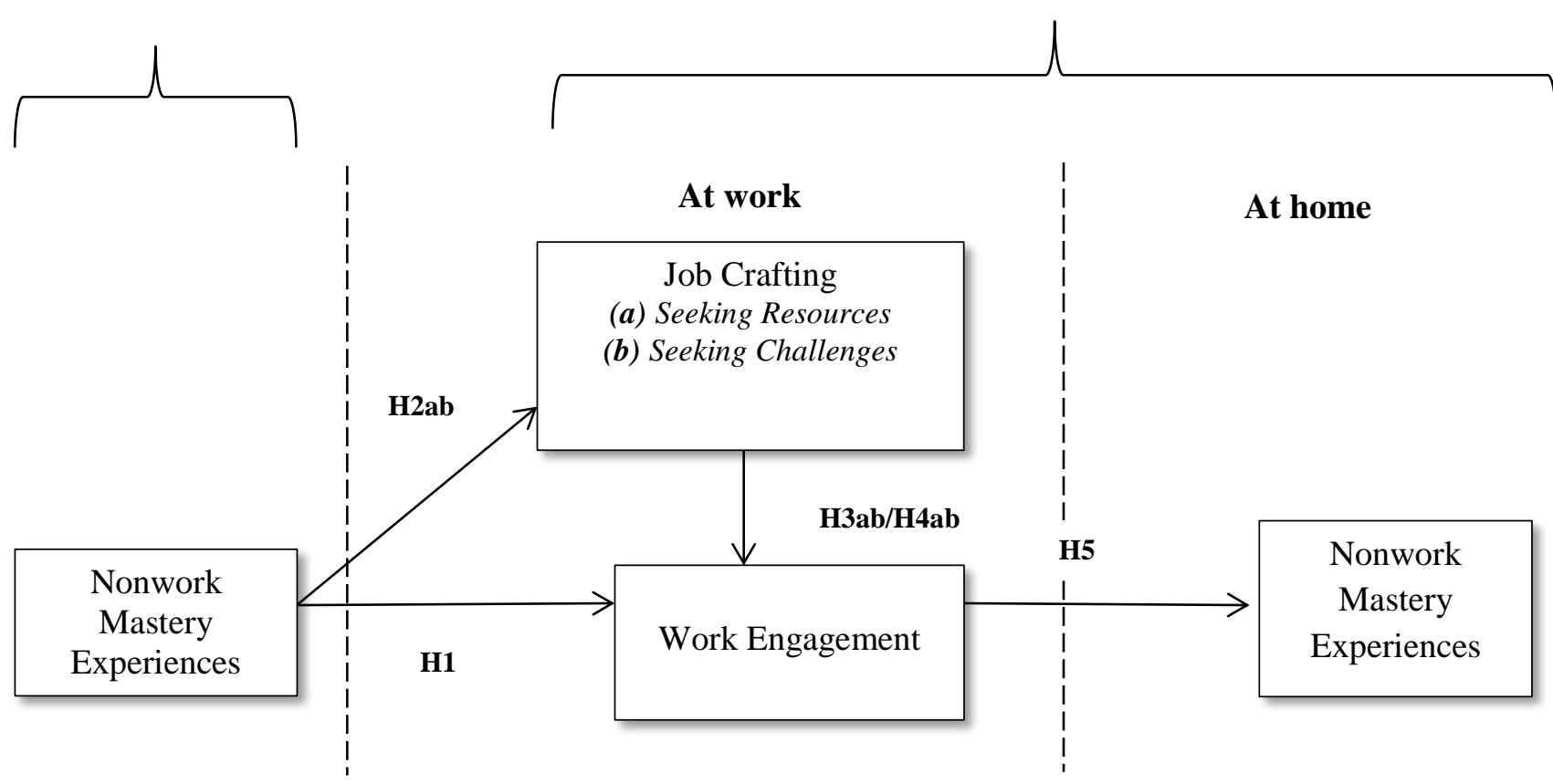

Note. Model refers to relationships at the within-person level of analysis only. Between-person relationships are not hypothesized. Nonwork mastery experiences were assessed in the morning before beginning work and refer to experiences the prior evening duri nonwork. Job crafting behaviors were assessed mid-day and refer to behaviors that employees have engaged since beginning work day. Work engagement was assessed at the end of the workday before leaving for home.

H4ab refers to the hypothesized mediation models. 
Figure 2. Multilevel Structural Equation Model Describing 1-1-1 Mediation Model between Day-Level Nonwork Mastery Experiences, Job Crafting, And Work Engagement

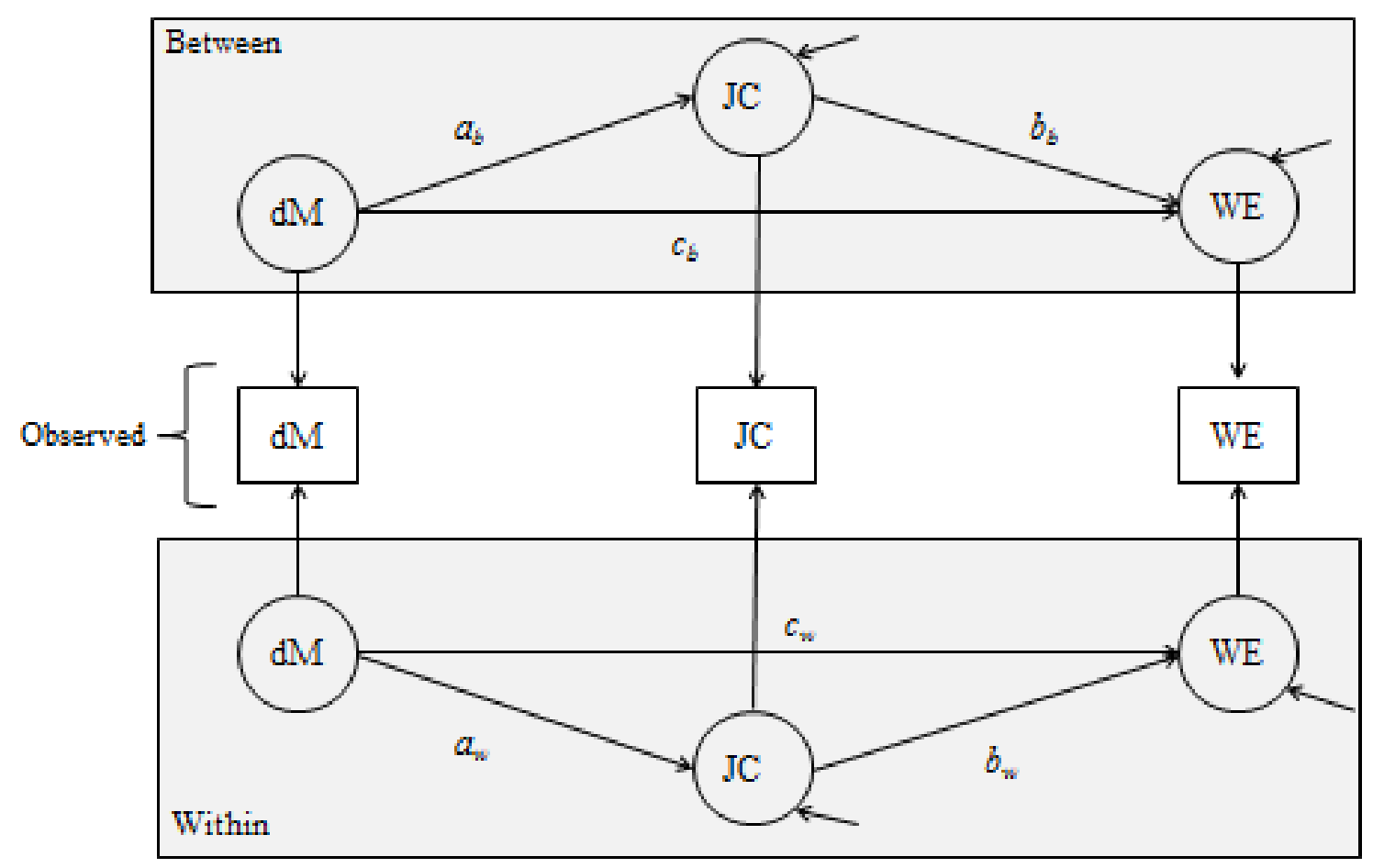

Note. $\mathrm{dM}=$ day-level nonwork mastery experiences; JC=job crafting (i.e., Seeking Resources or Seeking Challenges); WE=work engagement.

Figure is based on Preacher et al. (2011). 


\section{References}

Amabile, T. M., Barsade, S. G., Mueller, J. S., \& Staw, B. M. (2005). Affect and creativity at work. Administrative Science Quarterly, 50(3), 367-403.

Ashford, S. J., \& Black, J. S. (1996). Proactivity during organizational entry: The role of desire for control. Journal of Applied Psychology, 81, 199-214.

Ashford, S. J., Blatt, R., \& VandeWalle, D. (2003). Reflections on the looking glass: A review of research on feedback-seeking behavior in organization. Journal of Management, 29, 773-799.

Bakker, A. B., Albrecht, S. L., \& Leiter, M. P. (2011). Key questions regarding work engagement. European Journal of Work \& Organizational Psychology, 20, 4-28.

Bakker, A. B., \& Bal, P. M. (2010). Weekly work engagement and performance: A study among starting teachers. Journal of Occupational and Organizational Psychology, 83, 189-206.

Bakker, A. B., \& Demerouti, E. (2007). The job demands-resources model: State of the art. Journal of Managerial Psychology, 22, 309-328.

Bakker, A. B., Demerouti, E., Oerlemans, W., \& Sonnentag, S. (2013). Workaholism and daily recovery: A day reconstruction study of leisure activities. Journal of Organizational Behavior, 34, 87-107.

Bakker, A. B., Demerouti, E., \& Sanz-Vergel, A. I. (2014). Burnout and work engagement: The JD-R approach. Annual Review of Organizational Behavior, 1, 389411.

Bakker, A. B., Tims, M., \& Derks, D. (2012). Proactive personality and job performance: The role of job crafting and work engagement. Human Relations, 65, 1359-1378. 
Bakker, A. B., \& Xanthopoulou, D. (2009). The crossover of daily work engagement: Test of an actor-partner interdependence model. Journal of Applied Psychlogy, 94, 1562-1571.

Baron, R. M., \& Kenny, D. A. (1986). The moderator-mediator variable distinction in social psychological research: Conceptual, strategic, and statistical considerations. Journal of Personality \& Social Psychology, 51, 1173-1182.

Bauer, D. J., Preacher, K. J., \& Gil, K. M. (2006). Conceptualizing and testing random indirect effects and moderated mediation in multilevel models: New procedures and recommendations. Psychological Methods, 11, 142-163.

Berg, J. M., Dutton, J. E., \& Wrzesnieski, A. (2013). Job crafting and meaningful work. In B. J. Dik, Z. S. Byrne, \& M. F. Steger (Eds.), Purpose and meaning in the workplace (pp. 81-104). Washington, D. C.: American Psychological Association.

Berg, J. M., Wrzesniewski, A., \& Dutton, J. E. (2010). Perceiving and responding to challenges in job crafting at different ranks: When proactivity requires adaptivity. Journal of Organizational Behavior, 31, 158-186.

Biggs, A., Brough, P., \& Barbour, J. P. (2013). Strategic alignment with organizational priorities and work engagement: A multi-wave analysis. Journal of Organizational Behavior, 35, 301-317.

Bindl, U. K., \& Parker, S. K. (2011). Proactive work behavior: Forward-thinking and change-oriented action in organizations. In S. Zedeck (Ed.), APA handbook of industrial and organizational psychology, (Vol. 2) (pp.567-598). Washington, D. C.: American Psychological Association. 
Bindl, U. K., Parker, S.K., Totterdell, P., \& Hagger-Johnson, G. (2012). Fuel of the selfstarter: How mood relates to proactive goal regulation. Journal of Applied Psychology, 97, 134-150.

Binnewies, C., Sonnentag, S., \& Mojza, E. J. (2009). Daily performance at work: Feeling recovered in the morning as a predictor of day-level job performance. Journal of Organizational Behavior, 30, 67-93.

Binnewies, C., Sonnentag, S., \& Mojza, E. (2010). Recovery during the weekend and fluctuations in weekly job performance: A week-level study examining intraindividual relationships. Journal of Occupational and Organizaitonal Psychology, 83, 419-441.

Bledow, R., Schmitt, J., Frese, M., \& Kuhnel, J. (2011). The Affective Shift Model of work engagement. Journal of Applied Psychology, 96, 1246-1257.

Bliese, P. D. (2013). Multilevel: Multilevel functions. R Package Version 2.5. URL http://CRAN.R-project.org/package=multilevel.

Bliese, P. D., \& Ployhart, R. E. (2002). Growth modeling using random coefficient models: Model building, testing, and illustrations. Organizational Research Methods, $5,362-387$.

Breevart, K., Bakker, A. B., \& Demerouti, E. (2014). Daily self-management and employee work engagement. Journal of Vocational Behavior, 84, 31-38.

Breevart, K., Bakker, A., B., Demerouti, E., \& Hetland, J. (2012). The measurement of state work engagement: A multilevel factor analytic study. European Journal of Psychological Assessment, 28, 305-312. 
Browne, W. J., \& Draper, D. (2000). Implementation and performance issues in the Bayesian and likelihood fitting of multilevel models. Computational Statistics, 15, $391-420$.

Cavanaugh, M. A., Boswell, W. R., Roehling, M. V., \& Boudreau, J. W. (2000). An empirical examination of self-reported work stress among US managers. Journal of Applied Psychology, 85, 65-74.

Christian, M. S., Garza, A. S., \& Slaughter, J. E. (2011). Work engagement: A quantitive review and test of its relations with task and contextual performance. Personnel Psychology, 64, 89-136.

Clegg, C., \& Spencer, C. (2007). A circular and dynamic model of the process of job design. Journal of Occupational and Organizational Psychology, 80, 321-339.

Cohen, J. (1988). Statistical power anlaysis for the behavioral sciences $\left(2^{\text {nd }}\right.$ ed.). Mahwah, NJ: Lawrence Erlbaum Associates, Inc.

Cohen, J. (1992). A power primer. Psychological Bulletin, 112, 155-159.

Cole, M. S., Walter, F., Bedeian, A. G., \& O’Boyle, E. H. (2012). Job burnout and employee engagement: A meta-analytic examination of construct proliferation. Journal of Management, 38, 1550-1581.

Crant, J. M. (2000). Proactive behavior in organizations. Journal of Management, 26, 435-462.

Culbertson, S. S., Mills, M. J., \& Fullagar, C. J. (2012). Work engagement and workfamily facilitation: Making homes happier through positive affective spillover. Human Relations, 65, 1155-1177. 
de Bloom, J., Kompier, M., Geurts, S., de Weerth, C., Taris, T., \& Sonnentag, S. (2009).

Do we recover from vacation? Meta-analysis of vacation effects on health and wellbeing. Journal of Occupational Health, 51, 13-25.

Deci, E. L., \& Ryan, R. M. (1985). Intrinsic motivation and self-determination in human behavior. New York, NY: Plenum Press.

Demerouti, E., \& Bakker, A. B. (2014). Job crafting. In M. C. W. Peeters, J. de Jong, \& T. W. Taris (Eds.). An introduction to contemporary work psychology (pp. 414-433). Chichester, UK: Wiley-Blackwell.

Demerouti, E., Bakker, A. B., Geurts, S. A. E., \& Taris, T. W. (2009). Daily recovery from work-related effort during non-work time. Research in Occupational Stress and Well Being, 7, 85-123.

Demerouti E., Bakker, A. B., Nachreiner, F., \& Schaufel, W. B. (2001). The job demands-resources model of burnout. Journal of Applied Psychology, 86, 499-512.

Edwards, J. R., \& Rothbard, N. P. (2000). Mechanisms linking work and family: Clarifying the relationship between work and family constructs. Academy of Management Review, 25, 178-199.

Ellis, A. M., Bauer, T. N., Mansfield, L. R., Erdogan, B., Truxillo, D. M., \& Simon, L. S. (2015). Navigating uncharted waters: Newcomer socialization through the lens of stress theory. Journal of Management, 41, 203-235.

Enders, C. K., \& Tofighi, D. (2007). Centering predictor variables in cross-sectional multilevel models: A new look at an old issue. Psychological Methods, 12, 121-138. 
Eschelman, K. J., Madsen, J., Alarcon, G., \& Barelka, A. (2014). Benefiting from creative activity: The positive relationship between creative activity, recovery experiences, and performance-related outcomes. Journal of Occupational and Organizational Psychology, 87, 579-598.

Fay, D., \& Frese, M. (2001). The concept of personal initiative: An overview of validity studies. Human Performance, 14, 97-124.

Feurhahn, N., Sonnentag, S., \& Woll, A. (2014). Exercise after work, psychological mediators, and affect: A day-level study. European Journal of Work and Organizational Psychology, 23, 62-79.

Fredrickson, B. L., \& Joiner, T. (2002). Positive emotions trigger upward spirals toward emotional well-being. Psychological Science, 13, 172-177.

Frone, M. R. (2003). Work-family balance. In J. C. Quick \& L. E. Tetrick (Eds.), Handbook of occupational health psychology (pp. 143-162). Washington DC: American Psychological Association.

Fritz, C., Ellis, A. M., Demsky, C. A., Lin, B. C., \& Guros, F. (2013). Embracing work breaks: Recovering from work stress. Organizational Dynamics, 42, 274-280.

Fritz, M. S., \& MacKinnon, D. P. (2007). Required sample size to detect the mediated effect. Psychological Science, 18, 223-239.

Fritz, C., \& Sonnentag, S. (2005). Recovery, health, and job performance: Effects of weekend experiences. Journal of Occupational Health Psychology, 10, 187-199. 
Fritz, C., \& Sonnentag, S. (2006). Recovery, well-being, and performance-related outcomes: The role of work load and vacation experiences. Journal of Applied Psychology, 91, 936-945.

Fritz, C., \& Sonnentag, S. (2009). Antecedents of day-level proactive behavior: A look at job stressors and positive affect during the workday. Journal of Management, 35, 94111.

Fritz, C., Sonnentag, S., Spector, P. E., \& McInroe, J. A. (2010). The weekend matters: Relationships between stress recovery and affective experiences. Journal of Organizational Behavior, 31, 1137-1162.

Ganster, D. C., \& Rosen, C. C. (2013). Work stress and employee health: A multidisciplinary review. Journal of Management, 39, 1085-1122.

Gelfand, M. J., Erez, M., \& Aycan, Z. (2007). Cross-cultural organizational behavior. Annual Review of Psychology, 58, 479-514.

Green, A. S., Rafaeli, E., Bolger, N., Shrout, P. E., \& Reis, H. T. (2006). Paper or plastic? Data equivalence in paper and electronic diaries. Psychological Methods, 11, 87-105.

Greenhaus, J. H., \& Powell, G. N. (2006). When work and family are allies: A theory of work-family enrichment. Academy of Management Review, 31, 72-92.

Griffin, M. A., Neal, A., \& Parker, S. K. (2007). A new model of work role performance: Positive behavior in uncertain and interdependent contexts. Academy of Management Journal, 50, 327-347.

Hackman, J. R., \& Oldham, G. R. (1976). Motivation through the design of work: Test of a theory. Organizational Behavior \& Human Performance, 16, 250-279. 
Halbesleben, J.R. (2010). A meta-analysis of work engagement: Relationships with burnout, demands, resources, and consequences. In A.B. Bakker, \& M.P. Leiter (Eds.). Work engagement: A handbook of essential theory and research. East Sussex: Psychology Press.

Halbesleben, J. R. B., Neveu, J., Paustian-Underdahl, S. C., \& Westman, M. (2014). Getting to the "COR": Understanding the role of resources in Conservation of Resources theory. Journal of Management, 40, 1334-1364.

Hallberg, U. E., \& Schaufeli, W. B. (2006). "Same same” but different? Can work engagement be discriminated from job involvement and organizational commitment? European Psychologist, 11, 119-127.

Hamaker, E. (2012). Why researchers should think "within-person": A paradigmatic rationale. In M.R. Mehl \& T.S. Conner (Eds.). Handbook of research methods for studying daily life. New York, NY: Guilford.

Hanson, G. C., Hammer, L. B., \& Colton, C. L. (2006). Development and validation of a multidimensional scale of perceived work-family positive spillover. Journal of Occupational Health Psychology, 249-265.

Hayes, A. F. (2009). Beyond Baron and Kenny: Statistical mediation analysis in the new millennium. Communication Monographs, 76(4), 408-420.

Hobfoll, S. E. (1989). Conservation of resources: A new attempt at conceptualizing stress. American Psychologist, 44, 513-524. 
Hobfoll, S. E. (2001). The influence of culture, community, and the nested-self in the stress process: Advancing conservation of resources theory. Applied Psychology, 50, 337-421.

Hobfoll, S. E. (2011). Conservation of resources caravans in engaged settings. Journal of Occupational and Organizational Psychology, 84, 116-122.

Hornung, S., Rousseau, D. M., Glaser, J., Angerer, P., \& Weigl, M. (2010). Beyond topdown and bottom-up work redesign: Customizing job content through idiosyncratic deals. Journal of Organziational Behavior, 31, 187-215.

Hox, J. J. (2002). Multilevel analysis: Techniques and applications, $2^{\text {nd }}$ edition. New York, NY: Routledge.

Iida, M. Shrout, P. E., Laurenceau, J.-P. \& Bolger, N. (2012). Using diary methods in psychological research. In. H. Cooper (Ed.). APA handbook of research methods in psychology, Vol. 1, Foundations, planning, measures, and psychometrics. (pp. 277305). Washington, D. C.: American Psychological Association.

Kahn, W. A. (1990). Psychological conditions of personal engagement and disengagement at work. Academy of Management Journal, 33, 692-724.

Kenny, D. A., Korchmaros, J. D., \& Bolger, N. (2003). Lower level mediation in multilevel models. Psychological Methods, 8, 115-128.

Kinnunen, U., \& Feldt, T. (2013). Job characteristics, recovery experiences, and occupational well-being: Testing cross-lagged relationships across 1 year. Stress \& Health, 29, 369-382. 
Kinnunen, U., Feldt, T., Siltaloppi, M., \& Sonnentag, S. (2011). Job demands-resources model in the context of recovery: Testing recovery experiences as a mediators. European Journal of Work and Organizational Psychology, 20, 805-832.

Kira, M., van Eijnatten, F. M., \& Balkin, D. B. (2010). Crafting sustainable work: Development of personal resources. Journal of Organizational Change Management, 23, 616-632.

Koopman, J., Howe, H., Hollenbeck, J. R., \& Sin, H. (2015). Small sample mediation testing: Misplaced confidence in bootstrapped confidence intervals. Journal of Applied Psychology, 100, 194-202.

Kossek, E. E., Ruderman, M. N., Braddy, P. W., \& Hannum, K. M. (2012). Worknonwork boundary management profiles: A person-centered approach. Journal of Vocational Behavior, 81, 112-128.

Krajewski, J., Wieland, R., \& Sauerland, M. (2010). Regulating strain states by using recovery potential of lunch breaks. Journal of Occupational Health Psychology, 15, 131-139.

Krull, J. L., \& MacKinnon, D. P. (2001). Multilevel modeling of individual and group level mediated effects. Multivariate Behavioral Research, 36, 249-277.

Kuhnel, J., Sonnentag, S., \& Bledow, R. (2012). Resources and time pressure as daylevel antecedents of work engagement. Journal of Occupational and Organizational Psychology, 85, 181-198.

Kulik, C. T., Oldham, G. R., \& Hackman, J. R. (1987). Work design as an approach to person-environment fit. Journal of Vocational Behavior, 31, 278-296. 
Lazarus, R. S., \& Folkman, S. (1984). Stress, appraisal, and coping. NY: Springer.

Leana, C., Appelbaum, E., \& Shevchuk, I. (2009). Work process and quality of care in early childhood education: The role of job crafting. Academy of Management Journal, 52, 1169-1192.

Leiter, M. P., \& Maslach, C. (2006). Burnout. In H. Friedman (Ed.). Encyclopedia of Mental Health, (Vol. 1) (pp. 358-362). Toronto: Academic.

LePine, J. A., Podsakoff, N. P., \& LePine, M. A. (2005). A meta-analytic test of the challenge stressor-hindrance stressor framework: An explanation for inconsistent relationships among stressors and performance. Academy of Management Journal, 48, 764-775.

Luthans, F. (2002). Positive organizational behavior: Developing and managing psychological strengths. Academy of Management Executive, 16, 57-72.

Lyons, P. (2008). The crafting of jobs and individual differences. Journal of Business Psychology, 23, 25-36.

Maas, C. J. M., \& Hox, J. J. (2004). Robustness issues in multilevel regression analysis. Statistica Neerlandica, 58, 127-137.

Macey, W. H., \& Schneider, B. (2008). The meaning of employee engagement. Industrial \& Organizational Psychology, 1, 3-30.

MacKinnon, D.P. (2008). Introduction to statistical analyses. NY: Taylor \& Francis.

Meijman, T. F., \& Mulder, G. (1998). Psychological aspects of workload. In P. J. D. Drenth \& H. Thierry (Eds.), Handbook of work and organizational psychology, (Vol. 2) (pp. 5-33). Hove, England: Psychology Press. 
Mojza, E. J., Sonnentag, S., \& Bornemann, C. (2011). Volunteer work as a valuable leisure-tie activity: A day-level study on volunteer work, non-work experiences, and well-being at work. Journal of Occupational and Organizational Psychology, 84, 123-152.

Muthen, L. K., \& Muthen, B. O. (1998). Mplus user's guide: Statistical analysis with latent variables $\left(5^{\text {th }}\right.$ ed.). Los Angeles, CA: Muthen $\&$ Muthen.

Oerlemans, W. G. M., \& Bakker, A. B. (2014). Burnout and daily recovery: A day reconstruction study. Journal of Occupational Health Psychology. Advance online publication. http://dx.doi.org/10.1037/a0036904.

Ohly, S., Sonnentag, S., Niessen, C., \& Zapf, D. (2010). Diary studies in organizational research: An introduction and some practical recommendations. Journal of Personnel Psychology, 9, 79-93.

Ouwene, E., Le Blanc, P. M., Schaufeli, W. B., \& van Wijhe, C. I. (2012). Good morning, good day: A diary study on positive emotions, hope and work engagement. Human Relations, 65, 1129-1154.

Parker, S. K., Bindl, U., \& Strauss, K. (2010). Making things happen: A model of proactive motivation. Journal of Management, 36, 827-856.

Parker, S. K., \& Collins, C. G. (2010). Taking stock: Integrating and differentiating multiple proactive behaviors. Journal of Management, 36, 633-662.

Parker, S. K., Williams, H. J., \& Turner, N. (2006). Modeling the antecedents of proactive behavior at work. Journal of Applied Psychology, 91, 636-652. 
Petrou, P., Demerouti, E., Peeters, M. C. W., Schaufeli, W. B., \& Hetland, J. (2012). Crafting a job on a daily basis: Contextual correlates and the link to work engagement. Journal of Organizational Behavior, 33, 1120-1141.

Podsakoff, P. M., MacKenzie, S. B., Lee, J.-Y., \& Podsakoff, N. P. (2003). Common method biases in behavioral research: A critical review of the literature and recommended remedies. Journal of Applied Psychology, 88, 879-903.

Preacher, K. J. (in press). Advances in mediation analysis: A survey and synthesis of new developments. Annual Review of Psychology, 66, 4.1-4.28.

Preacher, K. J., Zhang, Z., \& Zyphur, J. J. (2011). Alternative methods for assessing mediation in multilevel data: The advantages of multilevel SEM. Structural Equation Modeling, 18, 161-182.

Preacher, K. J., Zyphur, M. J., \& Zhang, Z. (2010). A general multilevel SEM framework for assessing multilevel mediation. Psychological Methods, 15, 209-233.

Price, R. H., Choi, J. N., \& Vinokur, A. D. (2002). Links in the chain of adversity following job loss: How financial strain and loss of personal control lead to depression, impaired functioning, and poor health. Journal of Occupational Health Psychology, 7, 302-312.

R Core Team (2014). R: A language and environment for statistical computing. $R$ Foundation for Statistical Computing. Vienna, Austria. URL: http://www.Rproject.org.

Raudenbush, S. W., \& Bryk, A. S. (2002). Hierarchical linear models (2 $2^{\text {nd }}$ ed.). Newbury Park, CA: Sage. 
Raudenbush, S. W., \& Sampson, R. (1999). Assessing direct and indirect effects in multilevel designs with latent variables. Sociological Methods \& Research, 28, $123-$ 53.

Raudenbush, S. W., Spybrook, J., Congdon, R., Liu, X. F., Martinez, A., \& Bloom, H. (2011). Optimal design software for multi-level and longitudinal research (Version 3.01) [Software]. Available from www.wtgrantfoundation.org.

Reis, H. T., \& Gable, S. L. (2000). Event-sampling and other methods for studying everyday experience. In H. T. Reis \& C. M. Judd (Eds.), Handbook of research methods in social and personality psychology. (pp. 190-222). New York, N. Y.: Cambridge University Press.

Reis, D., Hoppe, A., \& Schroder, A. (2013). Reciprocal relationships between resources, work and study engagement and mental health: Evidence for gain cycles. European Journal of Work and Organizational Psychology. Advance online publication. doi: $10.1080 / 1359432 X .2013 .834891$

Rich, B. L., LePine, J. A., \& Crawford, E. R. (2010). Job engagement: Antecedents and effects on job performance. Academy of Management Journal, 53, 617-635.

Rieger, D., Reinecke, L., Frischlich, L., \& Bente, G. (2014). Media entertainment and well-being: Linking hedonic and eudaimonic entertainment experience to mediainduced recovery and vitality. Journal of Communication, 64, 456-478.

Rodriguez-Munoz, A., Sanz-Vergel, A. I., Demerouti, E., \& Bakker, A. B. (2012). Reciprocal relationships between job demands, job resources, and recovery opportunities. Journal of Personnel Psychology, 11, 86-94. 
Rook, J. W., \& Zijlstra, F. R. H. (2006). The contribution of various types of activities to recovery. European Journal of Work and Organizational Psychology, 15, 218-240.

Rothbard, N. P. (2001). Enriching or depleting? The dynamics of engagement in work and family roles. Administrative Science Quarterly, 46, 655-684.

Ruderman, M. N., Ohlott, P. J., Panzer, K., \& King, S N. (2002). Benefits of multiple roles for managerial women. Academy of Management Journal, 45, 369-386.

Salanova, M., Llorens, S., \& Schaufeli, W. B. (2011). "Yes I can, I feel good, and I just do it!" On gain cycles and spirals of efficacy beliefs, affect, and engagement. Applied Psychology: An International Review, 60, 255-285.

Salanova, M., \& Schaufeli, W. B. (2008). A cross-national study of work engagement as a mediator between job resources and proactive behavior. International Journal of Human Resources Management, 19, 116-131.

Schaufeli, W. B., \& Bakker, A. B. (2003). UWES: Utrecht Work Engagement scale. Preliminary manual. Utrecht: Netherlands. Occupational Health Psychology Unit, University of Utrecht.

Schaufeli, W. B., Salanova, M., Gonzalez-Roma, V., \& Bakker, A. B. (2002). The measurement of burnout and engagement: A confirmatory factor analytic approach. Journal of Happiness Studies, 3, 71-92.

Siltaloppi, M., Kinnunen, U., \& Feldt, T. (2009). Recovery experiences as moderators between psychological work characteristics and occupational well-being. Work \& Stress, 23, 330-348. 
Simbula, S., Guglielmi, D., \& Schaufeli, W. B. (2011). A three-wave study of job resources, self-efficacy, and work engagement among Italian schoolteachers. European Journal of Work and Organizational Psychology, 20, 285-304.

Sobel, M. E. (1982). Asymptotic confidence intervals for indirect effects in structural equation models. In S. Leinhardt (Ed.), Sociological methodology 1982 (pp. 290312). Washington, DC: American Sociological Association.

Sonnentag, S. (2001). Work, recovery activities, and individual well-being: A diary study. Journal of Occupational Health Psychology, 6, 196-210.

Sonnentag, S. (2003). Recovery, work engagement, and proactive behavior: A new look at the interface between nonwork and work. Journal of Applied Psychology, 88, 518528.

Sonnentag, S., \& Bayer, U. V. (2005). Switching off mentally: Predictors and consequences of psychological detachment from work during off-job time. Journal of Occupational Health Psychology, 10, 393-414.

Sonnentag, S., Binnewies, C., \& Mojza, J. (2008). “Did you have a nice evening?” A day-level study on recovery experiences, sleep, and affect. Journal of Applied Psychology, 93, 674-684.

Sonnentag, S., Dormann, C., \& Demerouti, E. (2010). Not all days are created equal: The concept of state work engagement. In A.B. Bakker, \& M.P. Leiter (Eds.). Work engagement: A handbook of essential theory and research. East Sussex: Psychology Press. 
Sonnentag, S., \& Fritz, C. (2007). The Recovery Experience Questionnaire: Development and validation of a measure assessing recuperation and unwinding from work. Journal of Occupational Health Psychology, 12, 204-221.

Sonnentag, S., \& Fritz, C. (in press). Recovery from work. In N. Anderson, D. S. Ones, H. N. Sinangil, \& V. Chockalingham (Eds.). Handbook of industrial, work, and organizational psychology. London: Sage.

Sonnentag, S., \& Jelden, S. (2009). Job stressors and the pursuit of sport activities: A day-level perspective. Journal of Occupational Health Psychology, 14, 165-181.

Sonnetag, S., \& Kruel, U. (2006). Psychological detachment from work during off-job time: The role of job stressors, job involvement, and recovery-related self-efficacy. European Journal of Work and Organizational Psychology, 15, 197-217.

Sonnentag, S., Mojza, E. J., Demerouti, E., \& Bakker, A. B. (2012). Reciprocal relations between recovery and work engagement: The moderating role of job stressors. Journal of Applied Psychology, 97, 842-853.

Sonnentag, S., \& Natter, E. (2004). Flight attendants' daily recovery from work: Is there no place like home? International Journal of Stress Management, 11, 366-391.

Sonnentag, S., \& Zijlstra, F. R. H. (2006). Job characteristics and off-job activities as predictors of need for recovery, well-being, and fatigue. Journal of Applied Psychology, 91, 330-350.

Staw, B. M., \& Boettger, R. D. (1990). Task revision: A neglected form of work performance. Academy of Management Journal, 33, 534-559. 
Stone, A. A., Shiffman, S., Schwartz, J. E., Broderick, J. E., \& Hufford, M. R. (2002). Patient non-compliance with paper diaries. British Medical Journal, 324, 1193-1194.

Tabachnick, B.C., \& Fidell, L.S. (2007). Using multivariate statistics, $5^{\text {th }}$ edition. Boston, MA: Pearson

ten Brummelhuis, L. L., \& Bakker, A. B. (2012). Staying engaged during the week: The effect of off-job activities on next day work engagement. Journal of Occupational Health Psychology, 17, 445-455.

ten Brummelhuis, L. L., Bakker, A. B., Hetland, J., \& Keulemans, L. (2012). Do new ways of working foster work engagement? Psicothema, 24, 113-120.

Tims, M., \& Bakker, A. B. (2010). Job crafting: Towards a new model of individual job redesign. SA Journal of Industrial Psychology, 36, 1-9.

Tims, M., Bakker, A.B., \& Derks, D. (2012). The development and validation of the job crafting scale. Journal of Vocational Behavior, 80, 173-186.

Tims, M., Bakker, A., \& Derks, D. (2014). Daily job crafting and the self-efficacyperformance relationship. Journal of Managerial Psychology, 29, 490-507.

Tims, M., Bakker, A. B., Derks, D., \& van Rhenen, W. (2013). Job crafting at the team and individual level: Implications for work engagement and performance. Group \& Organization Management, 38, 427-454.

Tims, M., Bakker, A. B., \& Xanthopoulou, D. (2011). Do transformational leaders enhance their followers' daily work engagement? Leadership Quarterly, 22, 121-131.

Van den Broeck, A., Vansteenkiste, M., De Witte, H., Soenens, B., \& Lens, W. (2010). Capturing autonomy, competence, and relatedness at work: Construction and initial 
validation of the Work-related Basic Need Satisfaction scale. Journal of Occupational \& Organizational Psychology, 83, 981-1002.

van der Leeden, R., \& Busing, F. (1994). First iteration versus IGLS/RIGLS estimates in two-level models: A Monte Carlo study with ML3, Unpublished manuscript, Department of Psychometrics and Research Methodology, Leiden University.

Van Hoof, M. L. M., Geurts, S. A. E., Beckers, D. G. J., \& Kompier, M. A. J. (2011). Daily recovery from work: The role of activities, effort, and pleasure. Work \& Stress, $25,55-74$.

Van Hoof, M. L. M., \& van Hooft, E. A. J. (2014). Boredom at work: Proximal and distal consequences of affective work-related boredom. Journal of Occupational Health Psychology. Advance online publication. http://dx.doi.org/10.1037/a0036821.

Van Maanen, J., \& Schein, E. H. (1979). Toward a theory of organizational socialization. In B. M. Staw (Ed.), Research in organizational behavior (pp. 209-264). Greenwich, CT: JAI.

Watson, D., Clark, L. A., \& Tellegen, A. (1988). Development and validation of brief measures of positive and negative affect: The PANAS scales. Journal of Personality \& Social Psychology, 54, 1063-1070.

Wayne, J. H., Musisca, N., \& Fleeson, W. (2004). Considering the role of personality in the work-family experience: Relationships of the big five to work-family conflict and facilitation. Journal of Vocational Behavior, 64, 108-130. 
Weigl, M., Hornung, S., Parker, S. K., Petru, R., Glaser, J., \& Angerer, P. (2010). Work engagement accumulation of task, social, personal resources: A three-wave structural equation model. Journal of Vocational Behavior, 77, 140-153.

Weiss, H. M., \& Rupp, D. E. (2011). Experiencing work: An essay on person-centric work psychology. Industrial and Organizational Psychology, 4, 83-97.

Westman, M., \& Eden, D. (1997). Effects of vacation on job stress and burnout: Relief and fade-out. Journal of Applied Psychology, 82, 516-527.

Wrzesnieski, A., \& Dutton, J. E. (2001). Crafting a job: Revisioning employees as active crafters of their work. Academy of Management Review, 26, 179-201.

Wrzesnieski, A., LoBuglio, N., Dutton, J. E., \& Berg, J. M. (2013). Job crafting and cultivating positive meaning and identity in work. Advances in Positive Organizational Psychology, 1, 281-302.

Xanthopoulou, D., Bakker, A. B., Demerouti, E., \& Schaufeli, W. B. (2009). Work engagement and financial returns: A diary study on the role of job and personal resources. Journal of Occupational and Organizational Psychology, 82, 183-200.

Xanthopoulou, D., Bakker, A. B., Heuven, E., Demerouti, E., \& Schaufeli, W. B. (2008). Working in the sky: A diary study on work engagement among flight attendants. Journal of Occupational Health Psychology, 13, 345-356.

Zacher, H., Brailsford, H. A., \& Parker, S. L. (2014). Micro-breaks matter: A diary study on the effects of energy management strategies on occupational well-being. Journal of Vocational Behavior, 85, 287-297. 
Appendix A

Standardized Announcement Email

\section{Subject: Participation is strongly encouraged! PSU and [name of organization] teaming up}

Good [morning] team,

I am excited to inform you that researchers specializing in Industrial/Organizational

Psychology, at Portland State University (PSU), have asked [name of organization], and particularly our group, to join forces with them to help conduct an exciting research project aimed at understanding issues related to employee well-being and engagement. We are thrilled that they have selected our group to participate in this research because they understand our commitment to excellence to achievement!

They are looking for as many people to participate as possible in order to garner a more representative and holistic picture of what it means to be an [department name] employee at [name of organization]. Participation in the study will require you to provide information about yourself and your work over a short period of time which you can do during work hours. I strongly encourage everyone to consider participating in their study.

The study kicks off in [insert date]. Keep an eye out for an email from Allison Ellis, a member of the research team, which will be sent out in the next several days. This email will provide more information and details on how to get started.

Thank you,

[Insert Signature] 
Appendix B

Invitation Email Template

Subject: PSU and [name of organization] teaming up - Please participate in a study by PSU!

Hi there! You are invited to participate in a research study that is being conducted by my research team and I at Portland State University (PSU). This study is aimed at understanding issues related to work-life balance and engagement and we want to hear from you!

\title{
What's involved?
}

This is a two-part study. If you sign up to participate we'll be asking you to:

1) Complete 1 baseline survey by [insert date].

2) Beginning the week of [insert date], we'll send you very short (about 5-10 minute) surveys throughout each day (M-F) that will ask you about yourself and your work.

\section{What's in it for you?}

For participating in our study we will be providing gift cards to Amazon.com! Plus, you'll be contributing to an interesting and exciting project that will inform our understanding of work life.

\section{What do you need to do to get started?}

It's important to note that your participation is entirely voluntary and any information you provide will be kept totally confidential. Want more details? Interested in participating? Please send me an email ASAP at ame2@pdx.edu and I'll reply with all the necessary information.

Thank you!

\author{
Allison Ellis, MS \\ By email: (ame2@pdx.edu)
}

By phone: (805) 610-0687 
Appendix C

Additional Information Page

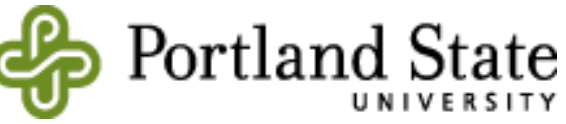

Thank you for your interest in participating in our study! Below are the details regarding the study and contact information should you have any questions. Based on your initial interest you will be sent the baseline survey in the next couple days at which point you can get started right away!

You are invited to participate in a research study conducted by Allison Ellis, Charlotte Fritz, and Caitlin Demsky from Portland State University. The researchers hope to learn more about work-life balance, engagement, and factors that impact behavior on the job. You were selected as a possible participant in this study because of your experiences as a full-time employee in the technology industry.

\section{What will you do?}

If you decide to participate, you will now be asked to complete a survey that will take approximately 20 minutes to complete. This is the longest survey you'll be asked to take. Because the current research is interested in changes throughout your workday, there will be three very short surveys sent to you each day for one week (one in the morning, afternoon, and at the end of your workday) - they will only take about 5-10 minutes.

\section{What can you expect?}

While participating in this study, it is possible that you may have thoughts or emotions that arise that are associated with your experience of work, it is also possible that you may experience a certain level of inconvenience associated with taking the time to complete the surveys. We have attempted to safeguard against this by keeping surveys very short and administering them at times that are most likely to be more convenient for most people. For your participation in this study you will have the option to receive a gift card to Amazon.com (amounts will vary based on participation) and may be entered into a drawing for additional prizes. In addition, taking part in this study may help to increase knowledge about work which may help others in the future.

\section{How do we make sure you're information stays confidential?}

Any information that is obtained in connection with this study and that can be linked to you or identify you will be kept confidential. This information will be kept confidential by asking you to create a participant code that only you know. This code will enable our researchers to link each of your surveys together for the purpose of examining change over the course of the week, but it will not be linked to your name. Please note any and all information gathered from the study will be provided back to [name of organization] 
management in aggregate form only, which means your individual responses will not be reported, only a summary of responses across all participating individuals.

\section{Is my participation voluntary?}

Your participation is voluntary. If you choose not to participate in the study it will not affect your employment in any way. You may also withdraw from this study at any time without affecting your employment.

\section{More questions?}

If you have questions or concerns about your participation in this study, please contact Allison Ellis at Psychology Department, Portland State University, 1721 SW Broadway, Portland, Oregon, 97207.

\section{Researcher Bios}

Allison M. Ellis is a graduate research assistant at Portland State University. Her research focuses on employee health and well-being, especially as it relates to employee engagement and positive performance-related behaviors including proactivity and creativity. She received her M.S. in Industrial/Organizational Psychology from Portland State University, and is currently pursuing her Ph.D. with focus in Occupational Health Psychology. (Portland State University, Psychology Department, P.O. Box 751, Portland, OR 97207-0751, USA. Tel.: +1 805610 0687, Fax: +1 (503) 725 3904, e-mail: ame2@pdx.edu).

Charlotte Fritz is anAssistant Professor in Industrial/Organizational Psychology at Portland State University. She graduated with her Ph.D. in Industrial/Organizational Psychology from the University of Braunschweig, Germany, in 2005. She then held a position as Assistant Professor in Industrial/Organizational Psychology at Bowling Green State University from 2005 to 2009. In her research she has examined relationships between job stress and unwinding from work on one hand and employee well-being and performance on the other hand. In addition, she has conducted research predictors and outcomes of proactive work behaviors. She is further interested in topics related to occupational health such as interruptions at work, physical indicators of job strain, and work-family conflict.

Caitlin A. Demsky is a graduate research assistant at Portland State University. Her research focuses on employee health and well-being, particularly as it relates to the intersection of the work-family interface and recovery from work. She received her M.S. in Industrial/Organizational Psychology from Portland State University, and is currently pursuing her Ph.D. with a focus in Occupational Health Psychology. (Portland State University, Psychology Department, P.O. Box 751, Portland, OR 97207-0751, USA. Tel.: +13137173022 , Fax: +1 (503) 725 3904, e-mail: cademsky@ @dx.edu). 
BUILDING RESOURCES

Appendix D

Trait-level Variables Assessed with Baseline Survey

\begin{tabular}{|c|c|c|c|c|}
\hline Construct & Sub-constructs & Source & $\begin{array}{l}\text { Number of } \\
\text { Items }\end{array}$ & $\begin{array}{l}\text { Response } \\
\text { Scale }\end{array}$ \\
\hline $\begin{array}{l}\text { Positive } \\
\text { Affectivity }\end{array}$ & & $\begin{array}{l}\text { Watson, Clark, } \\
\text { \& Tellegen } \\
(1988)\end{array}$ & 10 & $1-5$ \\
\hline $\begin{array}{l}\text { Proactive } \\
\text { Personality }\end{array}$ & & $\begin{array}{l}\text { Bateman \& } \\
\text { Crant (1993); } \\
\text { Siebert et al. } \\
\text { (1999) }\end{array}$ & 6 & $1-7$ \\
\hline $\begin{array}{l}\text { Promotion } \\
\text { Focus }\end{array}$ & & $\begin{array}{l}\text { Lockwood et al. } \\
\text { (2002); Bono et } \\
\text { al. (2013, } \\
\text { working paper) }\end{array}$ & 3 & $1-5$ \\
\hline \multirow[t]{3}{*}{$\begin{array}{l}\text { Need } \\
\text { Fulfillment }\end{array}$} & Competence & $\begin{array}{l}\text { Van den Broeck } \\
\text { et al. (2010) }\end{array}$ & 4 & $1-5$ \\
\hline & Relatedness & $\begin{array}{l}\text { Van den Broeck } \\
\text { et al. (2010) }\end{array}$ & 6 & $1-5$ \\
\hline & Autonomy & $\begin{array}{l}\text { Van den Broeck } \\
\text { et al. (2010) }\end{array}$ & 6 & $1-5$ \\
\hline \multirow[t]{4}{*}{ Job Crafting } & $\begin{array}{l}\text { Increasing } \\
\text { Structural } \\
\text { Resources } \\
\end{array}$ & $\begin{array}{l}\text { Tims et al. } \\
\text { (2012) }\end{array}$ & 21 & $1-5$ \\
\hline & $\begin{array}{l}\text { Decreasing } \\
\text { Hindering Job } \\
\text { Demands } \\
\end{array}$ & & & \\
\hline & $\begin{array}{l}\text { Increasing } \\
\text { Social Job } \\
\text { Resources }\end{array}$ & & & \\
\hline & $\begin{array}{l}\text { Increasing } \\
\text { Challenging Job } \\
\text { Demands }\end{array}$ & & & \\
\hline \multirow[t]{3}{*}{$\begin{array}{l}\text { Work } \\
\text { Engagement }\end{array}$} & Vigor & $\begin{array}{l}\text { Schaufeli \& } \\
\text { Bakker (2006) }\end{array}$ & 9 & $1-7$ \\
\hline & Dedication & & & \\
\hline & Absorption & & & \\
\hline Job Satisfaction & & $\begin{array}{l}\text { Judge \& Ilies } \\
\text { (2004), adapted } \\
\text { from Brayfield \& } \\
\text { Rothe (1951) }\end{array}$ & 5 & $1-5$ \\
\hline $\begin{array}{l}\text { Affective } \\
\text { Organizational }\end{array}$ & & $\begin{array}{l}\text { Meyer et al. } \\
\text { (1993), adapted } \\
\text { from Allen \& }\end{array}$ & 6 & $1-7$ \\
\hline
\end{tabular}


BUILDING RESOURCES

\begin{tabular}{|c|c|c|c|c|}
\hline Commitment & & Meyer (1990) & & \\
\hline $\begin{array}{l}\text { Task } \\
\text { Performance }\end{array}$ & & $\begin{array}{l}\text { Williams \& } \\
\text { Anderson } \\
\text { (1991), amended } \\
\text { by Lin } \\
\text { (unpublished } \\
\text { dissertation) }\end{array}$ & 6 & $1-7$ \\
\hline $\begin{array}{l}\text { Personal } \\
\text { Initiative }\end{array}$ & & $\begin{array}{l}\text { Frese \& Fay } \\
\text { (1997) }\end{array}$ & 7 & $1-7$ \\
\hline Creativity & & $\begin{array}{l}\text { Tierney et al. } \\
\text { (1999) }\end{array}$ & 8 & $1-7$ \\
\hline $\begin{array}{l}\text { Leader- } \\
\text { Member } \\
\text { Exchange }\end{array}$ & & $\begin{array}{l}\text { Liden \& Maslyn } \\
\text { (1998) }\end{array}$ & 11 & $1-7$ \\
\hline \multirow[t]{2}{*}{$\begin{array}{l}\text { Justice } \\
\text { Perceptions }\end{array}$} & $\begin{array}{l}\text { Individuals' } \\
\text { personal justice } \\
\text { experiences }\end{array}$ & $\begin{array}{l}\text { Ambrose \& } \\
\text { Schminke (2009) }\end{array}$ & 6 & $1-7$ \\
\hline & $\begin{array}{l}\text { Fairness of the } \\
\text { organization } \\
\text { generally }\end{array}$ & & & \\
\hline $\begin{array}{l}\text { Segmentation } \\
\text { Norms }\end{array}$ & & $\begin{array}{l}\text { Park et al. } \\
\text { (2011), adapted } \\
\text { from Kreiner et } \\
\text { al. (2006) }\end{array}$ & 4 & $1-7$ \\
\hline \multirow[t]{4}{*}{$\begin{array}{l}\text { Work } \\
\text { Characteristics }\end{array}$} & Task Variety & $\begin{array}{l}\text { Morgeson \& } \\
\text { Humphrey } \\
(2006)\end{array}$ & 4 & $1-5$ \\
\hline & $\begin{array}{l}\text { Task } \\
\text { Significance }\end{array}$ & & 4 & \\
\hline & Job Complexity & & 4 & \\
\hline & Interdependence & & 3 & \\
\hline
\end{tabular}


Appendix E

List of Items from Day-Level Measures

\section{Morning Survey}

\section{RECOVERY EXPERIENCES}

Recovery Experiences Questionnaire (Sonnentag \& Fritz, 2007)

Directions: Please respond to the following items with respect to how you spent your time yesterday after work.

Response Scale: $1=$ Strongly Disagree to 5=Strongly Agree

\section{Mastery}

1. I learned to do something new.

2. I sought out intellectual challenges.

3. I did things that challenged me.

4. I did something to broaden my horizons.

\section{POSITIVE AFFECT}

Positive Affect Negative Affect Scale (Watson, Clark, \& Tellegen, 1988)

Directions: Please indicate to what extent you feel this way as of this morning.

Response Scale: $1=$ Very slightly or not at all to 5=Extremely

1. Interested

2. Excited

3. Strong

4. Enthusiastic

5. Proud

6. Alert

7. Inspired

8. Determined

9. Attentive

10. Active

\section{EFFICACY BELIEFS}


Need fulfillment scale (Van den Broek et al., 2010)

Directions: Please indicate the extent to which you agree with the following statements as of this morning:

Response Scale: $1=$ Totally disagree to 5=Totally agree

1. I feel I am able to really master my tasks at my job.

2. I feel competent at my job.

3. I feel that I am good at the things I do in my job.

4. I have the feeling that I can even accomplish the most difficult tasks at work.

\section{Lunch time Survey}

\section{POSITIVE AFFECT}

Directions: Please indicate to what extent you feel this way as of right now.

Response Scale: $1=$ Very slightly or not at all to 5=Extremely

1. Interested

2. Excited

3. Strong

4. Enthusiastic

5. Proud

6. Alert

7. Inspired

8. Determined

9. Attentive

10. Active

\section{EFFICACY BELIEFS}

Need fulfillment scale (Van den Broeck et al., 2010)

Directions: Please think about your morning at work and indicate the extent to which you agree with the following statements. As of today:

Response Scale: 1=Totally disagree to 5=Totally agree 
1. I feel I am able to really master my tasks at my job.

2. I feel competent at my job.

3. I feel that I am good at the things I do in my job.

4. I have the feeling that I can even accomplish the most difficult tasks at work.

\section{JOB CRAFTING}

Job Crafting Scale adapted for the day-level (Tims et al., 2012; Petrou et al., 2012)

Directions: The following questions ask about your work experiences this morning. Please indicate how often you have engaged in each of these activities so far today:

Response Scale: $1=$ Not at all to 5=Most of my day so far has been spent doing this

\section{Day-Level Seeking Resources}

1. This morning, I asked others for feedback on my job performance.

2. This morning, I asked my colleagues for advice.

3. This morning, I asked my supervisor for advice.

4. This morning, I tried to learn new things at work.

\section{Day-Level Seeking Challenges}

5. This morning, I asked for more tasks if I finished my work.

6. This morning, I asked for more responsibilities.

7. This morning, I asked for more odd jobs.

\section{WORK ENGAGEMENT}

UWES Short adapted for day-level (Schaufeli et al., 2006; Tims et al., 2011)

Directions: The following 9 statements are about how you feel at work today. Please read each statement carefully and select a response that best describes how frequently you felt that way today.

Response Scale: $1=$ No, not at all, to $7=$ Yes, completely right

\section{Vigor}

8. 1. Today during work, I felt bursting with energy.

9. 2. Today during work, I felt strong and vigorous.

10. 3. Today when I got up in the morning, I felt like going to work. 


\section{Dedication}

11. 1. I was very enthusiastic about my work.

12. 2. Today, my job inspired me.

13. 3. I was proud of the work that I did.

\section{Absorption}

14. 1. I completely lost myself in my work.

15. 2. I felt happy when I was working intensely.

16. 3. I was immersed in my work. 
BUILDING RESOURCES

Appendix F

Table of Means for Focal Variables from Day 1 through Day 5

\begin{tabular}{|c|c|c|c|c|c|c|c|c|}
\hline \multirow[t]{2}{*}{ Day } & \multicolumn{2}{|c|}{$\begin{array}{c}\text { Nonwork } \\
\text { Mastery } \\
\text { Experiences }\end{array}$} & \multicolumn{2}{|c|}{$\begin{array}{c}\text { Seeking } \\
\text { Challenges }\end{array}$} & \multicolumn{2}{|c|}{$\begin{array}{l}\text { Seeking } \\
\text { Resources }\end{array}$} & \multicolumn{2}{|c|}{$\begin{array}{c}\text { Work } \\
\text { Engagement }\end{array}$} \\
\hline & $M$ & $S D$ & $M$ & $S D$ & $M$ & $S D$ & $M$ & $S D$ \\
\hline 1 (Mon) & 3.05 & .71 & 2.44 & 1.16 & 2.93 & .95 & 4.39 & 1.37 \\
\hline 2 (Tues) & 2.78 & .75 & 2.08 & 1.12 & 2.52 & .98 & 4.40 & 1.30 \\
\hline 3 (Wed) & 2.95 & .82 & 1.86 & 1.00 & 2.42 & .91 & 4.53 & 1.34 \\
\hline 4 (Thurs) & 2.86 & .76 & 1.90 & .96 & 2.47 & .91 & 4.66 & 1.16 \\
\hline 5 (Fri) & 2.93 & .75 & 1.97 & 1.11 & 2.63 & 1.05 & 4.84 & 1.19 \\
\hline
\end{tabular}

Figure F1. Mean Levels of Study Variables Across the Week

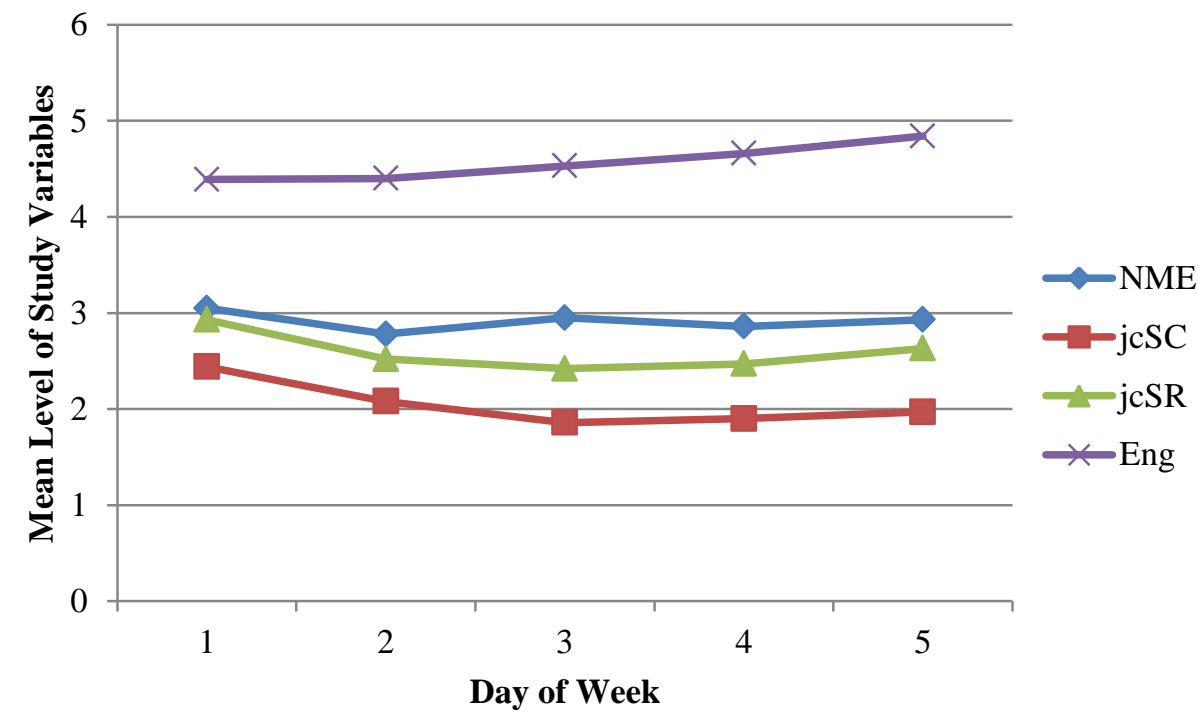

Note. $\mathrm{NME}=$ Nonwork mastery experiences. jcSC=Job Crafting Seeking Challenges. jcSR=Job Crafting Seeking Resources. Eng=Work Engagement 
Appendix G

\section{Additional Information on Growth Models}

Figure G1. Relationship between Day of Week and Day-Level Work Engagement for 10 Random Participants

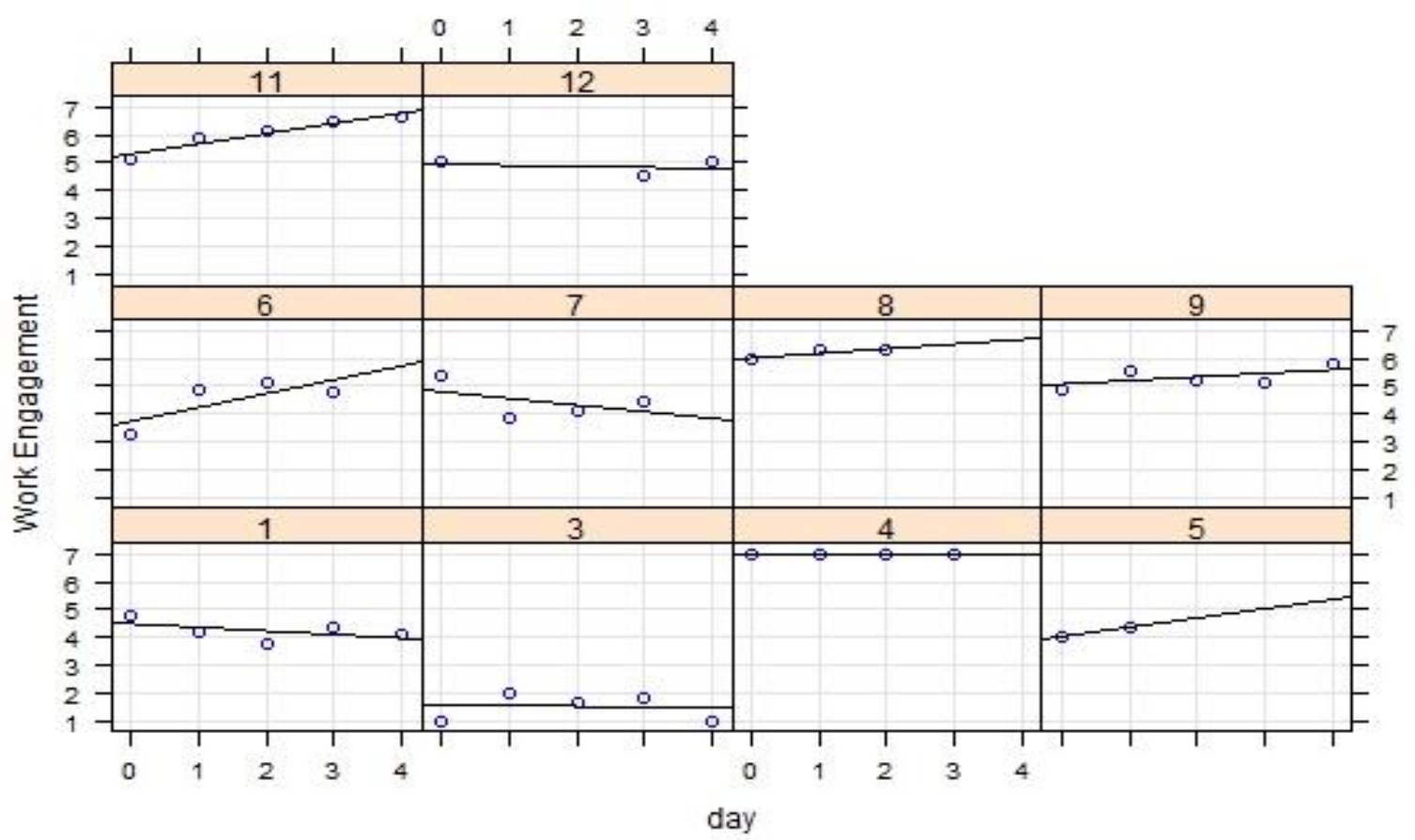


Figure G2. Interaction Plot Showing Relationship Between Day of Week, Trait Work Engagement, and Day-Level Work Engagement

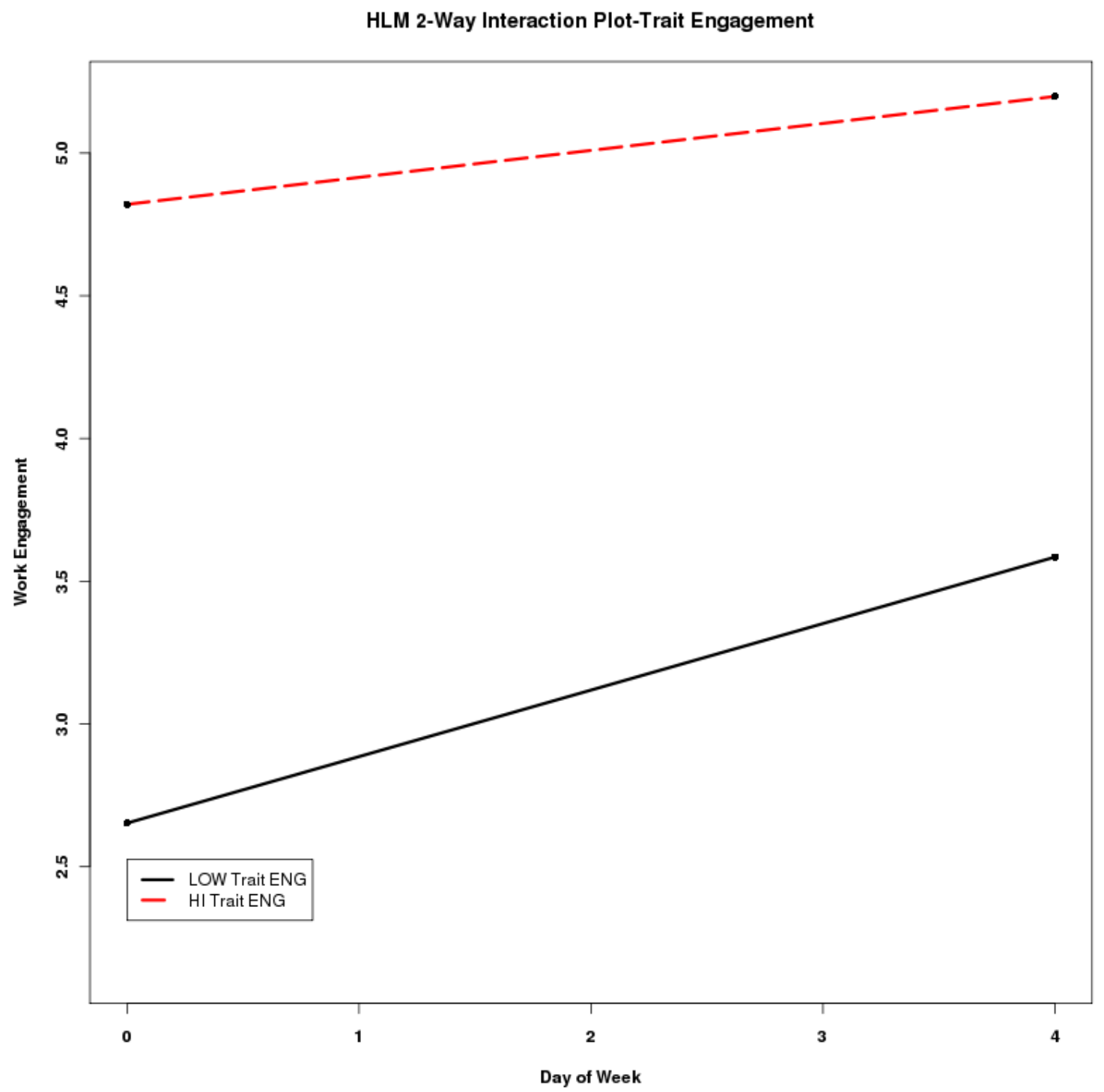

Note. Day of Week ( $0=$ Monday through $4=$ Friday) 
Figure G3. Interaction Plot Showing Relationship Between Day of Week, Trait Seeking Structural Resources, and Day-Level Work Engagement

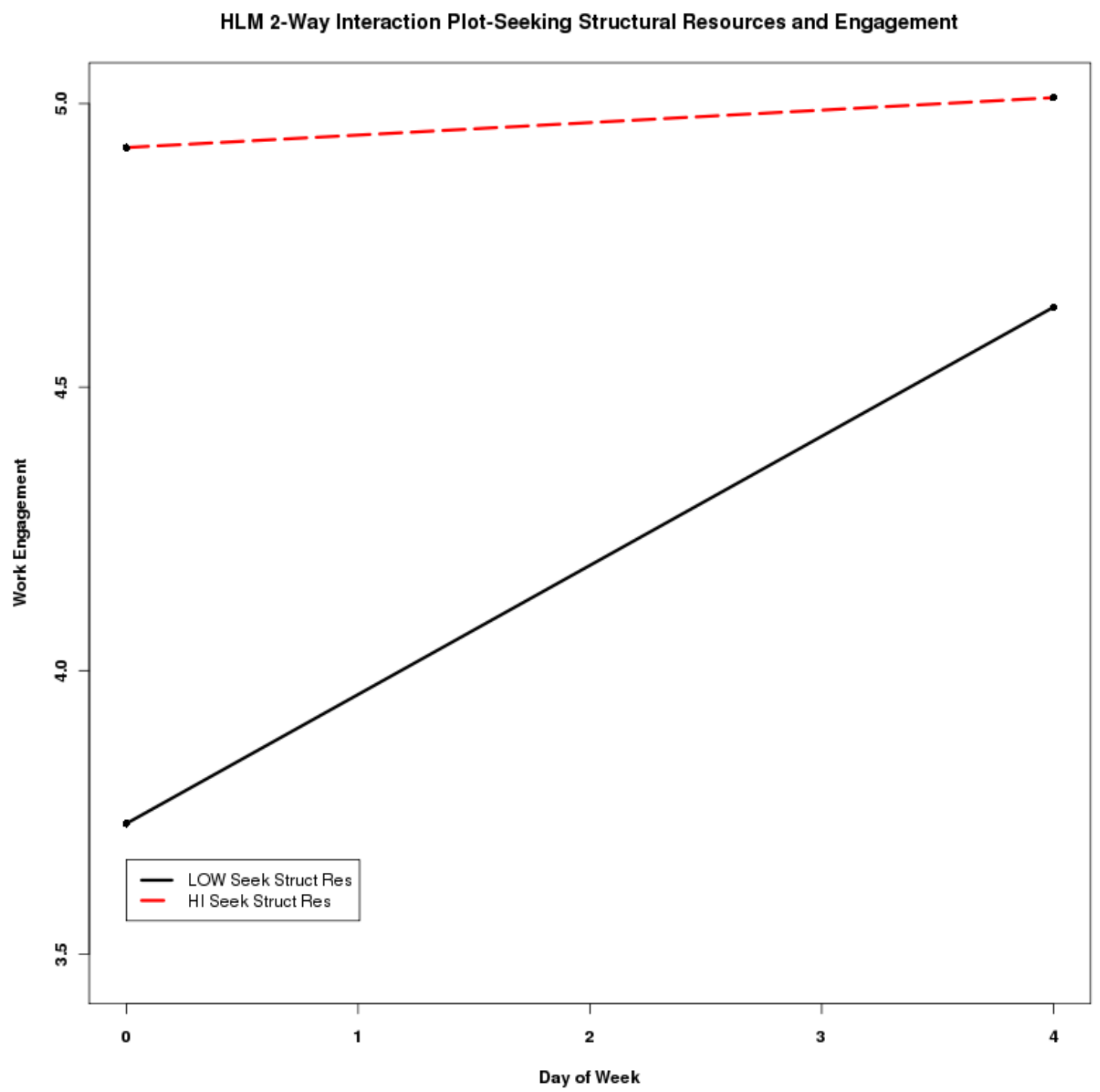

Note. Day of Week ( $0=$ Monday through $4=$ Friday). 
BUILDING RESOURCES

Table G1. Growth Model Parameter Estimates for Day-Level Work Engagement

\begin{tabular}{lllll}
\hline Variable & Estimate & SE & $\mathrm{t}$ Value & $\mathrm{p}$ \\
\hline Intercept & 4.38 & 0.15 & 30.14 & .000 \\
DAY & 0.09 & .03 & 2.75 & .006 \\
\hline
\end{tabular}

Note. Random intercepts and random slopes model. Estimates are unstandardized.

Day=Day of Week (0=Monday-5=Friday).

Table G2. Relationship Between Trait Work Engagement and Day-Level Work Engagement Intercept and Slopes

\begin{tabular}{lllll}
\hline Variable & Estimate & SE & $\mathrm{t}$ Value & $\mathrm{p}$ \\
\hline Intercept & -.10 & .72 & -.14 & .888 \\
DAY & .41 & .23 & 1.79 & .076 \\
ENG (trait) & .85 & .14 & 6.23 & .000 \\
DAY X ENG & -.05 & .04 & -.13 & .213 \\
(trait) & & & &
\end{tabular}

Note. Estimates are unstandardized. Day=Day of Week ( $0=$ Monday-5=Friday).

Table G3. Relationship Between Trait Seeking Structural Resources and Day-Level Work Engagement Intercept and Slopes

\begin{tabular}{lllll}
\hline Variable & Estimate & SE & $\mathrm{t}$ Value & $\mathrm{p}$ \\
\hline Intercept & .18 & 1.12 & .16 & .876 \\
DAY & .84 & .33 & 2.53 & .013 \\
JCSTR (trait) & 1.06 & .28 & 3.75 & .000 \\
DAY X JCSTR & -.18 & .08 & -2.19 & .030 \\
(trait) & & & & \\
\hline
\end{tabular}

Note. Estimates are unstandardized. Day=Day of Week ( $0=$ Monday-5=Friday).

JCSTR=Job Crafting Seeking Structural Resources. 
Table G4. Relationship Between Trait Seeking Social Resources and Day-Level Work Engagement Intercept and Slopes

\begin{tabular}{lllll}
\hline Variable & Estimate & SE & $\mathrm{t}$ Value & $\mathrm{p}$ \\
\hline Intercept & 3.23 & .77 & 4.21 & .000 \\
DAY & .03 & .22 & .12 & .907 \\
JCSCR (trait) & .34 & .24 & 1.45 & .152 \\
DAY X JCSCR & .03 & .07 & .43 & .667 \\
(trait) & & & & \\
\hline
\end{tabular}

Note. Estimates are unstandardized. Day=Day of Week ( $0=$ Monday-5=Friday). JCSCR=Job Crafting Seeking Social Resources.

Table G5. Relationship Between Trait Seeking Challenging Demands and Day-Level Work Engagement Intercept and Slopes

\begin{tabular}{lllll}
\hline Variable & Estimate & SE & $\mathrm{t}$ Value & $\mathrm{p}$ \\
\hline Intercept & 2.15 & .79 & 2.74 & .007 \\
DAY & .10 & .22 & .43 & .667 \\
JCCD (trait) & .59 & .21 & 2.83 & .007 \\
DAY X JCCD & .01 & .06 & .12 & .902 \\
(trait) & & & & \\
\hline
\end{tabular}

Note. Estimates are unstandardized. Day=Day of Week ( $0=$ Monday-5=Friday). JCSTR=Job Crafting Seeking Structural Resources. 